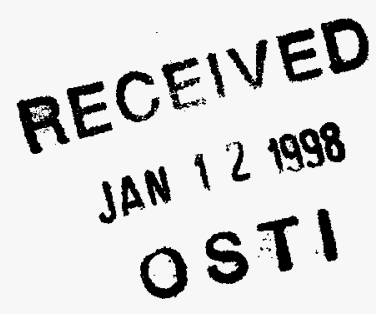

\title{
Encoal Mild Coal Gasification Project: Final Design Modifications Report
}

\author{
Topical Report \\ July 1997
}

Work Performed Under Contract No.: DE-FC21-90MC27339

For

U.S. Department of Energy

Office of Fossil Energy

Federal Energy Technology Center

Morgantown Site

P.O. Box 880

Morgantown, West Virginia 26507-0880

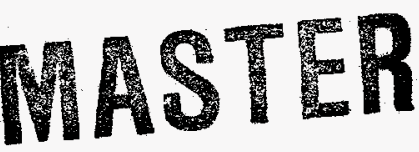

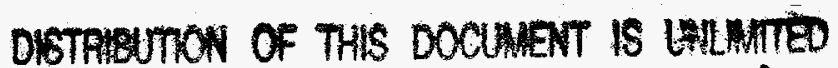

By
Encoal Corporation

P. O. Box 3038

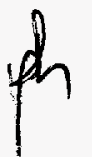

Gillette, Wyoming 82717-3038 


\section{Disclaimer}

This report was prepared as an account of work sponsored by an agency of the United States Government. Neither the United States Government nor any agency thereof, nor any of their employees, makes any warranty, express or implied, or assumes any legal liability or responsibility for the accuracy, completeness, or usefulness of any information, apparatus, product, or process disclosed, or represents that its use would not infringe privately owned rights. Reference herein to any specific commercial product, process, or service by trade name, trademark, manufacturer, or otherwise does not necessarily constitute or imply its endorsement, recommendation, or favoring by the United States Government or any agency thereof. The views and opinions of authors expressed herein do not necessarily state or reflect those of the United States Government or any agency thereof. 


\section{DISCLAIMER}

Portions of this document may be illegible electronic image products. Images are produced from the best available original document. 
LFC $\circledast$, ENCOAL $\circledast, P D F \circledast$, and $C D L \circledast$ are registered trademarks of the TEK-KOL Partnership that describe the process, technical services and products associated with the LFC $\circledast$ Technology developed and owned by TEK-KOL and its owners, SGI International and Zeigler Coal Holding Company. For simplification and readability purposes, the trademark symbols will not be used beyond this point in the attached paper. 


\section{ENCOAL MILD COAL GASIFICATION PROJECT: \\ FINAL DESIGN MODIFICATIONS REPORT \\ TABLE OF CONTENTS}

Page

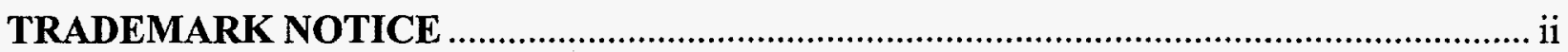

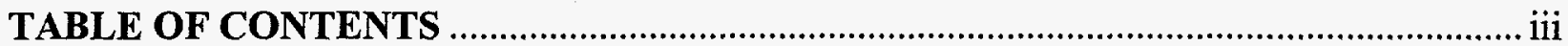

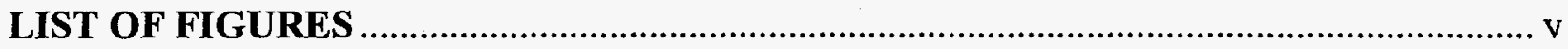

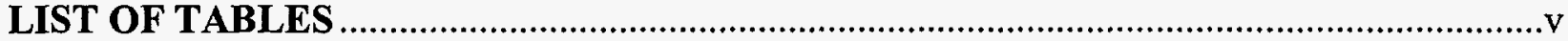

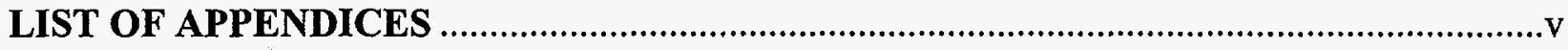

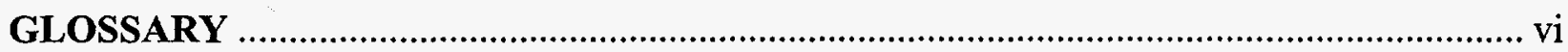

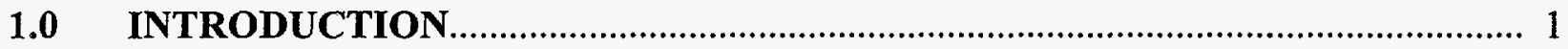

$2.0 \quad$ PROJECT BACKGROUND

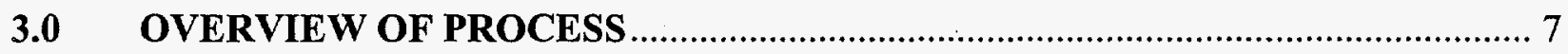

$4 \quad 4.0 \quad$ PLANT EQUIPMENT MODIFICATIONS ……….............................. 10

4.1 Solids Handling System ……………………............................................. 10

4.2 Dryer and Pyrolyzer Modifications.................................................................. 11

4.3 Dryer and Pyrolyzer Cyclones ........................................................................ 13

4.4 Pyrolyzer Quench Table and Quench Steam Condensing System .................. 15

4.5 PDF Deactivation System …………………............................................. 17

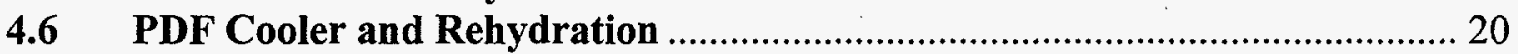

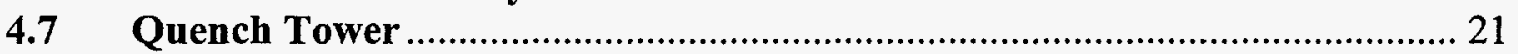

4.8 Electrostatic Precipitators ........................................................................... 22

$4.9 \quad$ CDL Handling and Storage ……………….......................................... 24

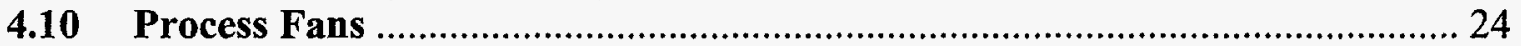

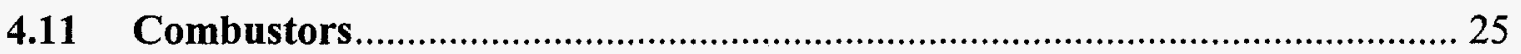

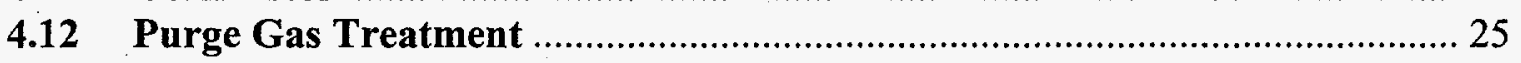

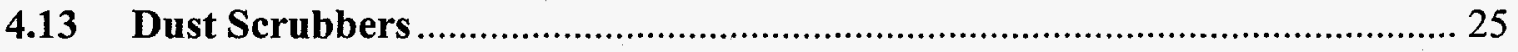

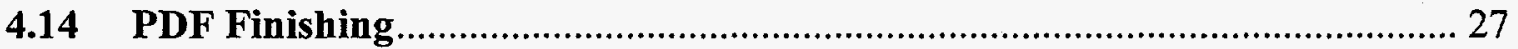

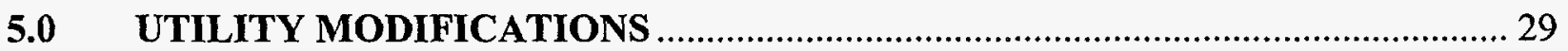

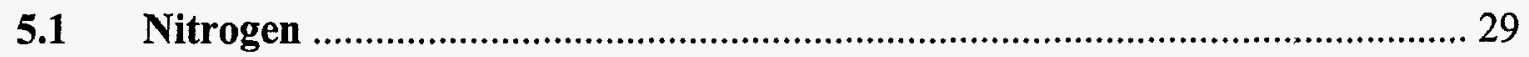

5.2 Instrument and Utility Air ...................................................................... 30

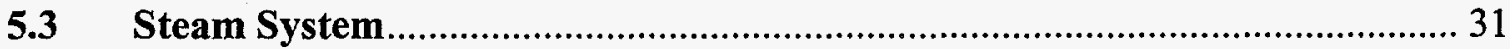

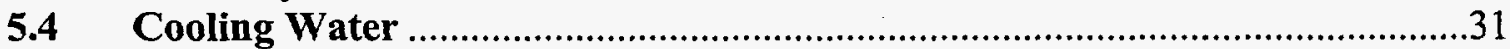

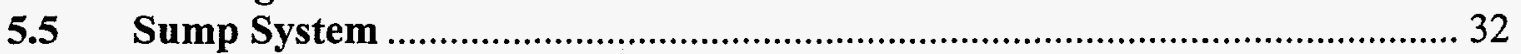

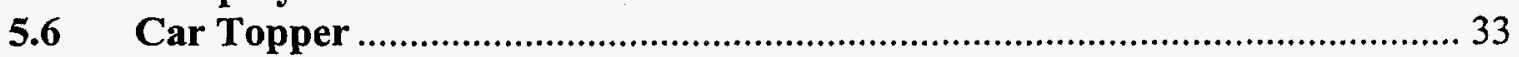

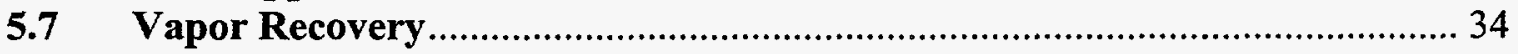

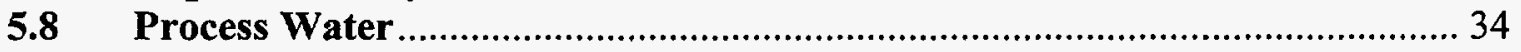




\section{ENCOAL MILD COAL GASIFICATION PROJECT:}

FINAL DESIGN MODIFICATIONS REPORT

TABLE OF CONTENTS (Continued)

\section{Page}

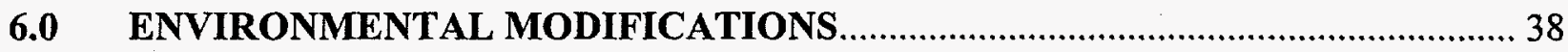

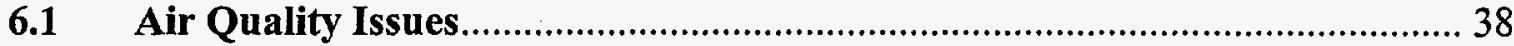

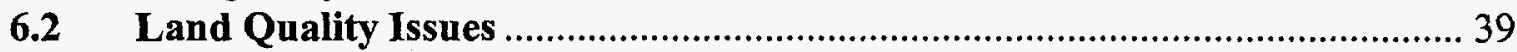

7.0 SAFETY AND ADMINISTRATIVE ITEMS .................................................... 42

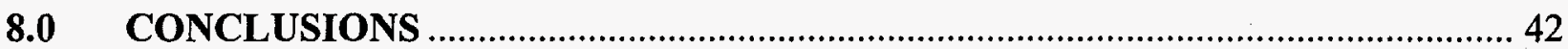

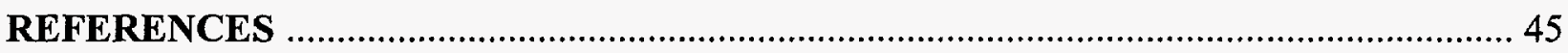




\section{LIST OF FIGURES}

... Item

Page

Figure 2.1: ENCOAL Project Organization ............................................................................. 2

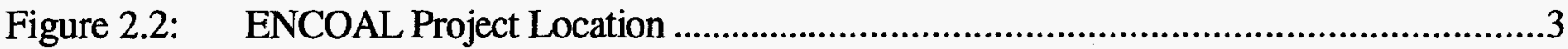

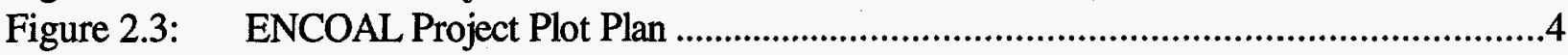

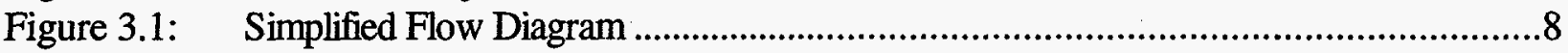

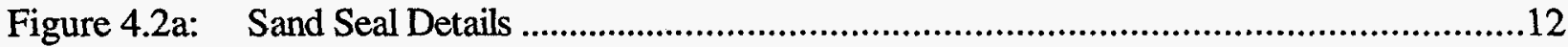

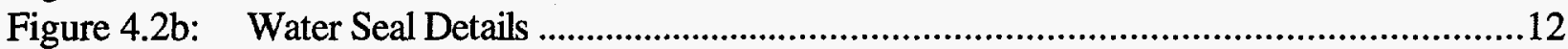

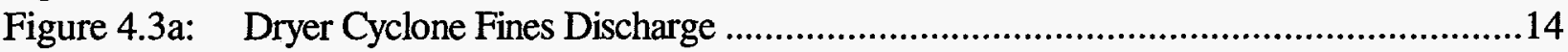

Figure 4.3b: Pyrolyzer Cyclone Fines Discharge .....................................................................14

Figure 4.4a: Pyrolyzer Quench Table Water Supply Header .......................................................15

Figure 4.4b: Quench Steam Fines Knock-out Drum …….......................................................16

Figure 4.4c: $\quad$ Dual Quench Steam Condensers ………..............................................................16

Figure 4.5a: Vibrating Fluidized Bed Unit .............................................................................17

Figure 4.5b: PDF Deactivation Building Under Construction …...............................................18

Figure 4.5c: $\quad$ PDF Deactivation Building Completed …..........................................................18

Figure 4.5d: PDF Deactivation Loop Simplified Process Flow Diagram ...................................19

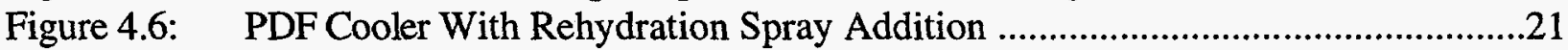

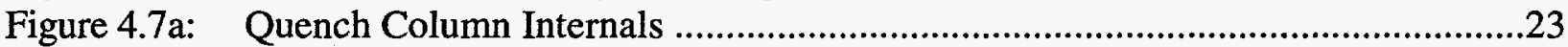

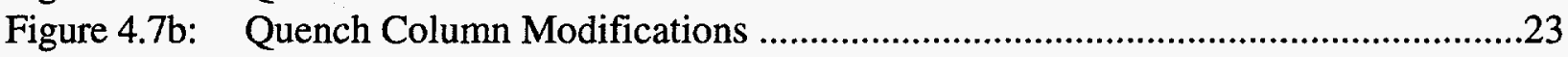

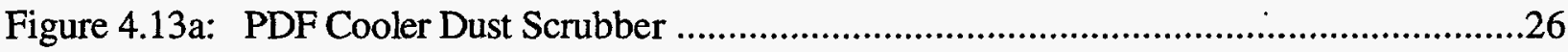

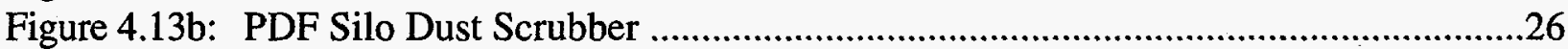

Figure 4.14: Proposed PDF Finisher; Aeroglide Tower Dryer ..............................................28

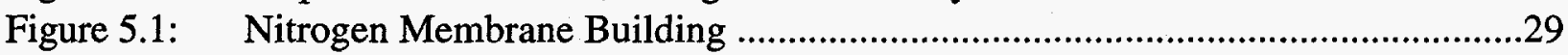

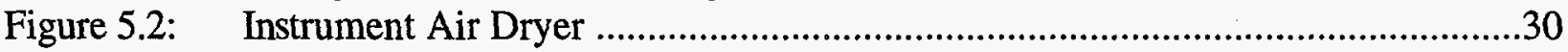

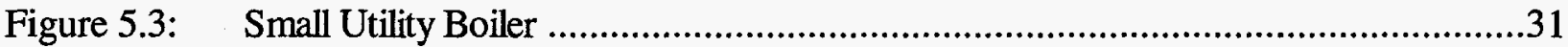

Figure 5.4: Cooling Water Booster Pumps and Distribution Header ......................................32

Figure 5.5: Drive-in Sump Under Construction ....................................................................33

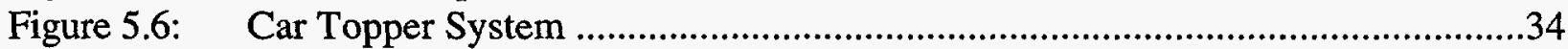

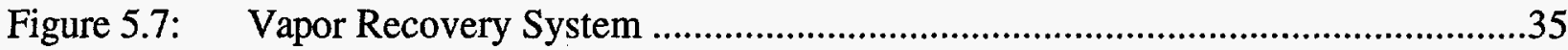

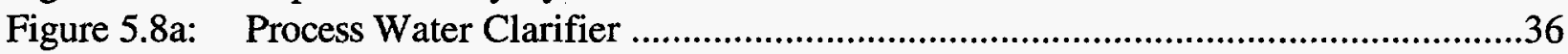

Figure 5.8b: Process Water Fines Removal Building ……………..........................................36

Figure 5.8c: Process Water Clarifier General Arrangement Drawing ..........................................37

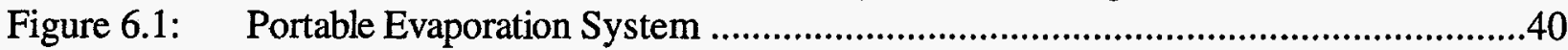

Figure 6.2: Permanent Precipitate Storage Reservoir ......................................................41

Figure 6.3: ENCOAL Land Farm .................................................................................

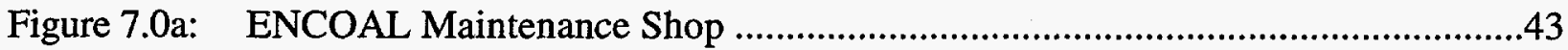

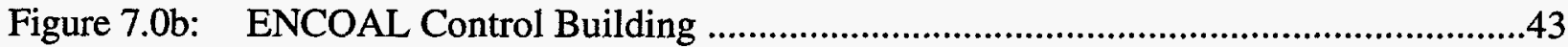

Figure 7.0c: ENCOAL Control Building Expansion Floor Plan .........................................44

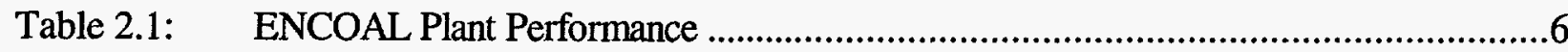

\section{LIST OF TABLES}

LIST OF APPENDICES

Appendix A： Civil and Mechanical Layouts/Equipment List .................................................A1-A9 


\section{GLOSSARY}

ASME

BS\&W

Btu

$\mathrm{CDL}$

$\mathrm{CH}_{4}$

$\mathrm{CO}$

$\mathrm{CO}_{2}$

DOE

ENCOAL

ESP

${ }^{\circ} \mathrm{F}$

$\mathrm{ft}$.

$\mathrm{ft}^{2}$

HP

$\mathrm{H}_{2} \mathrm{O}$

$\mathrm{H}_{2} \mathrm{~S}$

in.

Kellogg

$\mathrm{lb} / \mathrm{hr}$

LFC Technology

MM Btu/hr

Max

MSHA

$\mathrm{NO}_{\mathrm{x}}$

$\mathrm{O}_{2}$

PDF

PLC

$\%$

$\mathrm{pH}$

psia

psig

RPM

SMC

$\mathrm{SO}_{2}$

$\mathrm{SO}_{\mathrm{x}}$

turnkey

vol
American Society of Mechanical Engineers

Basic Sediment \& Water

British Thermal Units

Coal Derived Liquid

Methane

Carbon Monoxide

Carbon Dioxide

U.S. Department of Energy

ENCOAL Corporation, wholly-owned subsidiary of

Bluegrass Coal Development Company

Electrostatic Precipitators

Degrees Fahrenheit

Feet

Square Feet

Horsepower

Water

Hydrogen Sulfide

Inches

The M. W. Kellogg Company

Pounds per Hour

Liquid From Coal Technology

Million British Thermal Units per Hour

Maximum

Mine Safety and Health Administration

Nitrogen Oxides

Oxygen

Process Derived Fuel

Programmable Logic Controller

Percent

Measure of alkalinity and acidity on a scale of 0 to 14

Pounds per Square Inch Absolute

Pounds per Square Inch Gauge

Rotations per Minute

SMC Mining Company, renamed Bluegrass Coal Development

Company, wholly owned subsidiary of Zeigler Coal Holding

Company

Sulfur Dioxide

Sulfur Oxides

Subcontracting method that includes design, furnishing and installation responsibility

Volume 


\subsection{INTRODUCTION}

The design, construction and operation Phases of the ENCOAL Mild Coal Gasification Project have been completed. The plant, designed to process 1000 ton/day of subbituminous Power River Basin (PRB) low-sulfur coal feed and to produce two environmentally friendly products, a solid fuel and a liquid fuel, has been operational for nearly five years.. The solid product, Process Derived Fuel (PDF), is a stable, low-sulfur, high-Btu fuel similar in composition and handling properties to bituminous coal. The liquid product, Coal Derived Liquid (CDL), is a heavy, low-sulfur, liquid fuel similar in properties to heavy industrial fuel oil. Opportunities for upgrading the CDL to higher value chemicals and fuels have been identified. Significant quantities of both PDF and CDL have been delivered and successfully burned in utility and industrial boilers. A summary of the Project is given below and in ENCOAL's "Final Project Report"'[1].

The project has been cost-shared by the U.S. Department of Energy (DOE), under the Clean Coal Technology Program administered by the Morgantown Energy Technology Center under Cooperative Agreement number DE-FC21-90MC27339. A "Public Design And Construction Report" ${ }^{[2]}$ was published in December 1994 that described the ENCOAL plant as-built, IE tested and ready for operation. This Design Modifications Report is intended to update the original design report for the major changes that have been implemented since the plant became operational in July 1992. Changes integral to the process have become part of the Liquids From Coal (LFC) Technology as it has been demonstrated by the ENCOAL plant.

\subsection{BACKGROUND INFORMATION}

\section{Organization}

ENCOAL Corporation is a wholly owned subsidiary of Bluegrass Coal Development Company, (formerly named SMC Mining Company), which in turn is a subsidiary of Zeigler Coal Holding Company. ENCOAL entered into a Cooperative Agreement with DOE in September 1990 as a participant in Round III of the Clean Coal Technology Program. Under this agreement, the DOE shared $50 \%$ of the cost of the ENCOAL Mild Coal Gasification Project. The Cooperative Agreement was extended in October 1994 for an additional \$18,100,000 bringing the Project total to $\$ 90,600,000$ through September 17,1996 . No-cost extensions have moved the Cooperative Agreement end date to July 17, 1997 to allow for completion of final reporting requirements. A license for the use of the LFC Technology has been issued to ENCOAL from the technology owner, TEK-KOL. TEK-KOL is a general partnership between SGI International of La Jolla, California, the original LFC Technology developer and Bluegrass Coal Development Company. Figure 2.1 shows the current Project organization. The M.W. Kellogg Company (Kellogg) was an active member in the early years as the Engineering, Procurement and Construction subcontractor. 


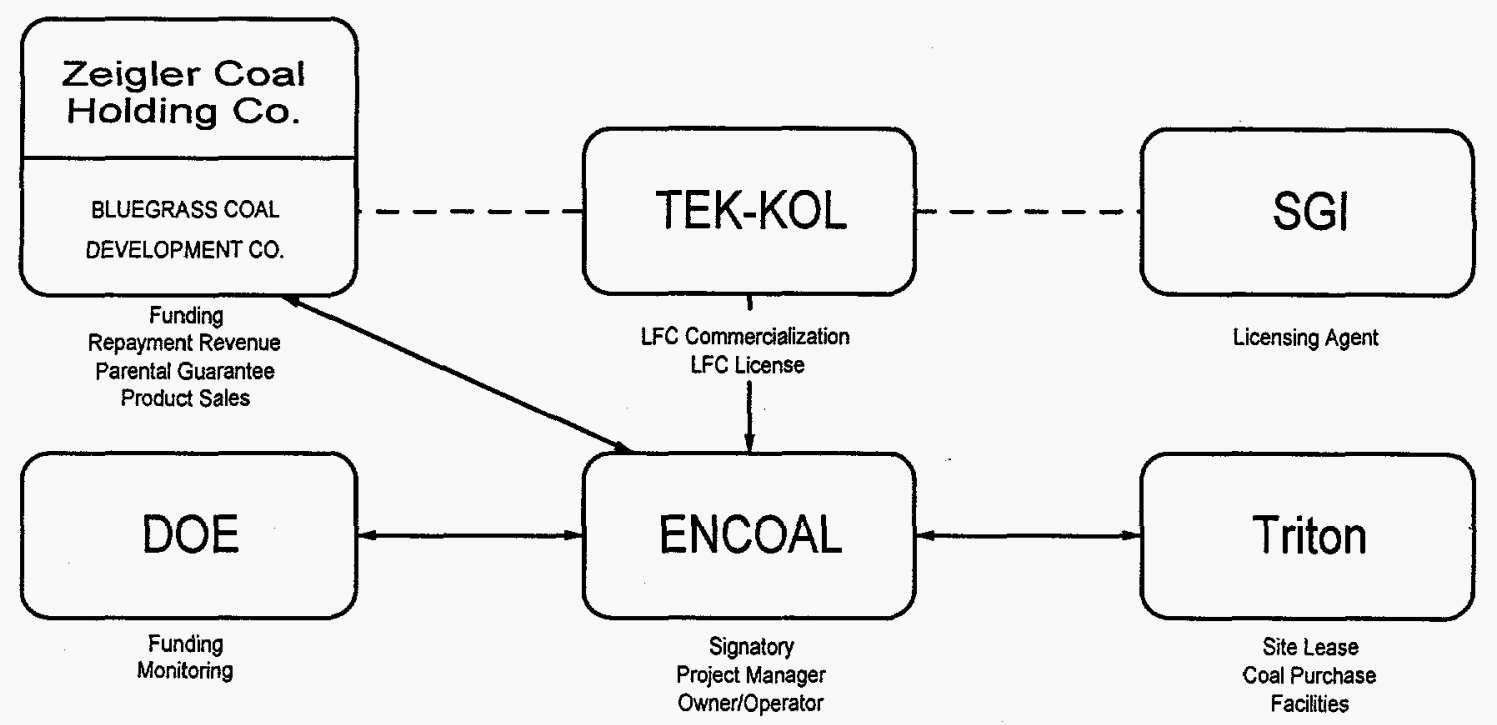

Figure 2.1: ENCOAL Project Organization

\section{Location}

The ENCOAL Project encompasses the design, construction and operation of a 1,000 TPD commercial demonstration plant and all required support facilities. The Project is located near Gillette, Wyoming at Triton Coal Company's Buckskin Mine. Figure 2.2 is a general location map. Selected in part because Triton is a sister company, existing roads, railroad, storage silos and coal handling facilities at the mine significantly reduced the need for new facilities for the Project. In addition, Triton could supply the raw coal for processing. Figure 2.3 shows the site layout for the existing Buckskin Mine facilities and the added ENCOAL Project facilities. The shaded areas are modifications to the original plot plan .

\section{Objectives}

The overall objective of the Project was to further the commercialization of the LFC Technology. This was to be done by demonstrating that the technology can reliably and economically convert low Btu PRB coal into superior, environmentally attractive low-sulfur, marketable products. In support of this overall objective, the following specific objectives were established that had a significant impact on the plant design:

(1) Provide products for commercial scale test burns

(2) Obtain data for the design of future commercial plants

(3) Demonstrate plant and process performance

(4) Provide capital and operating costs data

(5) Support future LFC Technology licensing efforts 
Figure 2.2: ENCOAL Project Location

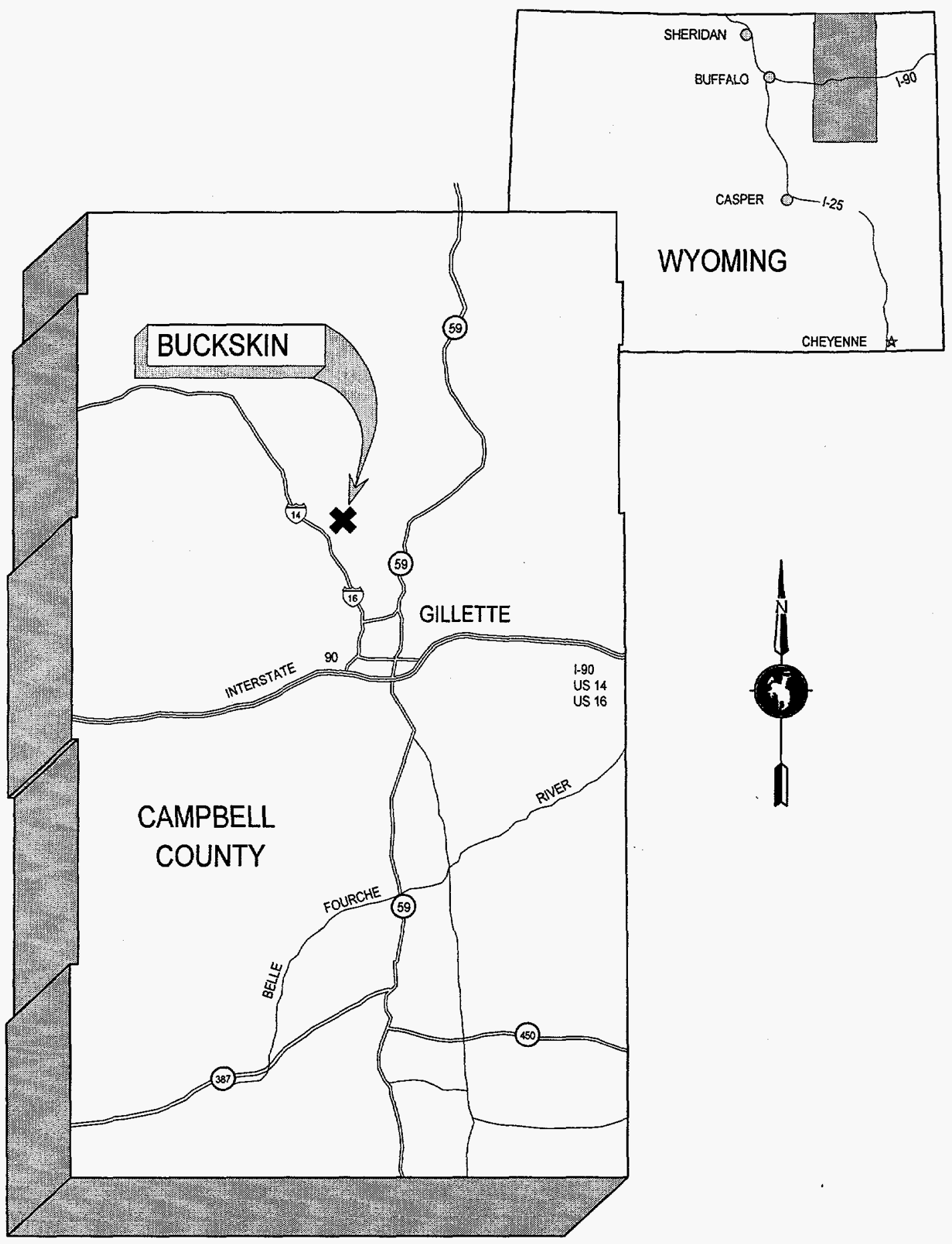




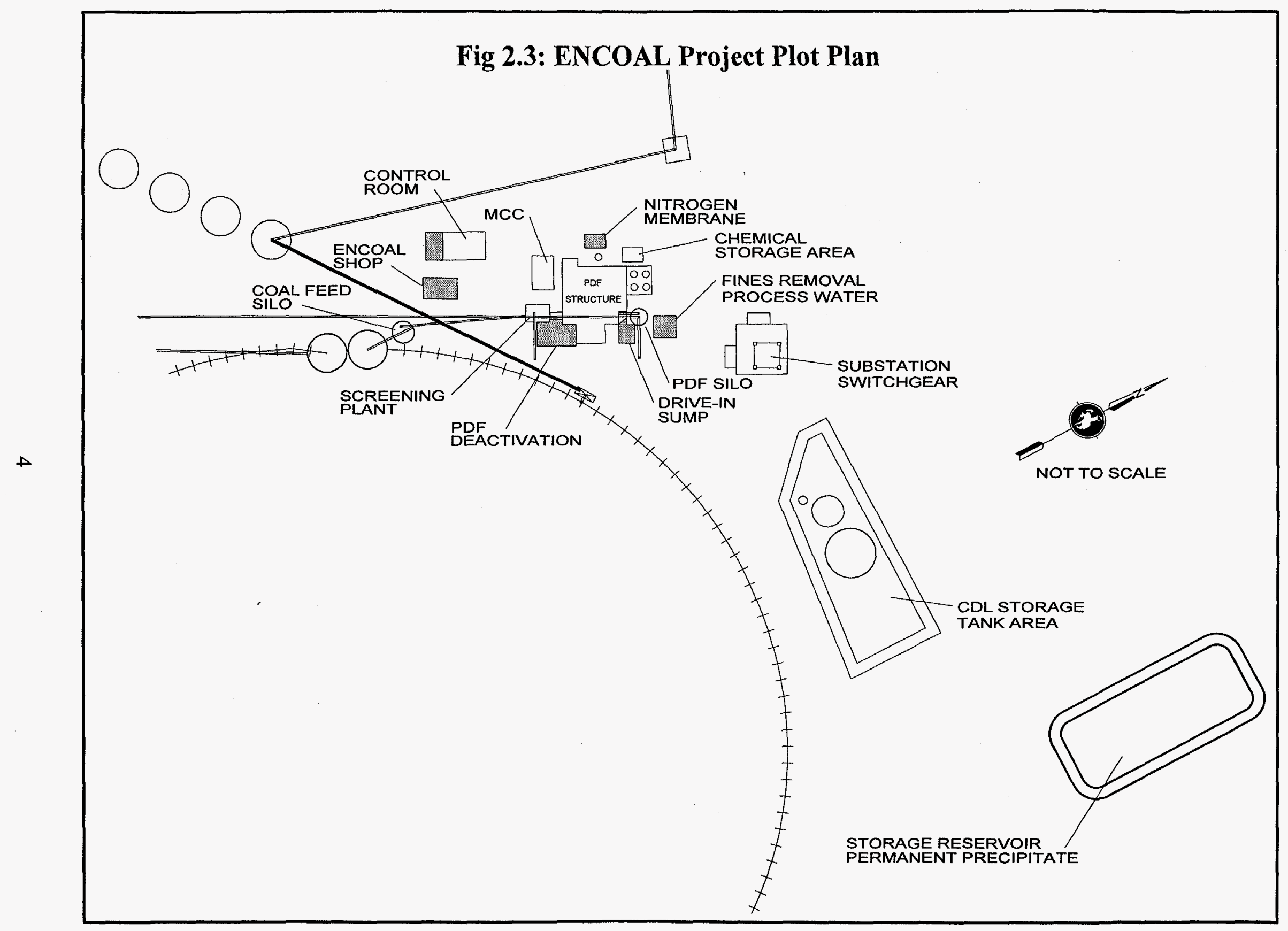


Given these objectives, the project team charged with the responsibility of designing the facilities developed an additional set of guidelines to further define the requirements and aid in the design:

(1) Keep scale-up from the SGI pilot plant reasonable.

(2) Use currently available commercial equipment as much as possible.

(3) Keep the process simple, postpone the refinement of CDL.

(4) Match the products to existing markets.

(5) Minimize all releases to the environment.

ENCOAL's processing plant was designed to commercial standards for a life of at least 10 years. It used commercially available equipment as much as possible, state-of-the-art computer control systems, BACT for air emissions, and environmental controls to minimize releases, and a simplified flowsheet to make only two products matched to existing markets. The intent was to demonstrate the core process and not make the project overly complicated or expensive. All plant modifications were designed with the same principles in mind.

\section{Project History}

ENCOAL's original parent company, SMC, worked on upgrading low rank coals from the early 1970 's to the mid 1980's. SGI began working on their LFC Technology in 1980. In 1986 SMC and SGI held their first discussions. The TEK-KOL Partnership was formed in 1987 and joint development of the LFC Technology has progressed steadily since then. While some process as well as mechanical design w'as done by Kellogg in 1988 for permitting and financing purposes, the final design effort was started in ernest in July, 1990 in anticipation of the DOE contract. Civil construction was started in October, 1990; mechanical erection began in May, 1991. Virtually all of the planned design work was completed by July 1991. Most major construction was complete by April, 1992 followed by plant testing and commissioning. Plant operation began in late May, 1992 and the first 24 hour run producing both PDF and CDL occurred on June 17. This report covers the major modifications to the original design implemented since the plant became operational in July 1992.

\section{Operating Experience}

Table 2.1 summarizes the operating experience of the ENCOAL plant. The table is divided into two distinct periods; (1) the early runs before installation of the deactivation loop discussed below which concentrated on solving equipment and stabilization problems and (2) runs after the VFB installation which were primarily production runs for test burns. As the table clearly shows, the operating hours for the plant and average length of runs improved markedly after the 1993 shutdown due to all the modifications made during the outage, a primary focus of this report. 


\begin{tabular}{|c|c|c|c|c|c|c|c|}
\hline \multicolumn{3}{|c|}{ Pre-VFB } & \multicolumn{4}{|c|}{ Post-VFB } & \multirow[b]{2}{*}{ *SUM } \\
\hline & 1992 & 1993 & 1994 & 1995 & 1996 & *1997 & \\
\hline $\begin{array}{l}\text { Raw Coal Feed } \\
\text { (Tons) }\end{array}$ & 5,200 & 12,400 & 67,500 & 65,800 & 68,000 & 28,000 & 246,900 \\
\hline $\begin{array}{l}\text { PDF Produced } \\
\text { (Tons) }\end{array}$ & 2,200 & 4,900 & 31,700 & 28,600 & 33,300 & 14,200 & 114,900 \\
\hline $\begin{array}{l}\text { PDF Sold } \\
\text { (Tons) }\end{array}$ & 0 & 0 & 23,700 & 19,100 & 32,700 & 7,400 & 82,900 \\
\hline $\begin{array}{l}\text { CDL Produced } \\
(\mathrm{Bbl})\end{array}$ & 2,600 & 6,600 & 28,000 & 31,700 & 32,500 & 14,700 & 116,100 \\
\hline Hours on Line & 314 & 980 & 4,300 & 3,400 & 3,600 & 1,944 & 14,538 \\
\hline $\begin{array}{l}\text { Average Length of } \\
\text { Runs (Days) }\end{array}$ & 2 & 8 & 26 & 38 & 44 & 81 & \\
\hline
\end{tabular}

Table 2.1: ENCOAL Plant Performance

Although designed for 1000 TPD feed, the plant capacity is now held to 500 TPD due to limited residence time in the deactivation loop. Installation of a second VFB was planned to bring the plant back to full capacity if necessary. The plant now produces approximately $250 \mathrm{TPD}$ of $\mathrm{PDF}$ and 250 barrels/day of CDL. The plant has performed increasingly better with respect to mechanical availability as the operations team has matured and equipment problems have been solved. Runs exceeding 120 days continuous operation are now routine with availability during the run at $90 \%$ or better, (e.g. May 1997 achieved $100 \%$ ).

Even with the restricted capacity, the ENCOAL plant has now delivered 17 unit trains and one truck shipment of blended and straight PDF to seven different utility customers. Over 200 jumbo tank cars of CDL have been delivered to eight industrial customers. In all cases the PDF and CDL products have been handled in existing rail cars and material handling systems with no special handling requirements. Utility test burns have shown that the fuel products can be used economically in commercial boilers and furnaces to reduce sulfur and $\mathrm{NO}_{\mathrm{x}}$ emissions significantly at utility and industrial facilities currently burning high sulfur bituminous coal or fuel oils. Ultimately, installation of commercial scale LFC plants should help reduce U.S. dependence on imports of foreign oil. The plant continues to operate and deliver products under private funding. 
The ENCOAL Project has demonstrated for the first time the integrated operation of several unique process steps:

- Coal drying on a rotary grate using convective heating

- Coal devolatilization on a rotary grate using convective heating

- Hot particulate removal with cyclones

- Integral solids cooling and deactivation

- Combustors operating on low Btu gas from internal streams

- $\quad$ Solids stabilization for storage and shipment

- Computer control and optimization of a mild coal gasification process

- Dust suppressant on PDF solid fuels

\subsection{OVERVIEW OF PROCESS}

The LFC process is a mild gasification or mild pyrolysis process which involves heating of coal under carefully controlled conditions to produce gaseous compounds. It is termed mild because the temperatures are moderate and reactions take place at near atmospheric pressure. Figure 3.1 shows a fairly detailed flow diagram of ENCOAL's application of the LFC Technology. The shaded areas represent changes to the original process flow sheet.

Run-of-mine coal is conveyed from the Buckskin Mine to a storage silo. The coal from this silo is screened to remove oversize and undersize materials. The specification coal feed, 2 " $x_{-}$" size, is hand sampled to measure the moisture, ash, carbon, hydrogen, sulfur, and other contents of the feed coal (it once passed through a GAMMA-METRICS coal analyzer - now removed). The coal is then fed into a slotted rotary grate dryer where it is heated by a hot gas stream. The residence time of the coal and temperature of the inlet gas have been selected to reduce the moisture content of the coal without initiating chemical changes. The solid bulk temperature is controlled so that no significant amount of methane, carbon monoxide or carbon dioxide is released from the coal.

The solids from the dryer are then transferred to a second rotary grate, the pyrolyzer, where the temperature of the dried coal is raised to about $1000^{\circ} \mathrm{F}$ by a hot recycled gas stream. The rate of heating of the solids i.e., the inlet temperature and flow rate of the hot recycled gas stream, is carefully controlled because it determines the properties of the solid and liquid products. In the pyrolyzer, a chemical reaction occurs which results in the release of volatile gaseous materials from the coal. Solids exiting the pyrolyzer are quickly quenched to stop the pyrolysis reaction, then transferred to a small surge bin that feeds the vibrating fluidized bed (VFB) deactivation unit - a major addition to the original plant.

In the VFB unit, the partially cooled, pyrolyzed solids contact a gas stream containing a controlled amount of oxygen. Termed "oxidative deactivation," a reaction occurs at active surface sites in the particles reducing the tendency for spontaneous ignition. The heat generated by this reaction is absorbed by a fluidizing gas stream which is circulated through a cyclone to remove entrained solids and a heat exchanger before being returned by a blower to the VFB. Oxygen content in the loop is 
Figure 3.1: Simplified Flow Diagram

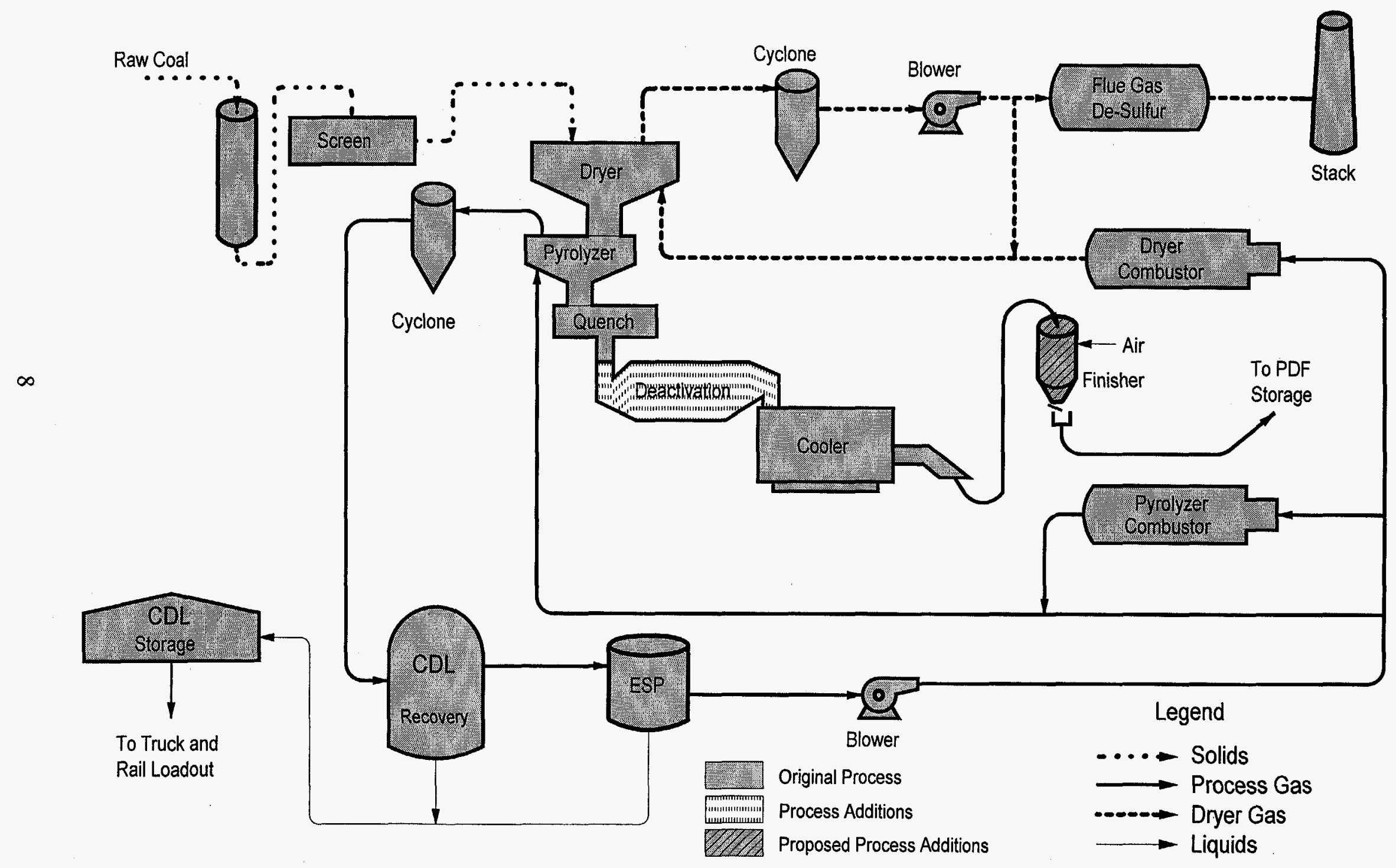


maintained by introducing the proper amount of air through a control valve. Excess gas in the loop is purged to the dryer combustor for incineration.

Following the VFB, the solids are cooled to near atmospheric temperature in an indirect rotary cooler. A controlled amount of water is added in the rotary cooler to rehydrate the PDF to near its ASTM equilibrium moisture content. This is also an important step in the stabilization of the PDF. The cooled PDF is then transferred to a storage bin. Because the solids have little or no free surface moisture and, therefore, are likely to be dusty, a patented dust suppressant called MK is added as PDF leaves the product surge bin.

At the present time, the PDF is not completely stabilized with respect to oxygen upon leaving the plant. The PDF must be "finished" by a short exposure to atmospheric conditions in a layered stockpile prior to being reclaimed and shipped. In addition to atmospheric stabilized PDF, a stable product can be made by blending run-of-plant PDF with either ROM coal or the atmosphere stabilized PDF, but there is a Btu penalty. ENCOAL has recently completed pilotscale equipment tests that successfully perform this finishing step using continuous process equipment. The design uses commercially available equipment to be installed just downstream of the rotary cooler mentioned above, and will effectively stabilize PDF without the layered stockpile step. Installation of this equipment is currently scheduled for the second half of 1997.

The hot gas produced in the pyrolyzer is sent through a cyclone for removal of the particulates and then cooled in a quench column to stop any additional pyrolysis reactions and to condense the desired liquids. Only the CDL is condensed in this step; the condensation of water is avoided. Electrostatic precipitators recover any remaining liquid droplets and mists from the gas leaving the condensation unit.

Almost half of the residual gas from the liquid recovery unit is recycled directly to the pyrolyzer, while some is first burned in the pyrolyzer combustor before being blended with the recycled gas to provide heat for the mild gasification reaction. The remaining gas is burned in the dryer combustor, which converts sulfur compounds to sulfur oxides. Nitrogen oxide emissions are controlled via appropriate design of the combustor. The hot flue gas from the dryer combustor is blended with the recycled gas from the dryer to provide the heat and gas flow necessary for drying.

The unrecycled portion of the off-gas from the dryer is treated in a wet gas scrubber and a horizontal scrubber, both using a water-based sodium carbonate solution. The wet gas scrubber recovers the fine particulates that escape the dryer cyclone, and the horizontal scrubber removes most of the sulfur oxides from the flue gas. The treated gas is vented to a stack. The spent solution is discharged into a pond for evaporation. The plant has several utility systems supporting its operation. These include nitrogen, steam, natural gas, compressed air, bulk sodium carbonate and a glycol/water heating and cooling system. 


\subsection{PLANT EQUIPMENT MODIFICATIONS}

The early operation of the ENCOAL plant facilities was typical of what would be expected from a first-of-its-kind technology application. Along with the many successful plant runs there were many more false starts. Valuable information was gained from every run, successful or not, and this information was carefully evaluated to define necessary equipment repairs, plant modifications and process adjustments.

In the last five years, numerous changes have been made to the ENCOAL plant facilities as well as to the computer programs that control its operation. These have taken place both during plant operation and during shutdowns. Planning for these changes starts during an operating mode in either case, sometimes involving contractors or operators on overtime making preparations for the modifications in a way that minimizes the length of a planned shutdown. The longest shutdown for modifications to date occurred from July 1993 to January 1994 for addition of the deactivation loop. Several shorter shutdowns were also required for other less involved modifications, some of which were remote to the main plant and work could proceed without interrupting plant operations, like the temporary process water handling system. The following sections describe the modifications made to the original plant equipment.

\subsection{Solids Handling System}

Problems in the solids handling systems in the ENCOAL plant were self inflicted in some areas, like spillage control. Dribble chutes, space for collection and clean-up and screw conveyors for the fines transfer were neglected in the original design. A means of removing raw coal from the feed coal silo without running through the plant became important during an unplanned lengthy shutdown. In the case of the flexible wall vertical plant feed and PDF conveyors (s-belts), the excessive spillage and fluid drive systems proved very troublesome. The GAMMA-METRICS on-line coal analyzers were eventually removed because of inferior software, cheap clone computers and a paucity of manufacturer's support. Sampling for the extensive calibration testing needed for these analyzers also was a problem because it had to be done by hand. Drag conveyors in the plant, all of the single chain design with hardened flights, have been very high maintenance items.

\section{$\underline{\text { S-belts }}$}

The Schultz Flex-O-Wall conveyors furnished with the original plant only had a few inches of clearance with the floor or nearest enclosure wall. High spillage is inherent because of the bucket design. The result was a maximum of a few hours run time before the material built up under the belts and began to be carried back, a fire hazard and thus causing a plant shutdown. During successive shutdowns, especially the VFB addition, dribble chutes were added, trenches jack-hammered into the floors and a screw conveyor added to eliminate the problems. The motors and fluid drive clutches ordered with these conveyors were sized too close to the nominal design and could not handle any surges.Eventually the motors were replaced and the fluid drives removed. 


\section{GAMMA-METRICS Analyzers}

The original LFC Technology concept included a closed loop process control scheme that relied on rapid, reliable on-line feed coal analysis as well as PDF solid product analysis. GAMMA-METRICS nuclear analyzers were purchased for the plant feed and product streams at an installed cost of well over $\$ 1,400,000$. The data from the analyzers was to provide feed forward and feed backward control of the process variables to allow optimization of the LFC process. Extensive efforts were made over the first four years of the project to calibrate these units so they would provide the needed process information. Hand sampling required for gathering the seemingly endless samples required by the manufacturer made the effort even more difficult.

Numerous 30 to 60 day sampling campaigns on a several-times-per-day basis were completed only to be thwarted by software or computer crashes that caused loss of all data. Plant shutdowns also caused some of the problems, but invariably the user unfriendly data gathering equipment furnished by GAMMA-METRICS would fail before the plant could be brought back on line. Manufacturers support was very poor. In the fall of 1996, both GAMMA-METRICS analyzers were removed to end the exorbitant cost of maintaining the nuclear sources. Samples of coal and PDF are now taken manually once per shift and analyzed on site to maintain process checks.

\section{Miscellaneous}

To solve the problem of removing raw coal from the storage silo without going through the plant, a by-pass chute was added in the screening building. In retrospect, this should be included with any PRB storage unit to handle hot coal or avoid potentially long storage times. A dribble chute was also added on the plant feed belt to catch spillage. Other dribble chutes, wear plates, flow diverters and cleanout doors were also added in several places. Today the system operates very well. The drag conveyors still are high maintenance but money and time has not been available to change them to the dual chain design that would be much more reliable (and costly to buy). Drag conveyors in general, and certainly single chain type, should be avoided in commercial plants.

\subsection{Dryer and Pyrolyzer Modifications}

\section{Dryer and Pyrolyzer Internal Seals}

ENCOAL's process uses convective heating in the Salem Furnace Company rabbled rotary hearth furnaces for the dryer and pyrolyzer units. This is accomplished by passing hot gasses through a slotted, rotating grate upon which rests a bed of coal. The seal between the rotating grate and the vessel wall, which prevents the hot gas below the grate from bypassing the coal bed, was a blade attached to the rotating member immersed in a stationary tub of sand. See Figure 4.2a for the details. This seal design proved to be very troublesome.

Besides the higher than expected wear, sand degradation, coal dust build-up and 
maintenance problems in both units, the sand seal in the pyrolyzer did not allow operation at full design differential pressure across the grate. In order to operate, the flow rate in the pyrolyzer loop had to be reduced to avoid blowing out the sand in the seal. The lower gas flow resulted in loss of efficiency in the cyclone, dust carryover in the piping, solids in the CDL product and plugging of lines. In addition, less heat was transferred to the coal resulting in less severe pyrolysis. Attempts were made to raise the on-gas temperature to compensate for the lower gas flow but this generated heavier CDL and raised the liquid dew point in the off-gas. Condensation of liquid then occurred ahead of the quench column where it combined with the dust in the system creating unacceptable ductwork plugging.

At significant expense, the manufacturer, working with ENCOAL, developed an alternate design using external water seals rather than the internal sand seal. Details of this design are shown in Figure 4.2b. With design and material furnished by the manufacturer, ENCOAL installed the pyrolyzer water seal during the VFB addition shutdown. Based on highly successful results during the following plant runs, a water seal was added to the dryer in January 1995. This revision was one of the major contributors to longer runs in the ENCOAL plant.

Clean up of the Salem grates became more of an issue once longer plant runs were possible. The manufacturer again was asked to assist with the problem and they came up with a steam broom, a series of nozzles located above the normal coal level directed toward the soaking pit outlet. During shutdown, steam is turned on and the nozzles blow the residual coal off the grate. The steam brooms are very helpful and are used during every shutdown to help avoid fires when opening up the process vessels.

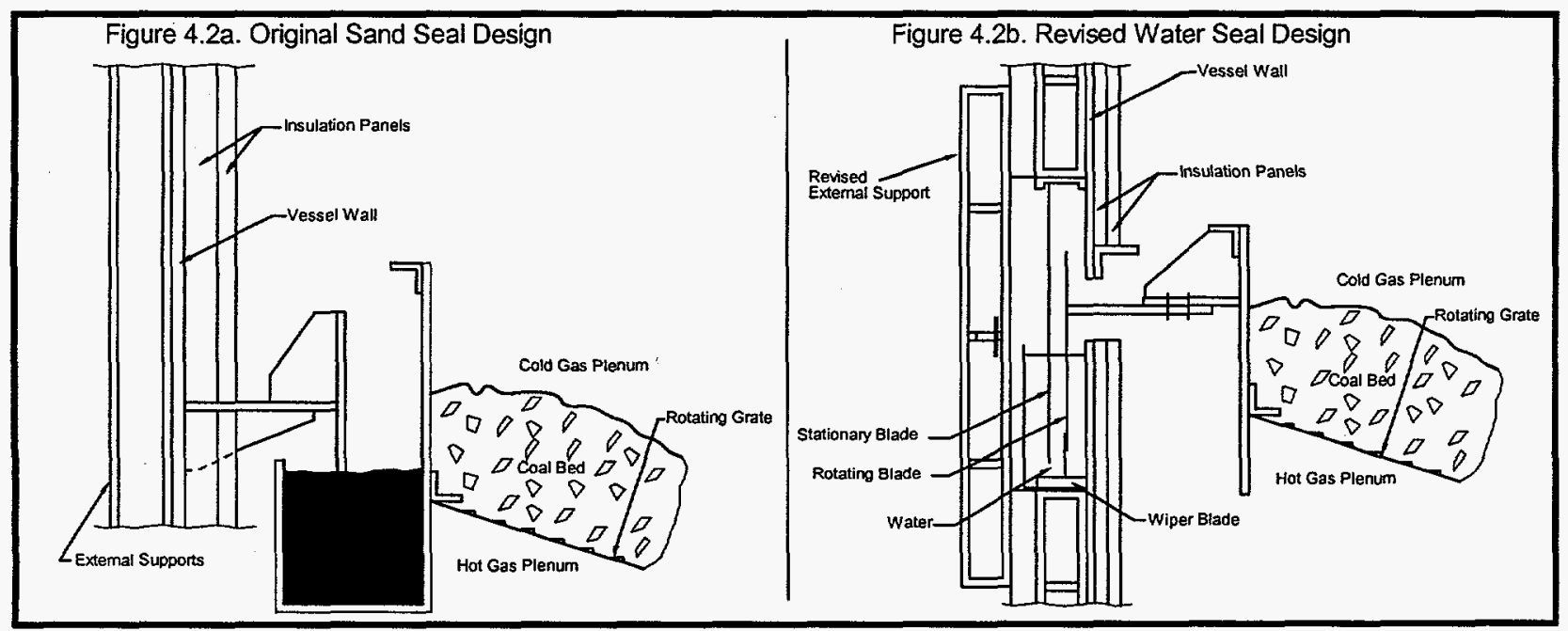

Figure 4.2. Comparison of Seal Designs - Dryer and Pyrolyzer 
In addition, a steam blaster was added to both units that swings down near the grate to clean the slots in the grate without entering the dryer or pyrolyzer. These have been used successfully to extend a run when the plugging of the grates is moderate. Manual cleaning is still required after many months of operation. This buildup is not a major problem. It is easily removed, consisting mostly of coal dust, not coke. It can be handled during normal yearly turnarounds in a commercial plant.

\subsection{Dryer and Pyrolyzer Cyclones}

\section{Dryer Cyclone}

Operation of the dryer cyclone was very successful with no modifications being made to the cyclone itself. However, the fines handling system at the discharge of the unit was significantly changed. The original design included indirect heat exchange via a screw cooler prior to being slurried to the sump system. Because of maintenance and plugging problems with the screw cooler, this unit was removed. The final layout simply mixes the fines with water immediately under the rotary valve airlock prior to draining to the plant sump system. (See Figure 4.3a: Dryer Cyclone Fines Discharge)

\section{Pyrolyzer Cyclone}

Operation of the pyrolyzer cyclone was not as successful as the dryer. The pyrolyzer cyclone was originally designed to be $97 \%$ efficient; however, problems with limited loop flow rates, cyclone pressure drop, and the small size and quantity of fines made this cyclone only $75 \%$ efficient. The pyrolyzer water seal modification discussed earlier did allow for higher flowrates and pressure drop, but the cyclone still did not perform as designed. This resulted in high sediment concentrations in the CDL. The gas inlet and the vortex finder were then modified to aid in flow direction and pressure drop increase. These modifications were somewhat successful yielding a CDL with an average sediment of $3 \mathrm{wt} \%$. Although not $97 \%$ efficient, the pyrolyzer cyclone operation is now acceptable.

Other modifications to the pyrolyzer cyclone include extensive changes to the fines handling system. The fines slurry mix tank and pump system originally designed for handling the pyrolyzer cyclone fines continually plugged and experienced high wear. This system was therefore removed. Like the dryer cyclone, the present fines handling system is a simple water-fines mixing box immediately under the rotary airlock prior to gravity draining to the sump system. This arrangement is easy to maintain and does not utilize any motorized equipment to operate. (See Figure 4.3b: Pyrolyzer Cyclone Fines Discharge) 


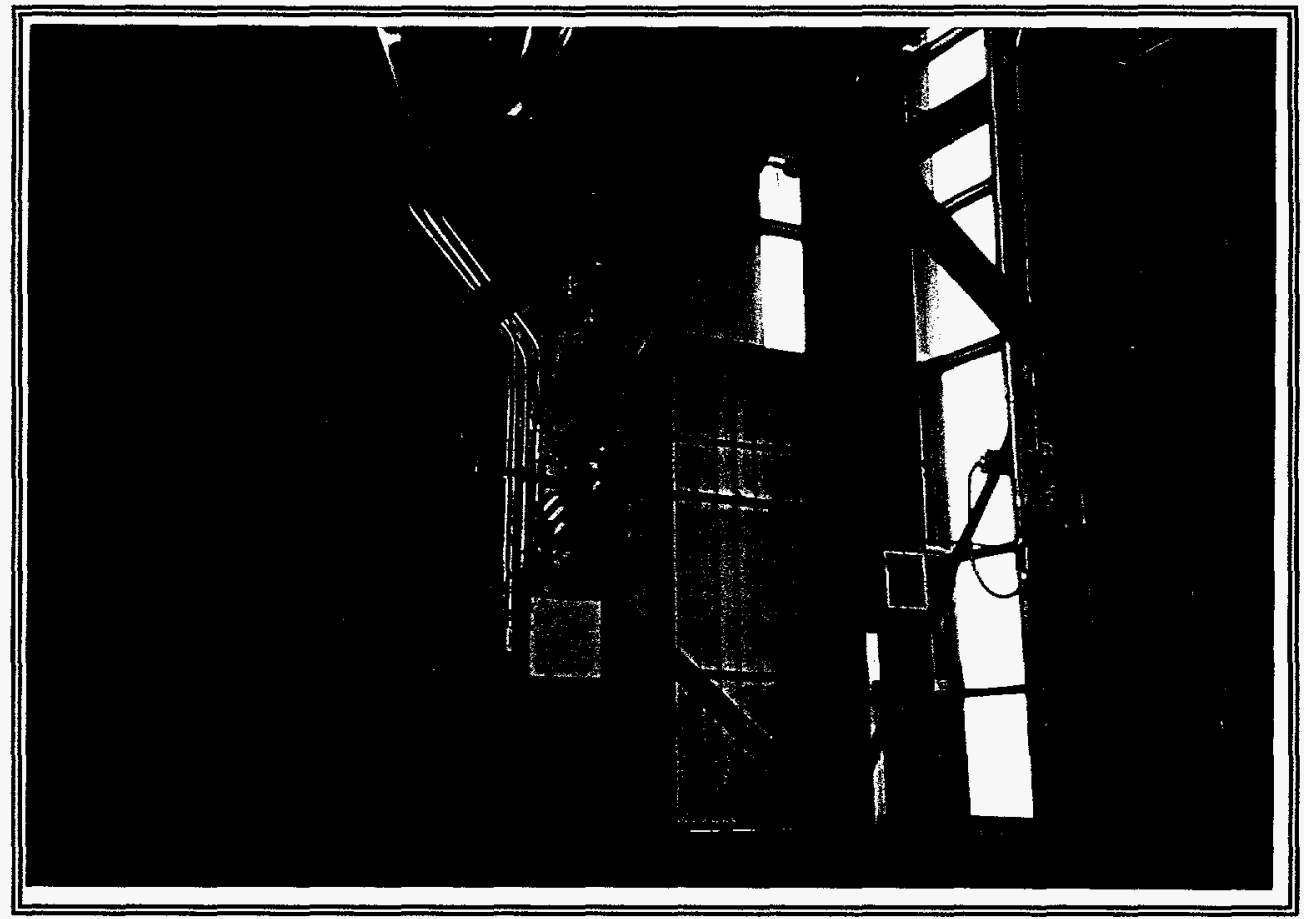

Figure 4.3a: Dryer Cyclone Fines Discharge.

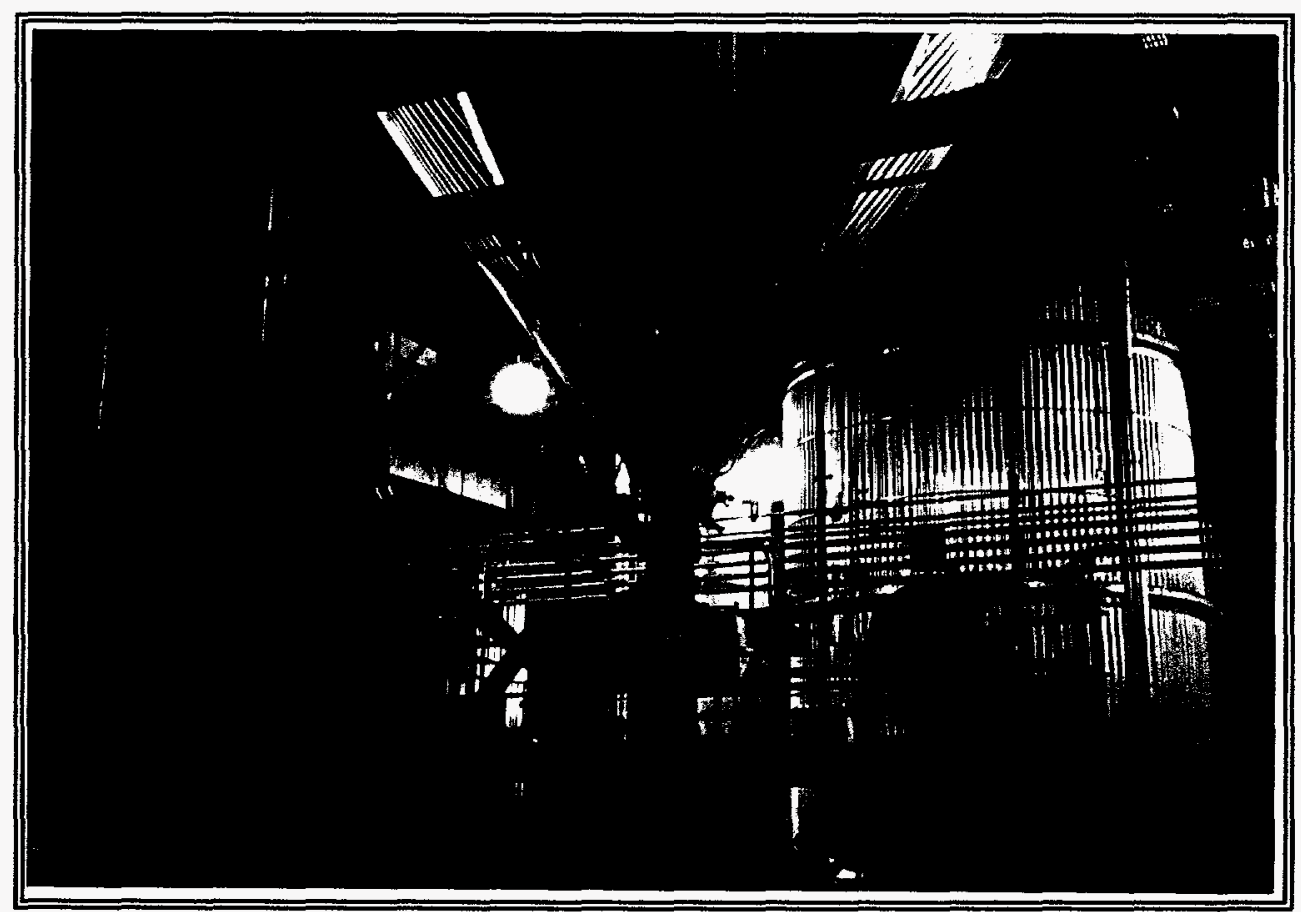

Figure 4.3b: Pyrolyzer Cyclone Fines Discharge. 


\subsection{Pyrolyzer Quench Table and Quench Steam Condensing System}

\section{Pyrolyzer Quench Table}

Few problems were encountered in the operation of the pyrolyzer quench table. The upper water seal was adjusted to keep from flooding the process during minor plant upsets, and the process water supply piping was modified for ease of maintenance. The quench table spray nozzle system supplied with the original equipment frequently plugged and could not be maintained while the plant was on-line. The nozzle assemblies were modified to be removable on-line for unplugging, and a supply header was fabricated to simplify the supply piping and organize the nozzles. This new arrangement was very successful in reducing the maintenance of the system and increasing operator understanding of the quench table operation. (See Figure 4.4a: Pyrolyzer Quench Table Water Supply Header)

\section{Pyrolyzer Quench Steam Condensing System}

Several problems were encountered with the operation of the quench steam condensing system. Excessive coal fines build-up was experienced in both the piping to the condenser and in the condenser tubes themselves. Plugging of the condenser caused over pressuring of the quench table, which in turn required the opening of a pressure relief valve. Many plant shutdowns were attributed to this phenomenon. A fines knock-out drum and piping wash nozzles were installed between the quench table and the condenser to strip the coal fines from the steam. (See Figure 4.4b: Quench Steam Fines Knock-out Drum) The knock-out drum addition was successful in allowing the plant to run for longer periods; however, extended plant operation would eventually foul the single condenser and cause a plant shutdown. A second, redundant condenser was then installed to allow for on-line switching between condensers without requiring a plant shutdown for cleaning. (See Figure 4.4c: Dual Quench Steam Condensers) With these modifications, the operation of the quench steam condensing system became routine.

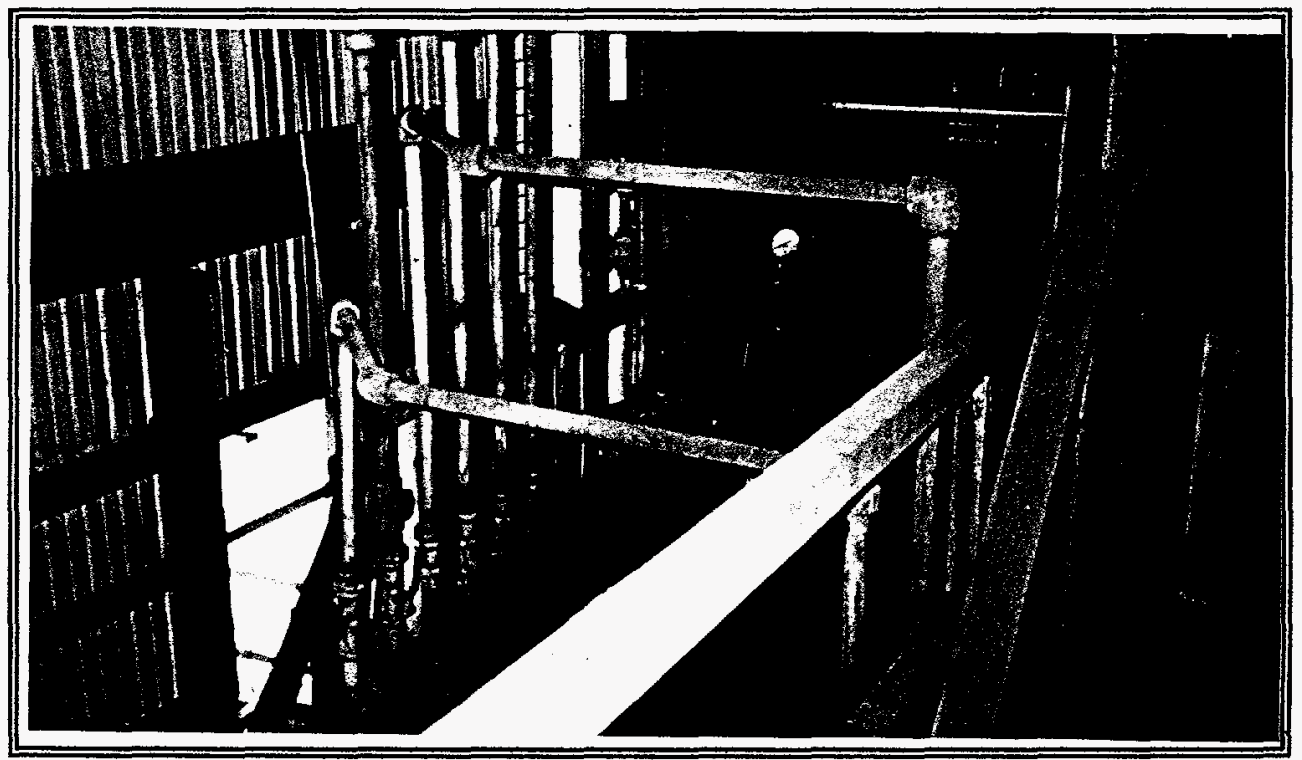

Figure 4.4a: Pyrolyzer Quench Table Water Supply Header. 


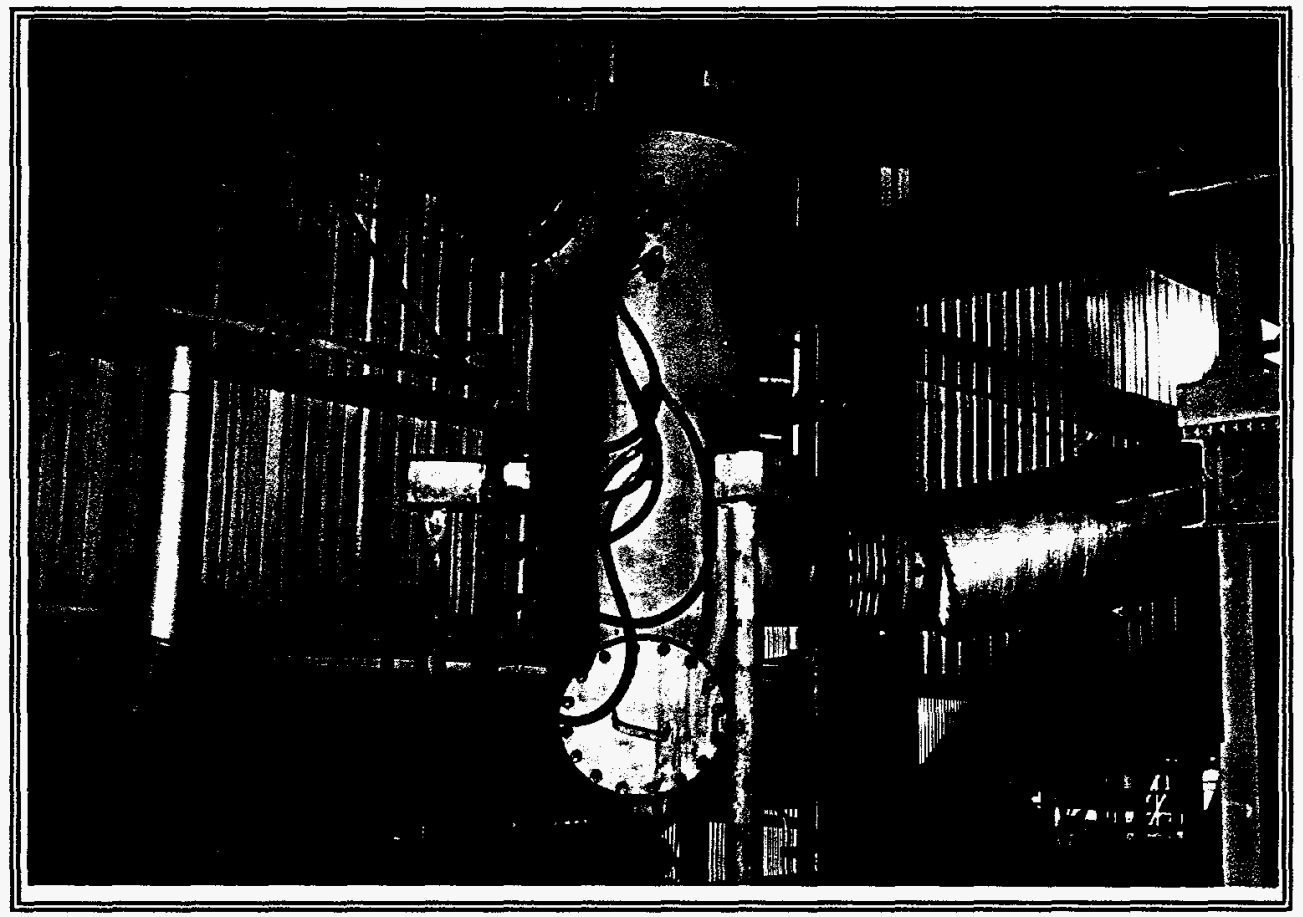

Figure 4.4b: Quench Table Steam Fines Knock-Out Drum.

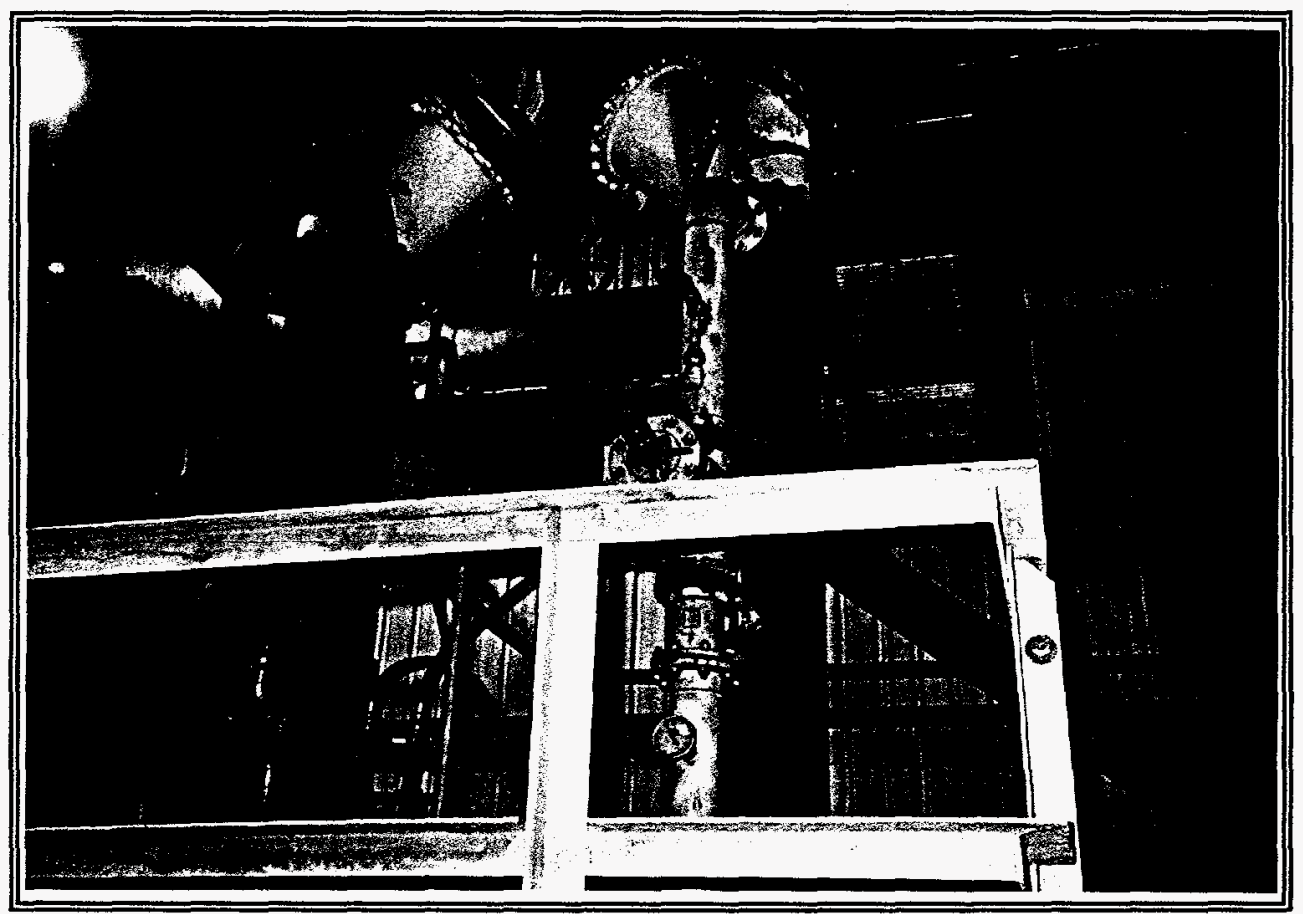

Figure 4.4c: Dual Quench Steam Condensers. 


\subsection{PDF Deactivation System}

Problems with PDF product self heating in 1992 and 1993 led to several minor plant modifications and extensive testing in hopes of using original plant equipment to produce stable PDF. Results of a January 1993 test run, however, indicated that PDF deactivation would require a separate, sealed vessel. Subsequent plant and laboratory tests were run in February and March of the same year in order to establish effective criteria for deactivation. Based upon the results of these tests, an option for PDF deactivation was chosen. The deactivation process is discussed below. For the modification, a $6^{\prime} \times 30^{\prime}$ vibrating fluidized bed unit and support equipment, the first of two planned systems, were installed in series with the original plant equipment to deactivate PDF. The system was designed to handle half plant throughput; when it had proven itself, a second VFB system would be installed. Installation of the PDF deactivation facilities, (ie VFB project), began in June 1993 adjacent to the ENCOAL plant. Construction and start-up of the facilities was completed in January 1994 and the new equipment is currently in operation. (See Figures 4.5a and 4.5b: PDF Deactivation System Construction, and Figure 4.5c: PDF Deactivation Building Completed)

\section{PDF Deactivation Loop Process Description}

Quench table processed coal is fed into the deactivation loop by a sealed drag conveyor where it is partially fluidized and treated with a controlled temperature and oxygen gas stream in a VFB unit. The deactivation gas stream consists of a fan to move the gas stream, a cyclone to remove entrained solid fines, a heat exchanger to control gas temperature, and a booster fan to bleed off gas to the dryer combustor. The residence time, oxygen content, and temperature of the gas stream were selected to deactivate the coal within the VFB unit. (See Figure 4.5d: PDF Deactivation Loop Simplified Process Flow Diagram)

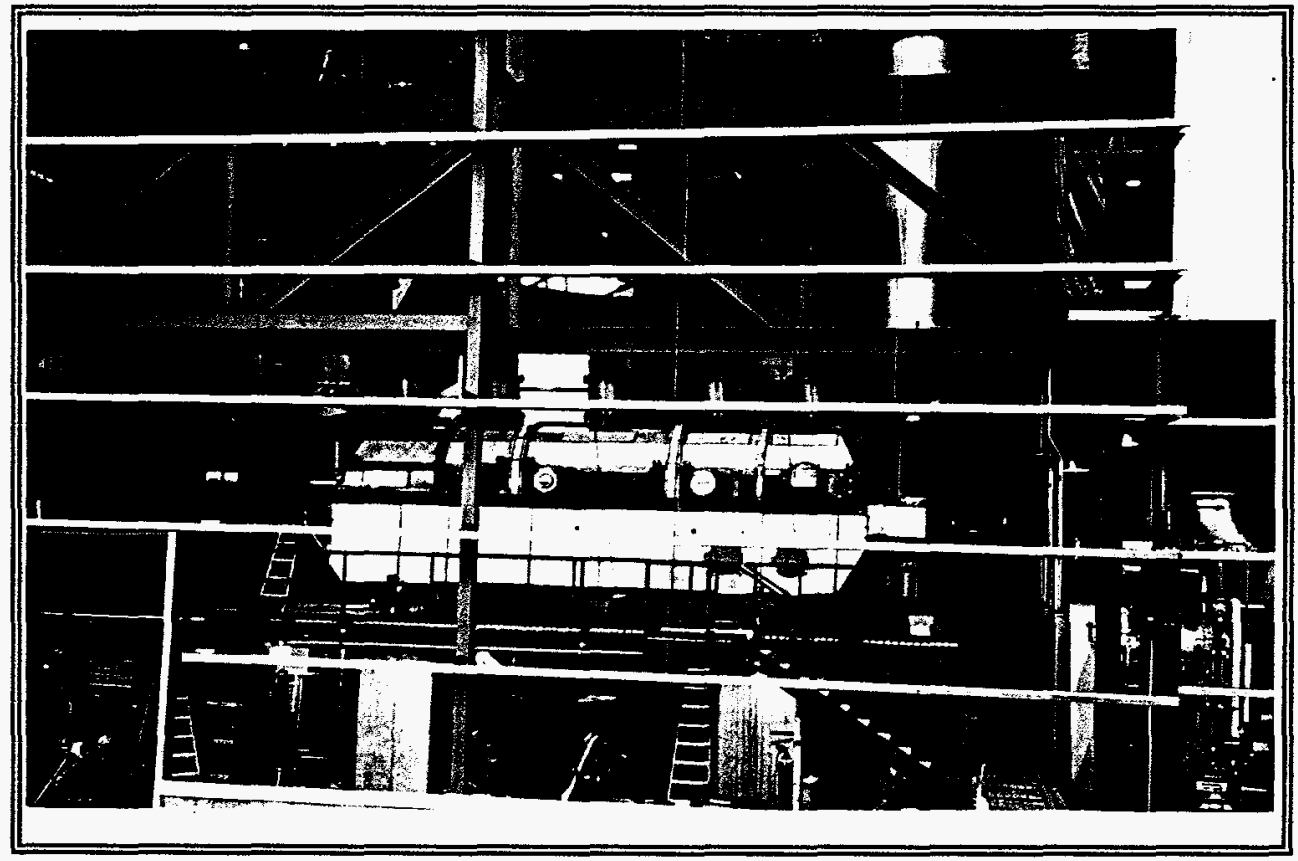

Figure 4.5a: Vibrating Fluidized Bed Unit. 


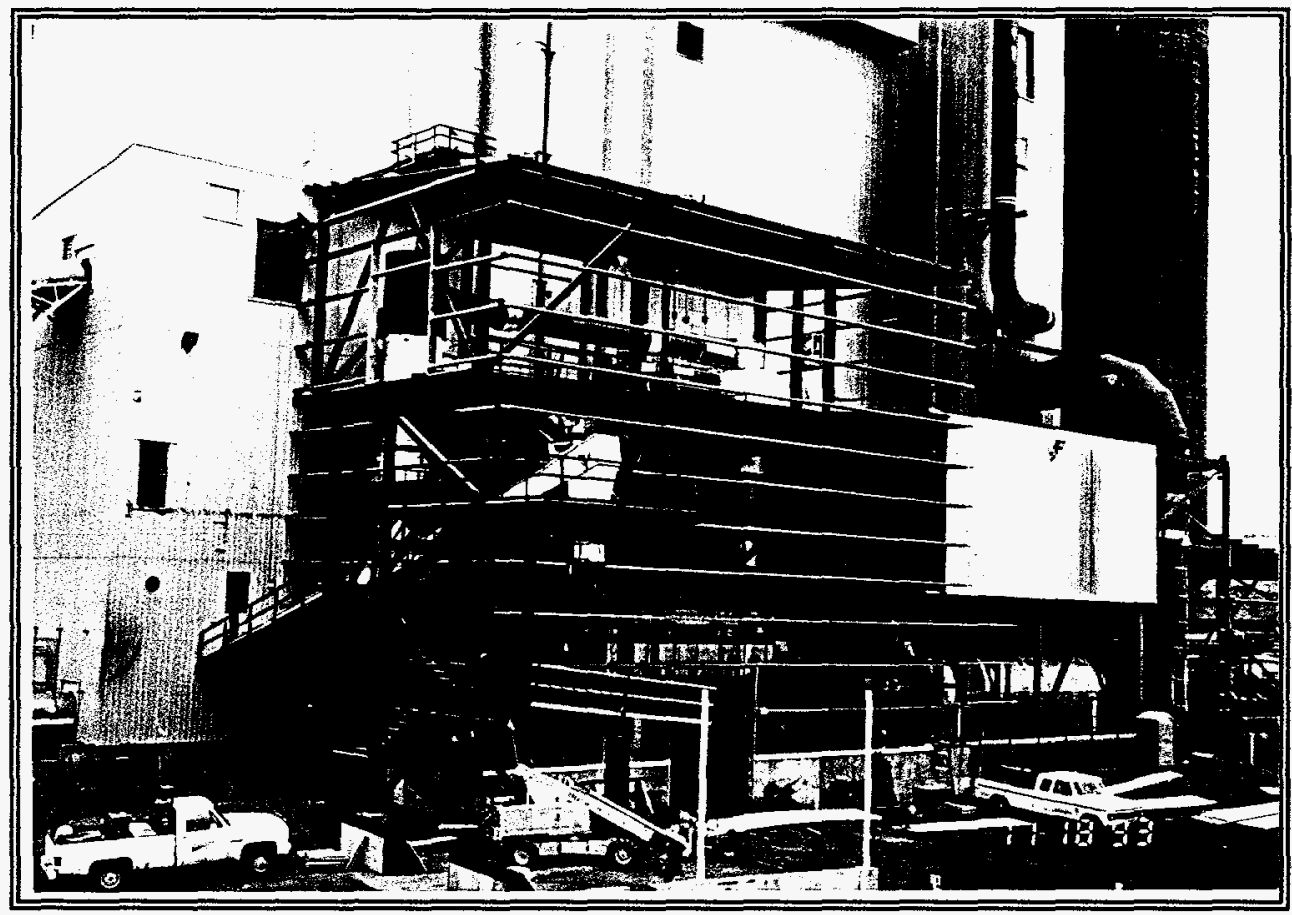

Figure 4.5b: PDF Deactivation System Under Construction.

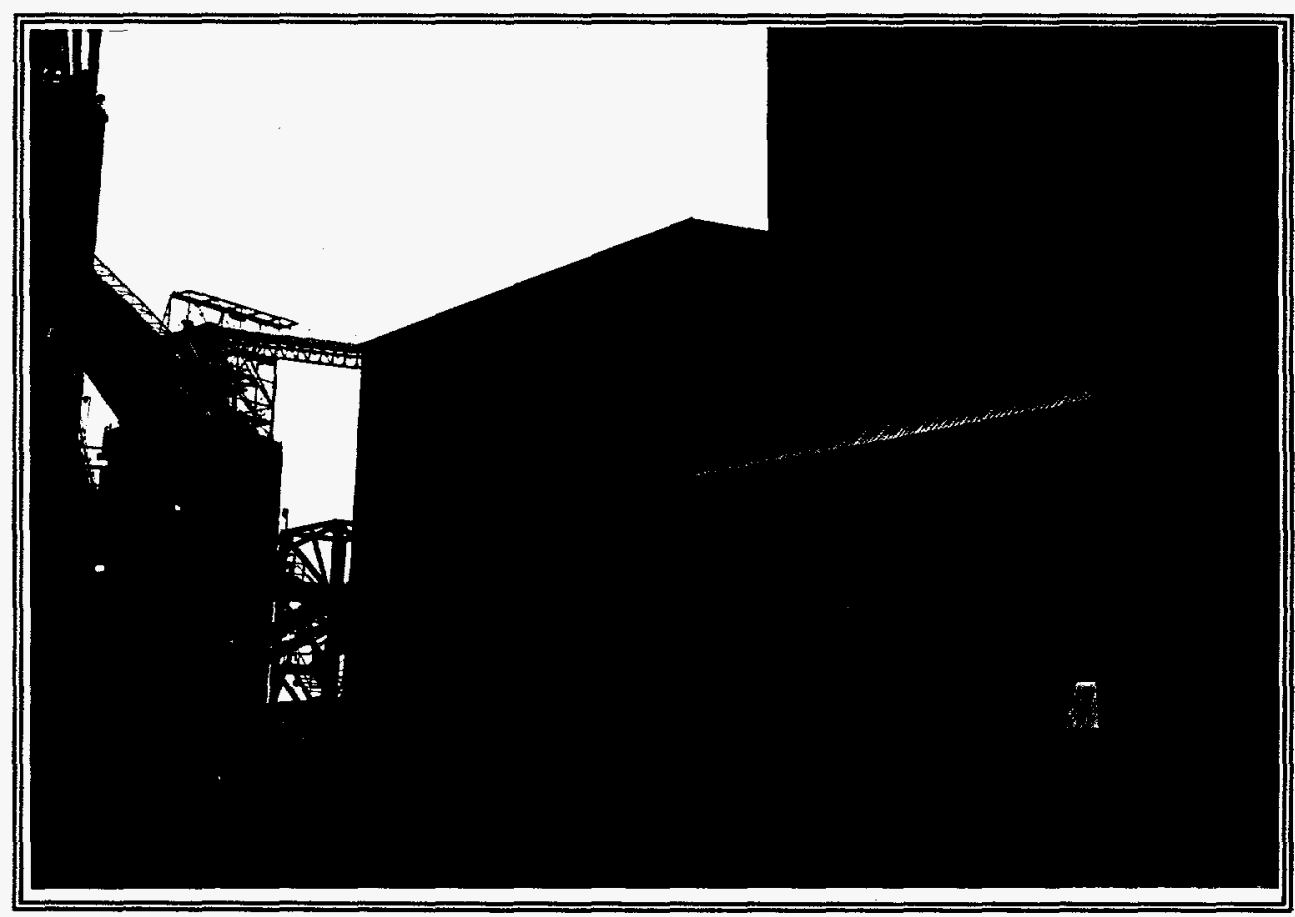

Figure 4.5c: PDF Deactivation Building Completed. 


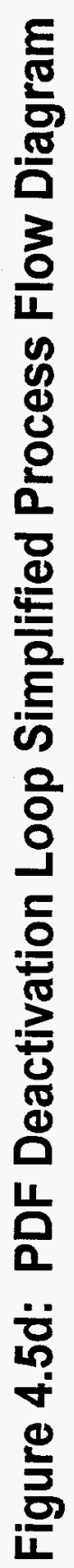

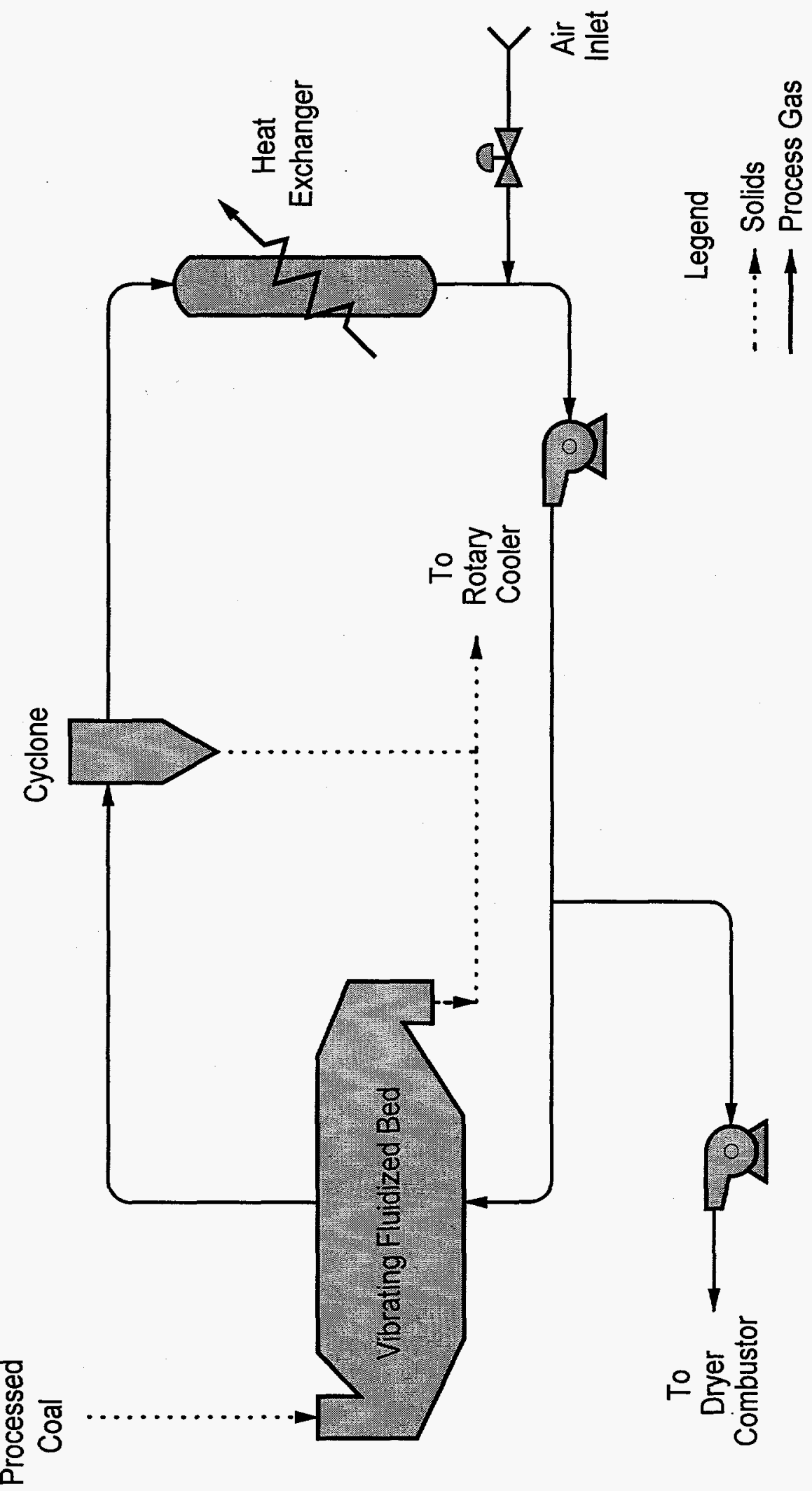




\section{VFB System Operation}

By the spring of 1994, plant production runs were considerably smoother and longer. The new deactivation system allowed for shipment of PDF to utility customers for the first time; however, even as PDF stability was notably improved with the addition of the VFB, deactivation of PDF still required additional oxygen prior to shipment. Over 20 different operating conditions were varied and evaluated to enhance the amount of oxygen absorbed in the VFB system, but were not entirely successful. The decision was made to "finish" the oxidation deactivation of the solids by laying the PDF on the ground outside the plant. This process, which came to be known as "pile layering", involves spreading the PDF in 12-inch layers thus allowing PDF particles to react with oxygen and become stable. As each thickness is stabilized, more PDF may be layered on top. This method of stabilization, (combined with blending with ROM coal, increased silo retention times, and slightly higher rehydration rates), has been used to deactivate PDF for all shipments to date.

In-plant stabilization of PDF, however, still required more evaluation. This evaluation process was conducted in 1995 and 1996 in series with the plant operation, and discussion of this work is found below in Section 4.14: PDF Finishing.

\subsection{PDF Cooler and Rehydration}

The cooler is a rotating cylindrical vessel which measures 11 feet diameter and 50 feet in length, and is used to cool PDF to atmospheric temperature in the LFC Process. The unit indirectly cools the PDF using internal cooling water tubes and tumbling action to accomplish the heat exchange. This unit was found to be a very efficient heat exchanger, and little mechanical or operating problems were encountered. In fact, concerns of external tube fouling with dust were alleviated as the tumbling action of the PDF kept the tube surfaces clean during operation.

Several temporary modifications were made to the PDF cooler in late 1992 in an effort to improve PDF stability using in-plant equipment. These modifications included the addition of a fan, ductwork, and entrained fines removal equipment to circulate a controlled oxygen atmosphere through the cooler. These modifications proved unsuccessful, and it was determined that a separate, sealed vessel would be required to deactivate PDF as discussed in Section 4.5 above. The gas circulation system was therefore removed from the cooler.

\section{$\underline{\text { Rehydration }}$}

Other modifications made to the unit, however, were more successful. The original design of the ENCOAL plant placed the rehydration step in the process at the top of the PDF silo, spraying water on the PDF as it dropped vertically into storage. This rehydration technique proved to be inconsistent as it was difficult to obtain uniform distribution of water on the PDF, and there was not adequate mixing as PDF entered the 
silo. In addition, as PDF rehydrates to equilibrium moisture, the resulting heat of reaction necessitates heat removal, or the PDF overheats and becomes unstable.

The cooler was modified to include a small water lance and spray nozzle to inject rehydration water into the interior of the unit. The nozzle placement in the cooler was designed to be adjustable to ensure the proper amount of water could be injected without flashing to steam. The tumbling action of the cooler was found to provide more than adequate mixing, and the heat of reaction due to rehydration is taken away by the indirect heat exchange with cooling water. With the relocation of the rehydration spray to the interior of the cooler, the distribution of rehydration water and the consistency of PDF moisture quality greatly improved. (See Figure 4.6: PDF Cooler with Rehydration Spray Addition)

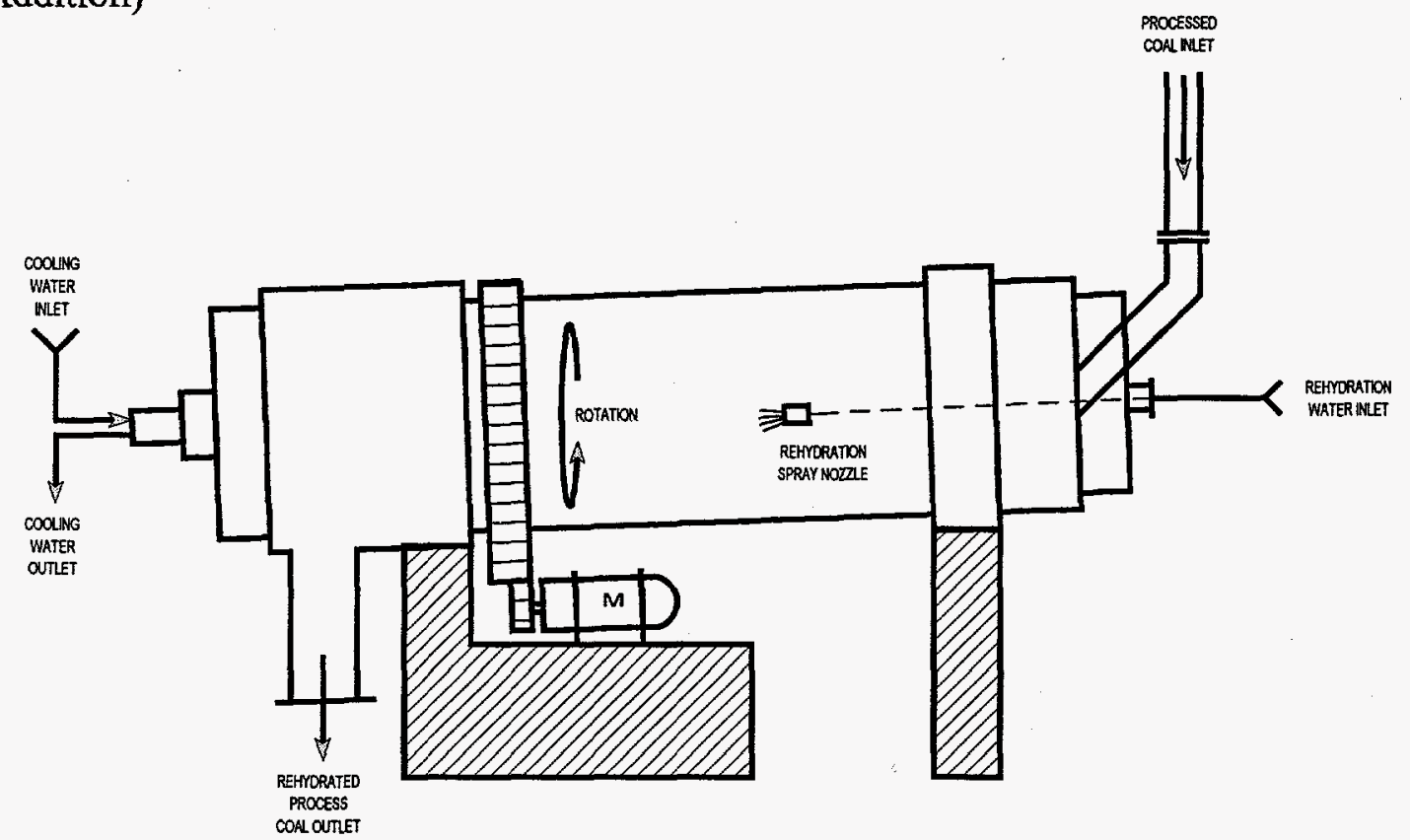

Figure 4.6: PDF Cooler With Rehydration Spray Addition.

\subsection{Quench Tower}

The quench tower in the ENCOAL plant is a $12.5^{\prime}$ diameter by $90^{\prime}$ tall condensation unit where the overhead gas from the pyrolyzer is cooled to form CDL. It has 12' of Glitch Grid Tray packing giving approximately two theoretical stages to reach equilibrium. A distributer bar with nozzles at the top of the packing breaks the refluxed CDL cooling oil into droplets that cool the gas and absorb the condensible hydrocarbons. This column has worked very well during its five years of operation. No buildup of solids on the walls or in the packing has ever been observed even though it was predicted by some that cokingwould occur.

One problem did occur in the column inlet piping and gas distributor. An oily mixture of 
coal fines and heavy pitch would build up at the column inlet distributor as shown in Figure 4.7a. This accumulation caused several plant shutdowns and many hours of cleanup in the piping, (and general area when the oils were inadvertently spilled). After several attempts to make larger and larger weep holes work in the distributor, it was completely removed. The revised distributor is depicted in Figure $4.7 \mathrm{~b}$ has eliminated the problem and the plant has operated for nearly two years without measurable buildup. In the preceding two years the piping had to be cleaned out about every three months.

\subsection{Electrostatic Precipitators}

Much time was spent in repairing the ESP's in 1992 and 1993. Numerous plant shutdowns were caused by failed insulators in all three units. ENCOAL worked in conjunction with the ESP manufacturer to establish the cause of the insulator failures. As

a result of this effort, several modifications were implemented and are listed as follows:

1) New non-glazed, ceramic insulators were fabricated and installed in the units. These new insulators are made of a material that is resistant to cracking and are of a slightly different design than the originals.

2) Heating blankets and external insulation were added on the insulator cans and the blankets were set to a temperature that maintain $250^{\circ} \mathrm{F}$ at the insulator. The high temperatures keep the surface of the insulator hot and do not allow liquids to condense on the insulator surface.

3) Thermocouples were installed on all of the insulator cans to monitor the can temperature during plant operation. An operator alarm is activated if the can temperature falls below the set temperature.

4) The gas flows through the three ESP units were balanced. A balanced flow ensures that process gas is distributed equally and not concentrated through one ESP.

5) A nitrogen purge was added to all insulator mounts to keep CDL from condensing on the insulator surface, and thereby avoiding an insulator failure.

These modifications were very successful in solving the operational difficulties with the ESP's. Once the initial insulator failures were overcome, the ESP's operated very well for the remaining $3 \frac{1}{2}$ years of operation. 
Figure 4.7: Quench Tower Gas Distributor Modification
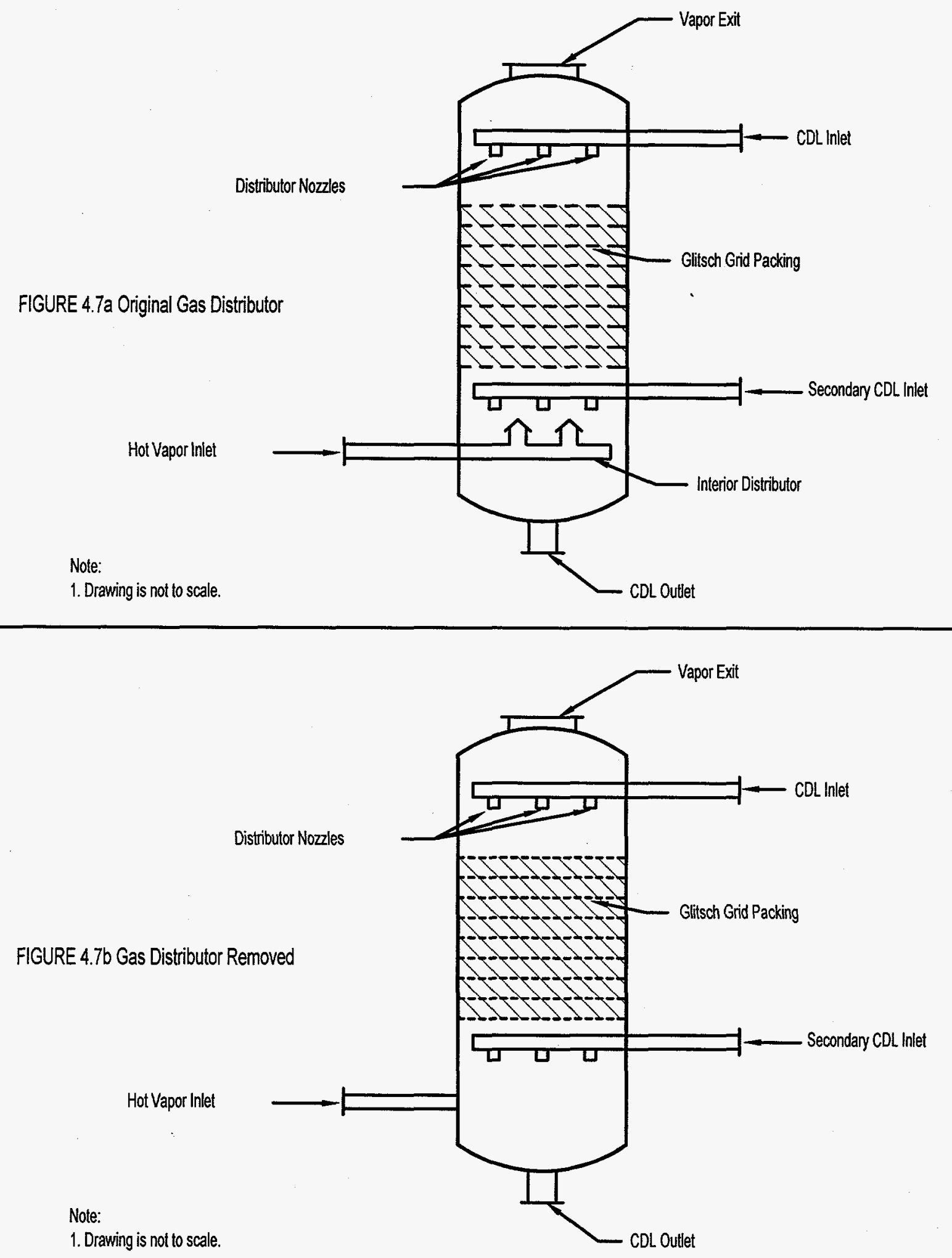


\subsection{Handling and Storage}

Essentially no modifications were made to the original CDL handling and storage systems with the exception of the loadout facilities. The CDL loadout flow meter was removed after loading the first rail car. The meter fouled with $\mathrm{CDL}$ and became inoperable. It was decided that maintenance of this instrument would be high and a system of tank car measurement and weighing of the cars was utilized for all further shipments. The loadout pump was also relocated from the loadout area to the CDL storage tank. Insufficient suction head of the pump necessitated its relocation to be closer to the main storage tank. Overall, the CDL handling system operated quite well and was one of the least modified systems in the plant. In particular, the glycol/water heat tracing of the CDL lines proved to be ideal even during the extreme winter temperatures of Wyoming. The CDL system could be started from a "cold" stop, with little or no impact on the system operation.

Independent of the plant operation, sediment removal from CDL was tested in late 1996 in an attempt to reduce the solids content of the oil and expand CDL market opportunities. A small centrifuge was installed and tested at various conditions. From these tests, it was determined that a centrifuge could be used to remove $95 \%$ of the sediment with less than a $5 \%$ loss of $\mathrm{CDL}$ by weight. A conceptual design was made to implement a CDL solids removal system using the results of this test. The system would consist of a feed surge tank, pump, and a centrifuge to handle the CDL, and a fines bin, mixer, and a pelletizer to handle the sludge generated by the removed solids. Dryer or pyrolyzer cyclone fines can be blended with the sludge and agglomerated to produce a pellet PDF product. This agglomeration step was tested in early 1997 , and fines to sludge ratios of $85 \%$ to $15 \%$ were successful in producing an acceptable pellet. Further CDL solids removal testing is ongoing and implementation of a full-scale system depends on market response to the "cleaned" CDL.

\subsection{Process Fans}

Both the dryer and the pyrolyzer fans were found to operate acceptably as designed for the process flow and temperature conditions, but were grossly inadequate in terms of sealing the process gases. In both units, the casing gaskets were replaced, and the casings themselves had to be modified and seal welded in the field to correct poor quality fabrication. The vendor supplied shaft seals were also found to be inadequate. Major modifications were made to the dryer fan in particular to accommodate a new mechanical carbon gland seal on a casing that was not designed to be gas tight. Once installed, the new carbon seals were more effective, but would eventually leak due to accelerated wear by fines in the process gas. Even with nitrogen purges, the fines in the process gas would contaminate the seal surface and excessively wear the carbon rings after only a few weeks of operation. Several iterations were made on sealing the units, and finally an ENCOAL "home-made" packing gland type seal with high temperature grease was found to be the best and longest lasting seal. Today, a carbon gland seal with a nitrogen purge is used on the suction side of the fan and a packing gland-grease seal is used on the pressure side.

\subsection{Combustors}


Control of the combustors was found to be difficult during start-up. The combination of oxygen excursions in the dryer loop and oscillation of the air to fuel ratios plagued the operation. In particular, the transition from secondary air to primary air in the combustor ramping sequence was not smooth. The original design primary air control valves did not regulate flows well under low flow conditions. Once the combustors were ramped past the transition point, the air control would improve, but the fuel to air ratios would fluctuate. An eight inch trim control valve was therefore added to both the pyrolyzer and dryer primary air intakes, and much improved stability of the combustor air flows was obtained. Programming changes were also made to both combustors that allowed natural gas flow to follow the combustion air flow rates. This change was necessary to dampen oscillations and prevent oxygen excursions due to improper air to fuel ratios.

Since the initial control problems were overcome, operation of the combustors has been generally uneventful. Minor adjustments to the programming occurred during the remaining $4 \frac{1}{2}$ years of use, and the combustion of the $30-50 \mathrm{Btu} / \mathrm{scf}$ plant recycle gas was very successful.

\subsection{Purge Gas Treatment}

The sodium carbonate solution sulfur recovery scrubber system in use at the ENCOAL plant is another system that has worked very well and has not required major modifications. This system first uses a venturi scrubber of the same patented design as the dust scrubbers to remove particulates from the purge gas stream. A Kellogg patented wet gas scrubber with three water curtains follows the venturi. Sodium carbonate solution used in both scrubbers removes $97 \%$ or more of the sulfur compounds in the purge gas stream.

Because the scrubber system is handling water, $\mathrm{SO}_{2}$ and $\mathrm{SO}_{3}$ at temperatures well below the dew point of sulfuric acid, the material of construction selected was fiberglass reinforced plastic. The temperature limit for this material is $170^{\circ} \mathrm{F}$. To protect the purge gas piping water sprays were added ahead of the venturi scrubber with firewater backup to insure they would work. In addition, to provide over temperature protection to the whole dryer loop, an emergency cooling water spray system was added in the dryer ongas ductwork. These systems have performed very well and no purge gas equipment has ever been damaged, or subjected to temperatures exceeding design.

\subsection{Dust Scrubbers}

Operation of the original two raw coal dust scrubbers proved that the patented design of these units worked very well to collect dust from conveyor transfer points. However, during start-up and shutdown conditions, there are times when the facilities are not operating at design conditions, and dried, underpyrolyzed coal (off-spec PDF) is produced. This condition led to excessive amounts of dust at the PDF transfer points early on in plant operation. Two additional dust scrubbers were therefore installed to 
gather dust from the PDF s-belt, PDF cooler, and the PDF silo transfer points. (See Figures 4.13a and 4.13b: PDF Transfer Point Dust Scrubbers)

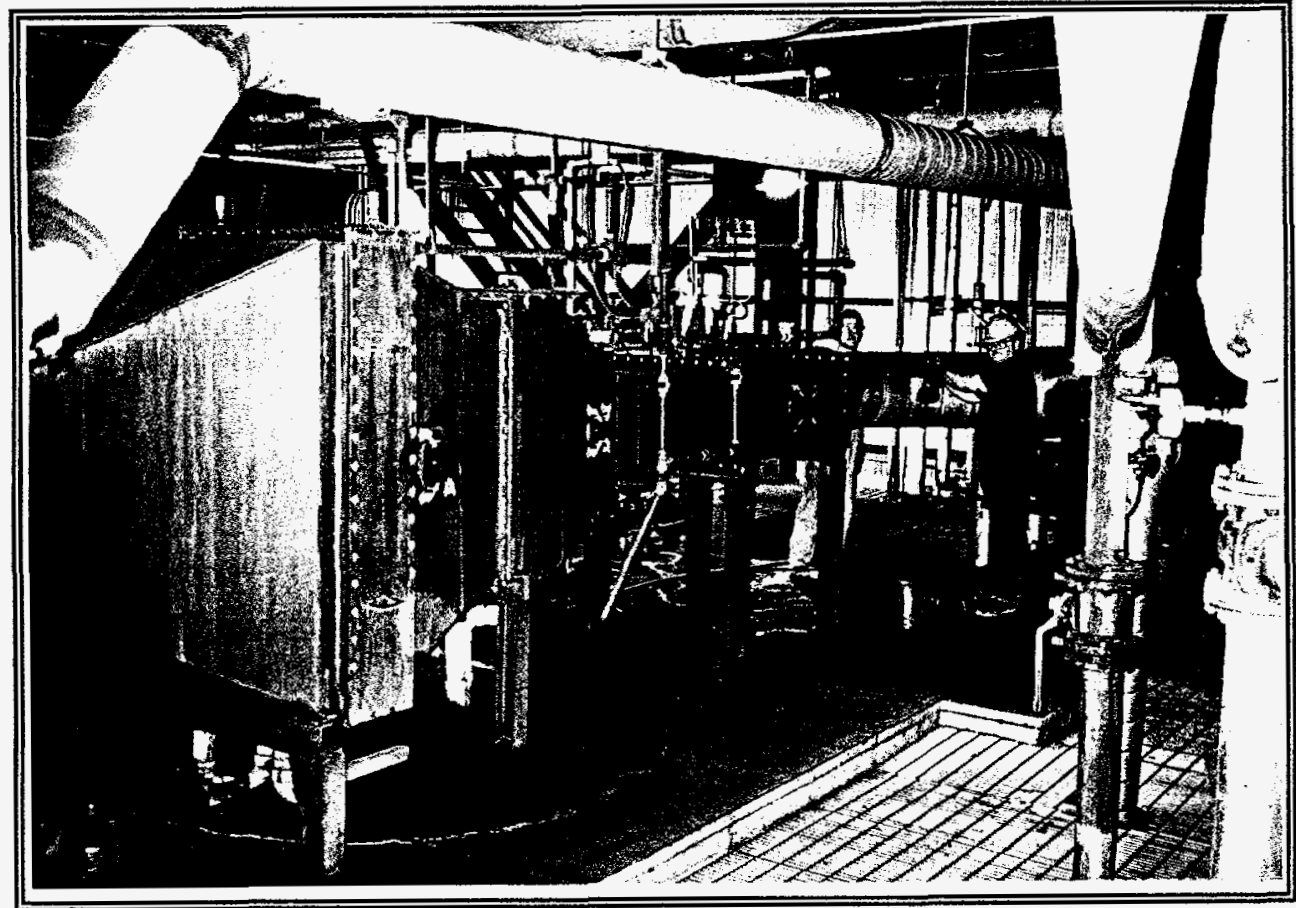

Figure 4.13a: PDF Cooler Dust Scrubber.

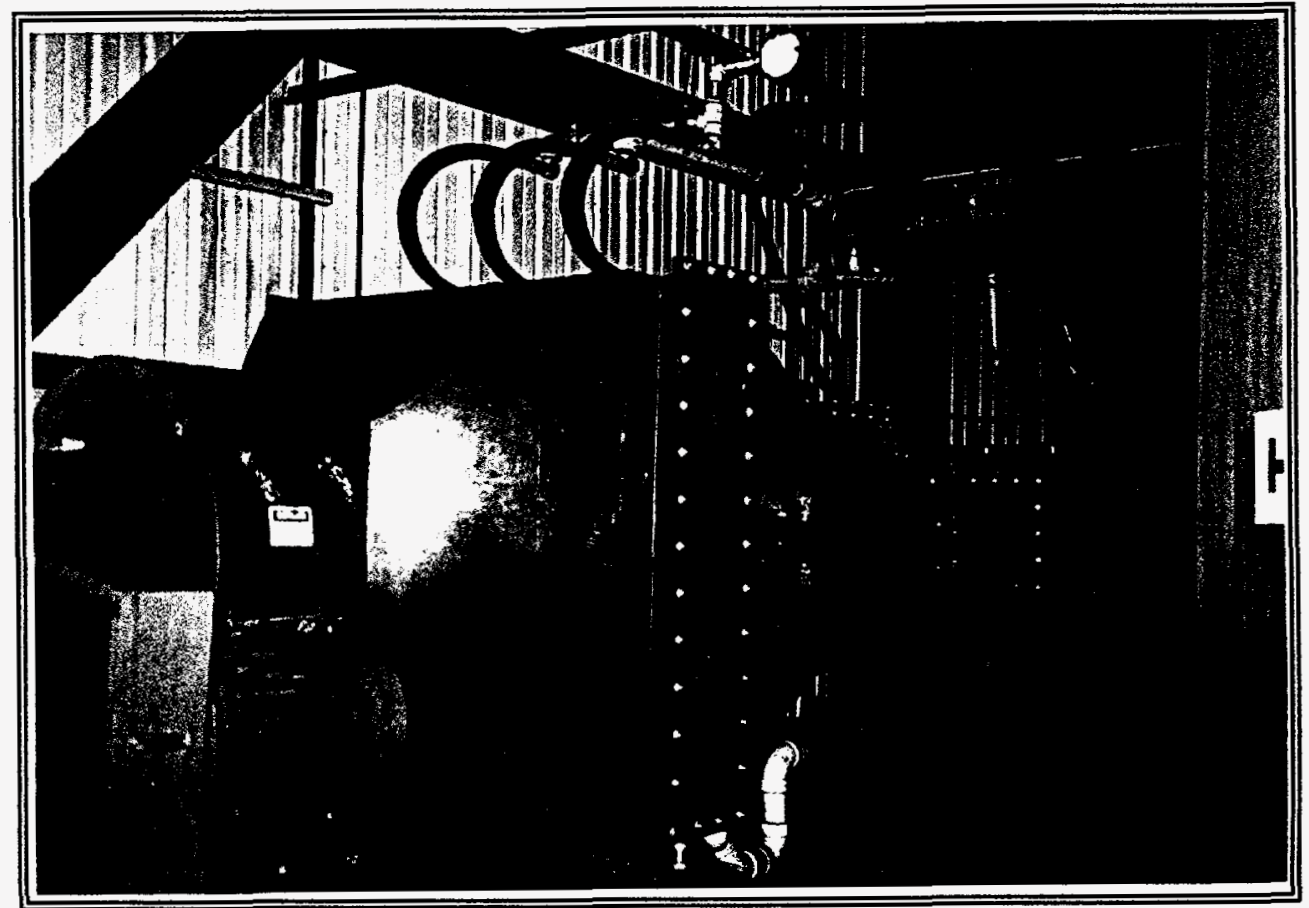

Figure 4.13b: PDF Silo Dust Scrubber. 


\subsection{PDF Finishing}

\section{Background}

As discussed in Section 4.5 above, extensive testing and plant modifications were made in an effort to stabilize PDF using in-plant equipment. The addition of the PDF Deactivation (VFB) system in 1993 was designed to accomplish this task, however it was determined that additional oxidative deactivation of the PDF was necessary. In order to produce shipments of PDF for utility test burns, "pile layering" of PDF on the ground was utilized. This method of stabilization is labor intensive and negatively impacts PDF quality by degradation of size, moisture, and ash content by being handled outside the plant.

A PDF stability task force was assembled in late 1994 to develop an acceptable in-plant stabilization method and test this design in the ENCOAL plant. Several avenues were pursued including spray-on additives, additional plant equipment, and changes in plant operation. The task force met with engineers and scientists from the Pittsburg Energy Technology Center (PETC) and the Morgantown Energy Technology Center (METC) to identify areas where assistance was needed in solving stability problems. As a result of the meeting, a Cooperative Research and Development Agreement (CRADA), a separate, research-oriented accord with PETC, was developed, and a project combining the applied research efforts of ENCOAL, Western Syncoal, PETC, and METC was formed. These entities would develop measurement methods, define reaction kinetics and mechanics, and evaluate new stabilization techniques. As a result, a Bureau of Mines test, nicknamed "Jar-O$\mathrm{R}$," was modified to measure product reactivity and is still used to measure the oxygen appetite of upgraded Powder River Basin coal.

By July 1995 , the stabilization task force, working with the resources represented by the CRADA, performed successful bench scale tests for oxidizing PDF at low temperatures, and the team recommended the construction and testing of a Pilot Air Stabilization System (PASS) to complete the oxidative deactivation of PDF without drying the product. At this time, the CRADA completed its contributions to the stabilization research.

Design and installation of the Pilot Air Stabilization System (PASS) was completed in November 1995, and the unit operated from late November through January of the next year. PASS testing was successful: the PASS unit processed $1 / 2$ to 1 ton of solids per hour, 24 hours a day, for $2 \frac{1}{2}$ months. Even more important, stable PDF was produced for the first time and stable, uncompacted piles were made without ground stabilization techniques. The data obtained were used to develop specifications and design requirements for a full-scale, in-plant PDF finishing unit based upon an Aeroglide tower dryer design. (See Figure 4.14a: Aeroglide Tower Dryer) As part of the commercialization effort, these same data were then scaled up for application to a larger plant. Financial restrictions have delayed the fabrication and installation of the ENCOAL plant full-scale finishing unit, but ENCOAL will continue to seek private funding for this project. 
Figure 4.14: Proposed PDF Finisher; Aeroglide Tower Dryer.

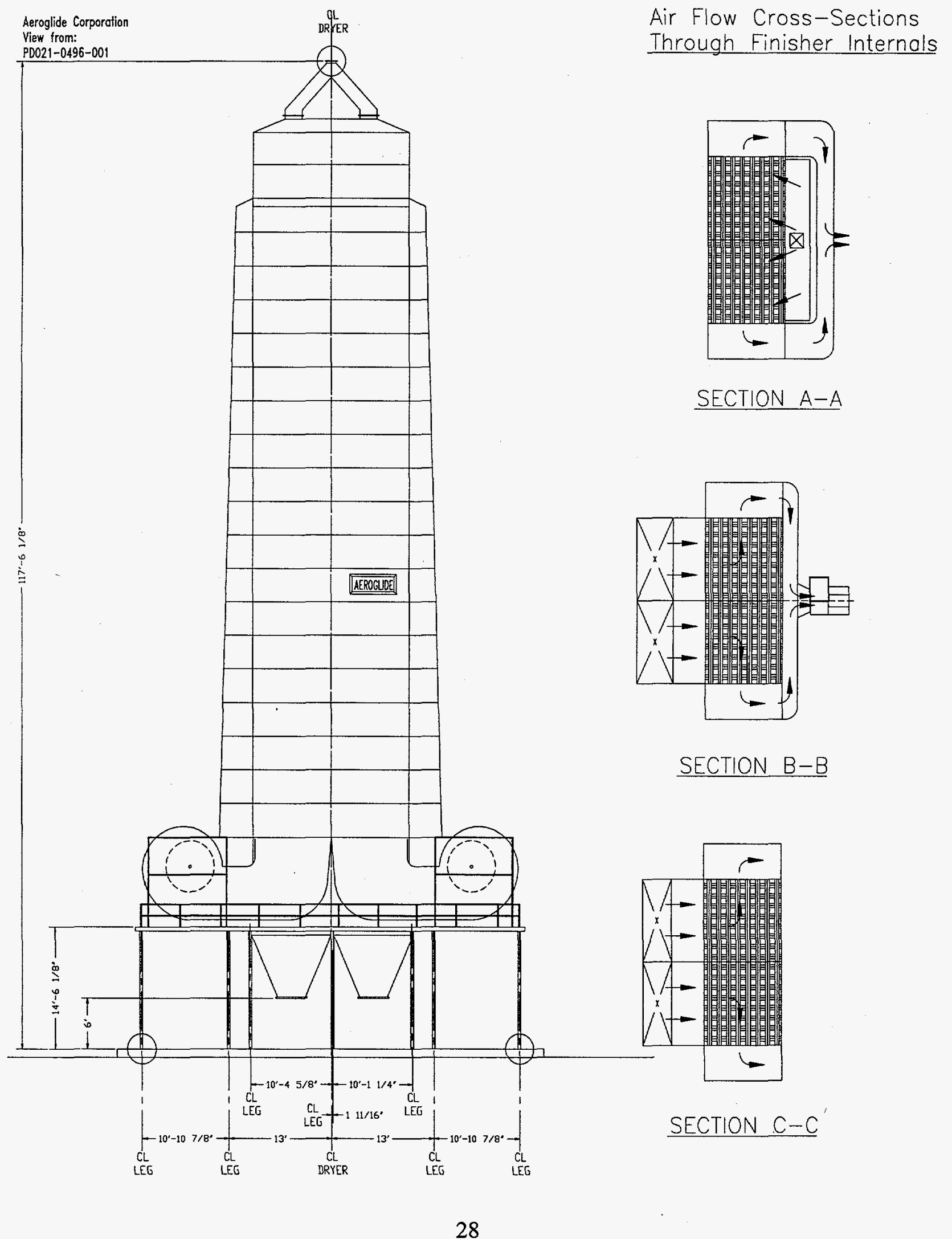




\section{0}

In most cases, the original ENCOAL plant utility systems required few modifications during the last 5 years of operation. Systems such as glycol/water, natural gas, potable water, and firewater were essentially unchanged from the original design. In other cases however, changes were necessary to make a system more reliable and easier to operate. Utility modifications took advantage of plant shutdowns whenever possible, involving contractors or plant operators for implementation. The longest plant shutdown for utility modifications to date occurred from mid-March 1995 to May 1995 for the addition of the permanent process water fines removal system. Several shorter shutdowns were also required for other less involved modifications, some of which were remote to the main plant and work could proceed without interrupting plant operations. The following sections describe the changes made to specific plant utility systems.

\section{$5.1 \quad$ Nitrogen}

Capacity limitations with the original natural gas fired nitrogen vaporizer lead to an eventual equipment exchange with the vaporizer vendor. The new vaporizer utilizes a glycol/water pump, a shell and tube heat exchanger, and a separate glycol piping system to vaporize the required nitrogen for plant start-up and purging needs. A separate glycol system was placed in parallel with the plant system to ensure consistent flow of glycol even during power outages for safety reasons.

Other changes to the nitrogen system included the addition of a centralized distribution header for ease of operation and system isolation, and a nitrogen membrane package to generate nitrogen on-site. The membrane system includes an air compressor, membrane filter skid, and a surge tank to provide plant nitrogen. The membrane skid has sufficient capacity to support all normal plant operations. The original liquid nitrogen system remains on-line in parallel, and supplants the membrane system during start-up and plant upsets. The system has reduced the overall plant operating costs and is maintained under contract by the nitrogen supplier.

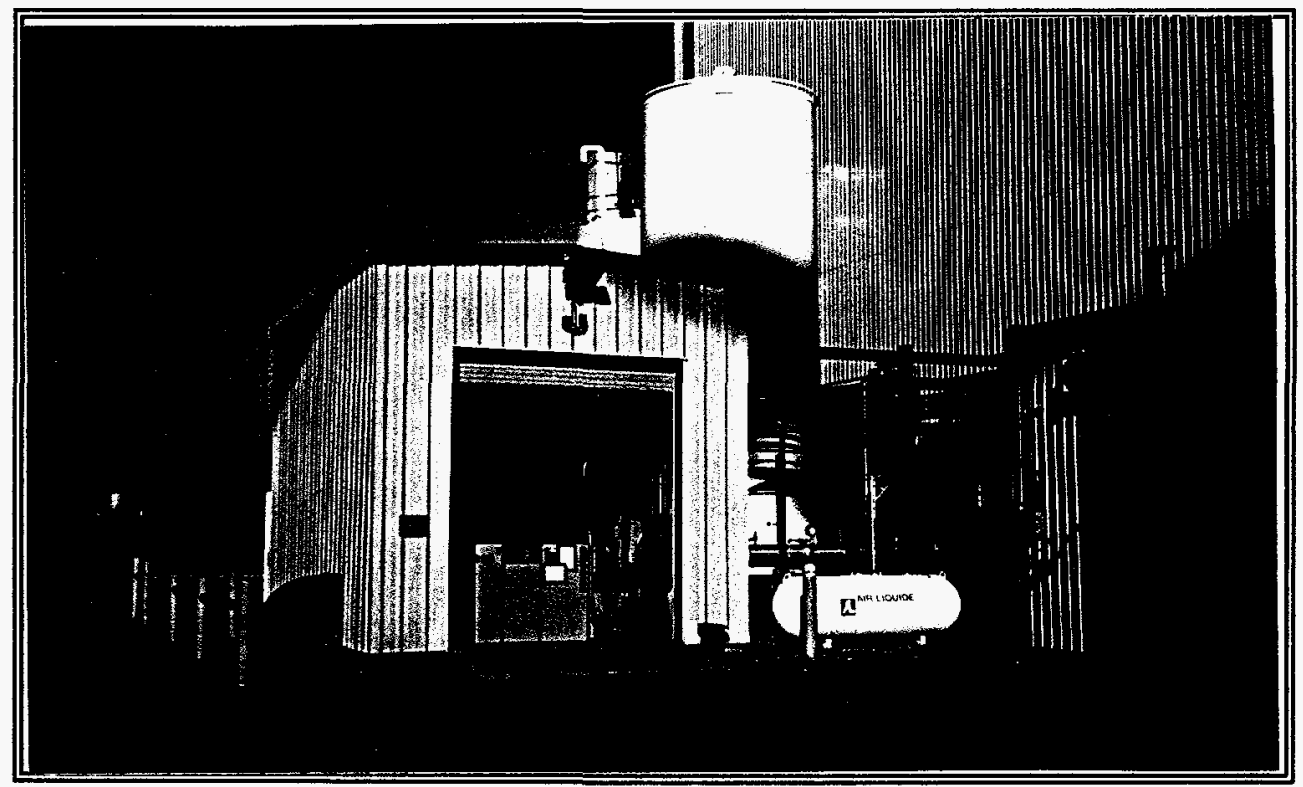

Figure 5.1: Nitrogen Membrane Building. 


\subsection{Instrument and Utility Air}

Few changes were made to the instrument and utility air distribution piping system during the operation; however, some changes were made to the air compressors and air dryers to increase equipment reliability. The air compressor coolers were raised approximately three feet to aid flow of compressor oil to and from the coolers, and the piping outside the main structure was glycol/water heat traced to prevent freezing during extreme winter temperatures.

Occasional problems with condensed water in the instrument air system in early runs caused delays in start-up and hindered plant operation. The problem was found to be in the regeneration of the instrument air dryer desiccant. The original dryer used "warm dry air" for desiccant regeneration, and the efficiency of this dryer was therefore greatly dependent upon the temperature of the purge air. If the purge air was too cool, the desiccant would remain "damp" and the instrument air would not be thoroughly dried. A new heated air dryer was installed in October 1993 that uses electric heat coils instead of "warm dry air" for desiccant regeneration. This system has proven to be more reliable and consistently keeps the instrument air dry. (See Figure 5.2: Instrument Air Dryer)

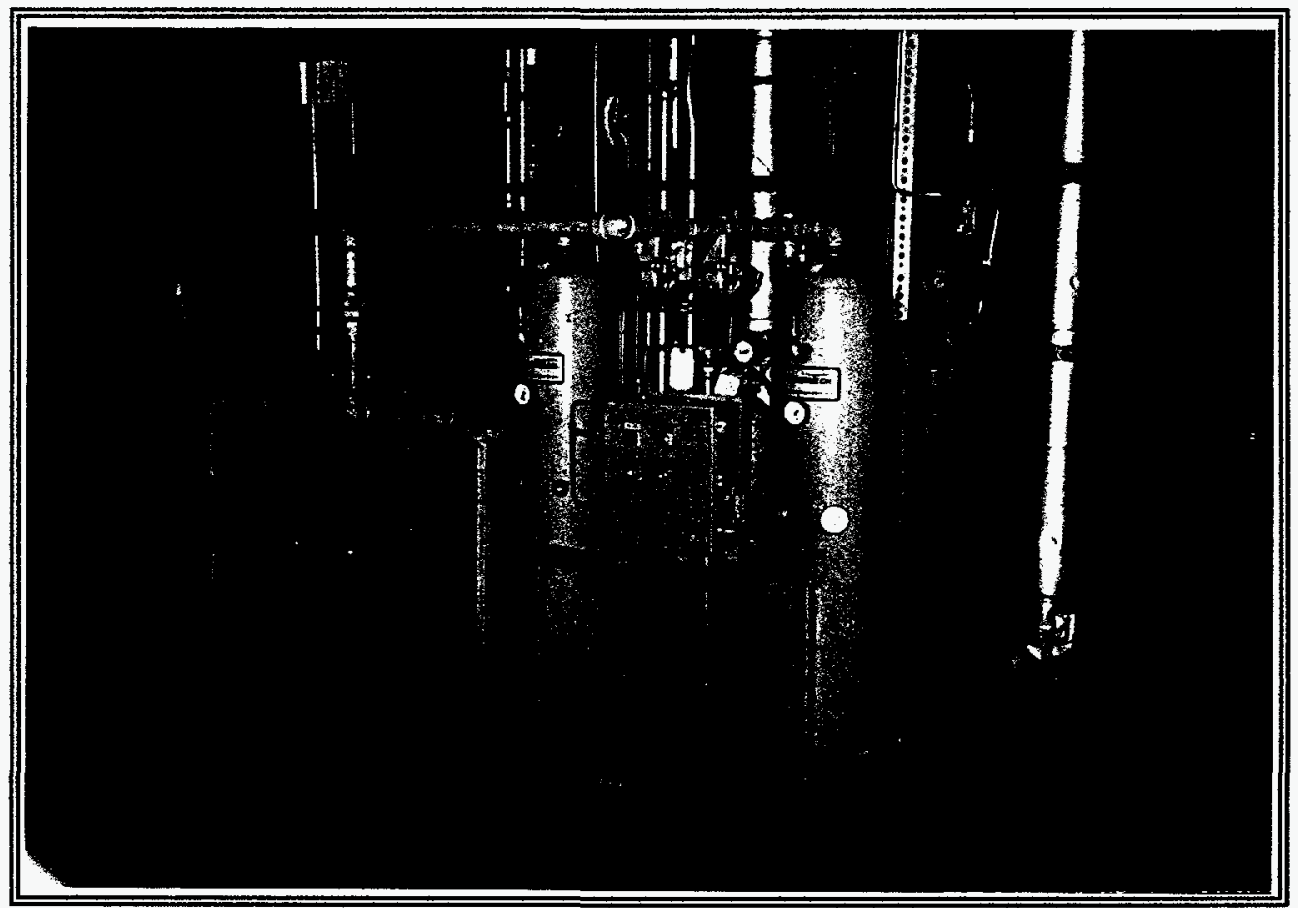

Figure 5.2: Instrument Air Dryer. 


\subsection{Steam System}

Utility steam is generated by a $10,000 \mathrm{lb} / \mathrm{hr} 135$ psig boiler to supply steam for clean-up, emergency VFB system purging, analyzer heat tracing, and steam/glycol heat exchange during plant outages. This boiler was found to be of proper capacity for plant outages when major cleaning and glycol/water system heat exchange was necessary. However, while the plant was on-line, the capacity of the boiler was too large for the light steam duty, causing the boiler to cycle excessively. A second $1,000 \mathrm{lb} / \mathrm{hr}$ boiler was installed in 1995 to be used during plant operating periods when the steam requirements were small. This boiler was installed in parallel with the original boiler, and allowed for the large boiler to be shut down during long plant runs. This operation allowed for more efficient use of boiler feed water chemicals, and was less demanding on boiler maintenance. (See Figure 5.3: Small Utility Boiler)

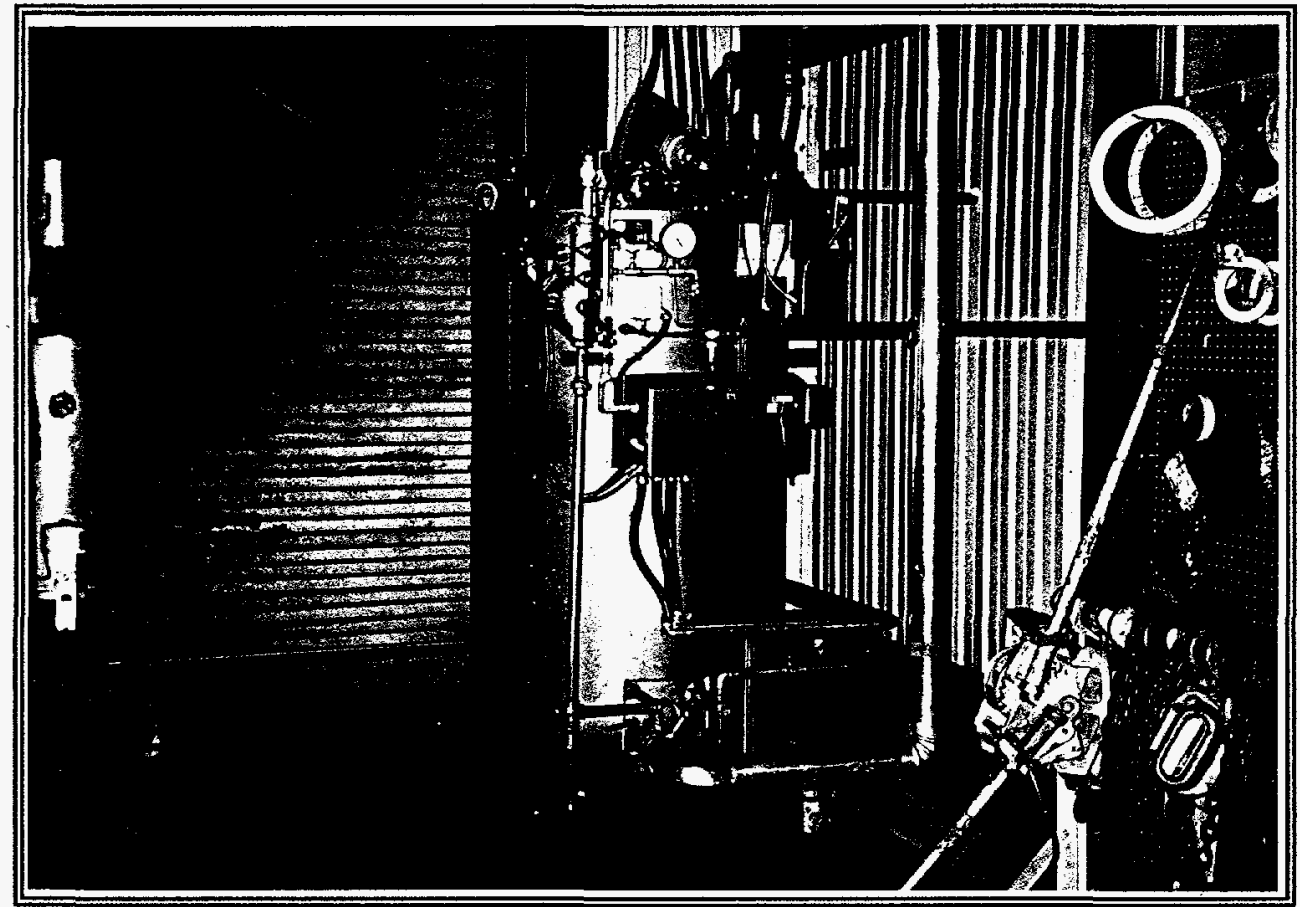

Figure 5.3: Small Utilitỳ Boiler.

\subsection{Cooling Water}

Several modifications or additions were made to the plant cooling water circulation system during the 5 years of operation. Early in the project, a chlorination system was added to control algae growth, and a scale inhibitor was added to reduce scale deposits in the piping and heat exchangers. Once the chlorine and anti-scalant systems were added, problems with strainer blinding and reduced flows were overcome. 
As major plant equipment was added to the ENCOAL plant, such as the PDF deactivation and process water fines removal systems, additional demands were placed on the cooling water system. In order to increase overall cooling water flows, the impellers in the main cooling water pumps were exchanged for larger diameter models in 1993 . These pumps were modified again in 1995, increasing the impeller size and repowering from $75 \mathrm{hp}$ to $100 \mathrm{hp}$. These two changes almost doubled the flow rate capacity of the pumps, and allowed for proper cooling water supply for all the present day plant needs.

The plant high pressure water system was also extensively modified from the original design. The original cooling water booster pump was found to be undersized very early in plant operation. This pump was replaced and a main distribution header installed to ease plant operation and system isolation. A second redundant pump was later installed to enhance system reliability and to ensure emergency back-up water could be supplied at all times. (See Figure 5.4: Cooling Water Booster Pumps and Distribution Header)

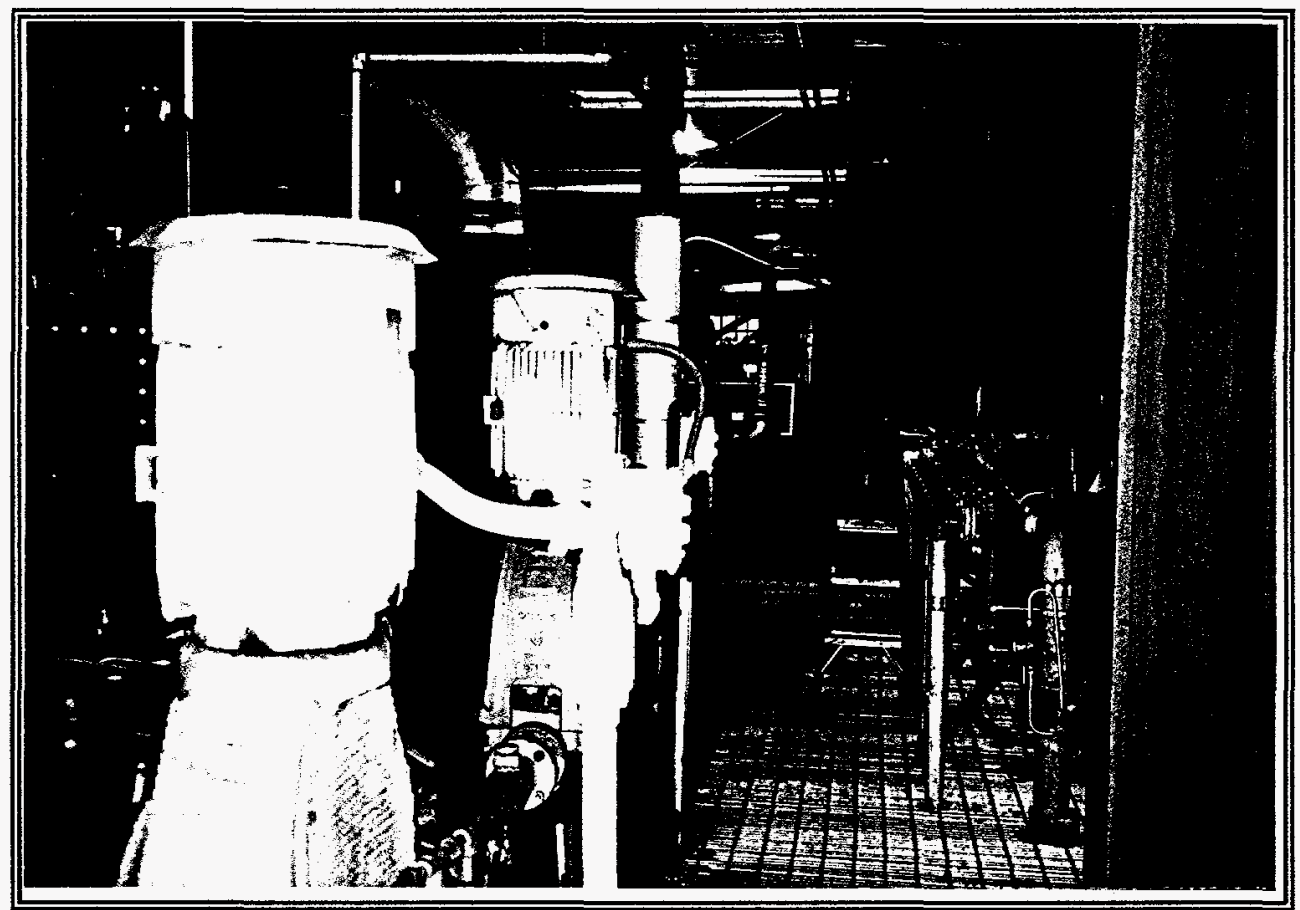

Figure 5.4: Cooling Water Booster Pumps and Distribution Header.

\subsection{Sump System}

The ENCOAL plant contains several sumps to collect the various washdown water, dust scrubber effluent, and equipment drains prior to being pumped to the site waste water treatment pond for settling of fines. The original plant sump system routed these individual sump discharges to the screening building sump prior to being pumped the Buckskin mine underground piping network. This routing was immediately determined to be inadequate and 
unreliable due to extensive plugging problems and overloading of the Buckskin Mine underground piping system. Major modifications were made to the plant sump system piping to remove bends wherever possible, and pipes were routed above ground inside the plant to ease maintenance of the lines. A new, large drive-in sump was constructed adjacent to the PDF silo to serve as the ENCOAL plant main sump collection point. All plant sumps and equipment drains were rerouted to this centralized collection area. The new sump design uses a sloped bottom sump and overflow weir plate to collect and settle out large fines and trash prior to "cleaned" water being pumped directly to the mine waste water pond. The settled fines and trash may be removed by a loader and dump truck, and a new direct line to the waste water pond eliminated problems with overloading the Buckskin Mine piping system. Once the sump modifications were completed, delays in plant start-up were avoided and operation became much more reliable. (See Figure 5.5: Drive-in Sump Under Construction)

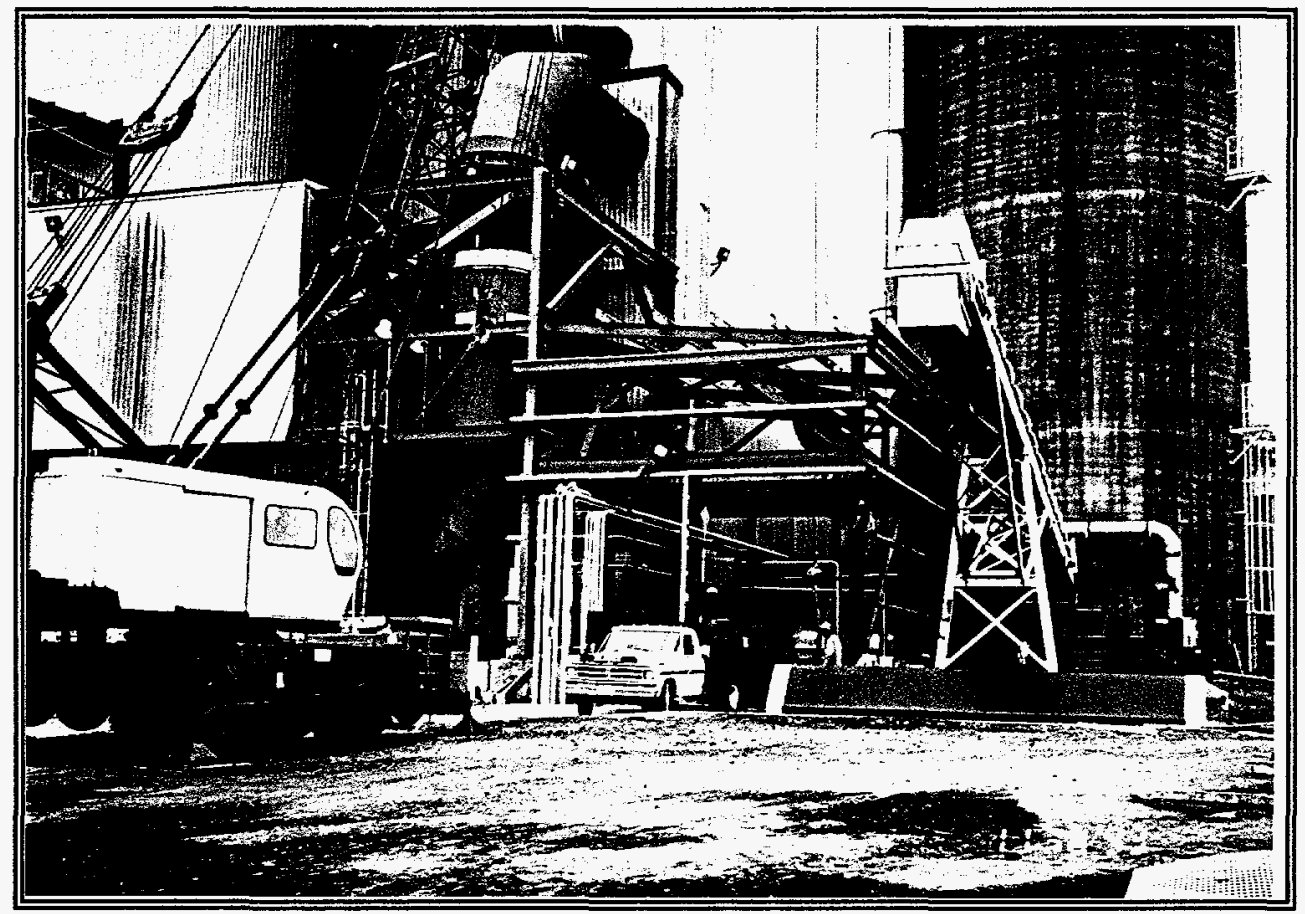

Figure 5.5: Drive-in Sump Under Construction.

\subsection{Car Topper}

Not included in the original ENCOAL plant design, the car topper system was developed to aid in the transport of PDF in conventional coal cars. Due to the average size of the PDF product being $1 / 4^{\prime \prime}$, a rail car topping system was installed to apply a coat of MK, ENCOAL's patented dust suppressant, on the PDF in the rail cars to stop small particles from blowing out during transport. This system was first utilized in 1995, and was found to be very effective in preventing PDF loss. The system consists of an MK storage tank, pump, and adjustable spray bar to apply the MK as the train is being loaded. (See Figure 5.6: Car Topper System). 


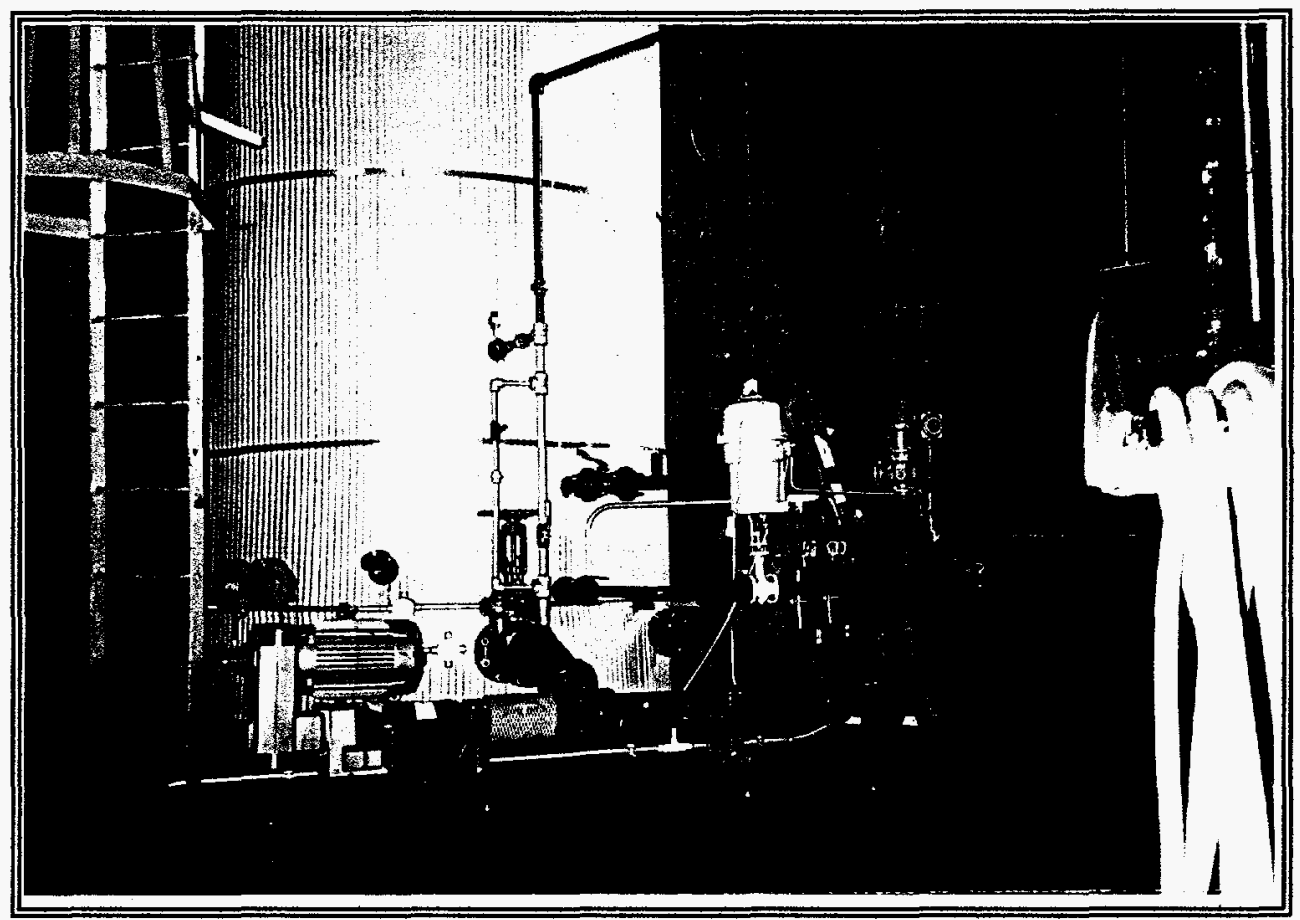

Figure 5.6: Car Topper System.

\subsection{Vapor Recovery}

Excessive odor from the plant process water circulation and sump system in early plant operation lead to the design and installation of another new utility system called vapor recovery. Extensive ambient air testing was done to ensure there were no harmful levels of toxic materials in the ENCOAL plant. However, odors did hava a nauseating effect on some people working in the plant for extended periods. Therefore the vapor recovery system was added. The system uses a small blower and an activated carbon filter to collect and filter odorous air from the process water containment areas in the plant. Once filtered, the gases are exhausted to atmosphere outside the plant. This system has proven to be very successful in reducing plant odors. (See Figure 5.7: Vapor Recovery System)

\subsection{Process Water}

The ENCOAL plant process water system was the most modified and changed utility during the 5 years of operation. The original design used a very small capacity pump and circulation system called "oily water". Its purpose was to gather and contain all washdown and seal water that could include dissolved hydrocarbons, and used this water to slurry fines from the pyrolyzer cyclone to be injected as rehydration water on PDF. While the system did work well to contain the water, the surge capacity and circulation system was found to be undersized and could not effectively handle the quantities of slurried fines in the water. In addition to these problems, two other small utility systems called quench spray water and seal 
water were also found to be inadequate. The entire quench table spray system and a portion of the seal water system were combined with the "oily water" system, and renamed process water. Temporary surge tanks were used to increase capacity, and new pumps were installed to increase flow.

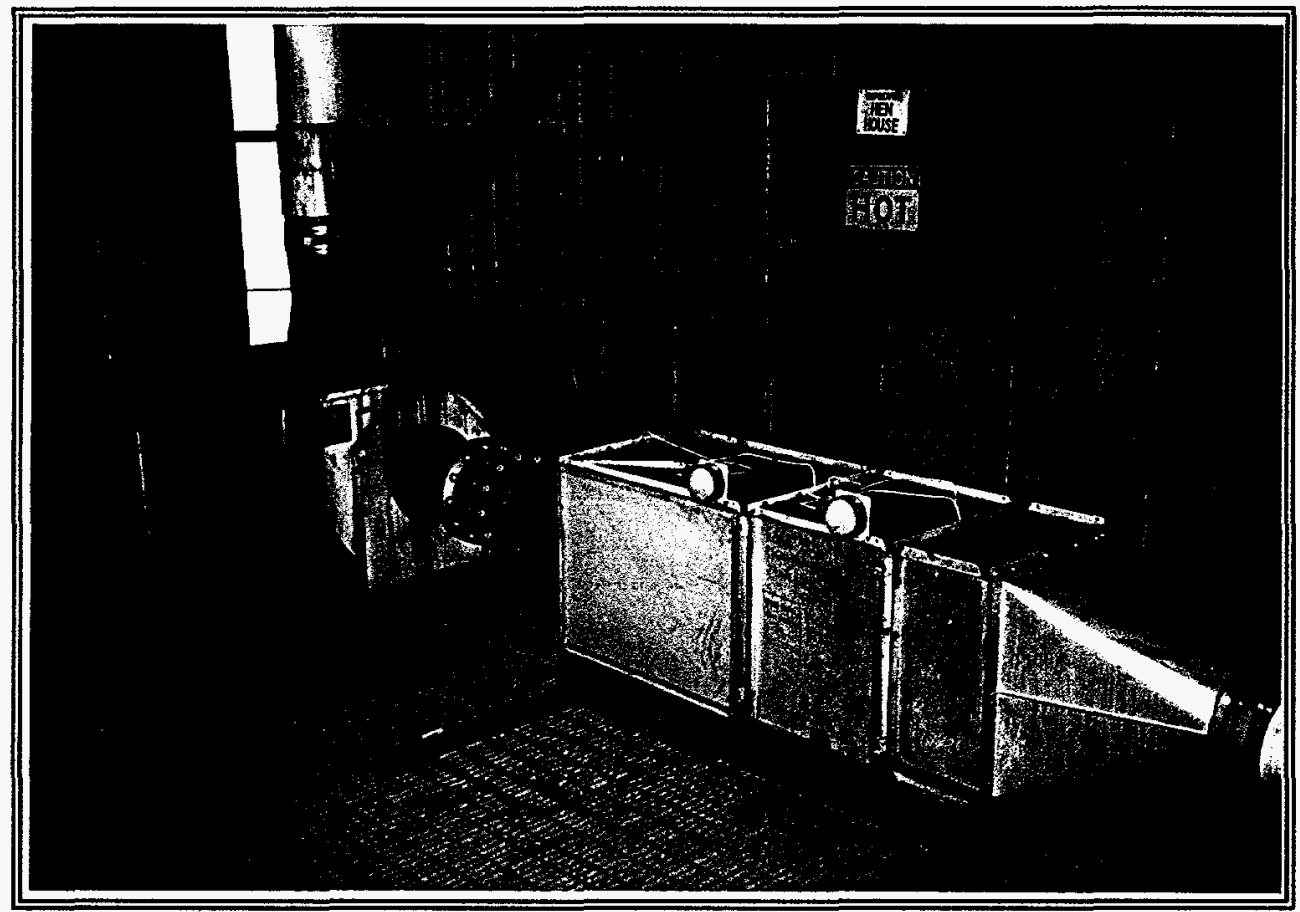

Figure 5.7: Vapor Recovery System.

Problems with fines accumulation in the system continued to plague the plant however, and numerous shut-downs were attributed to plugging the quench table nozzles and Salem water seals. A temporary process water fines removal system was installed in 1994 that utilized a large decanter tank and flocculent injection to settle fines from the system. This system allowed the plant to operate for longer periods of time while necessary data was collected for permanent fines removal equipment.

The permanent process water fines removal equipment was procured and installed in early 1995. This system consists of a process water collection system, clarifier, vacuum drum filter, heat exchanger, and two new slurry pumps that effectively removes the entrained fines while maintaining a reliable circulation of process water throughout the facility. The fines removal equipment was housed in a separate, contained building near the PDF silo. Filter cake discharged from the vacuum filter is hauled to the ENCOAL land farm for hydrocarbon treatment as discussed in Sections 6.0 and 6.2 below. (See Figures 5.8a, b, and c: Process Water Fines Removal System). Appendix A includes floor plans for the process water fines removal building. 


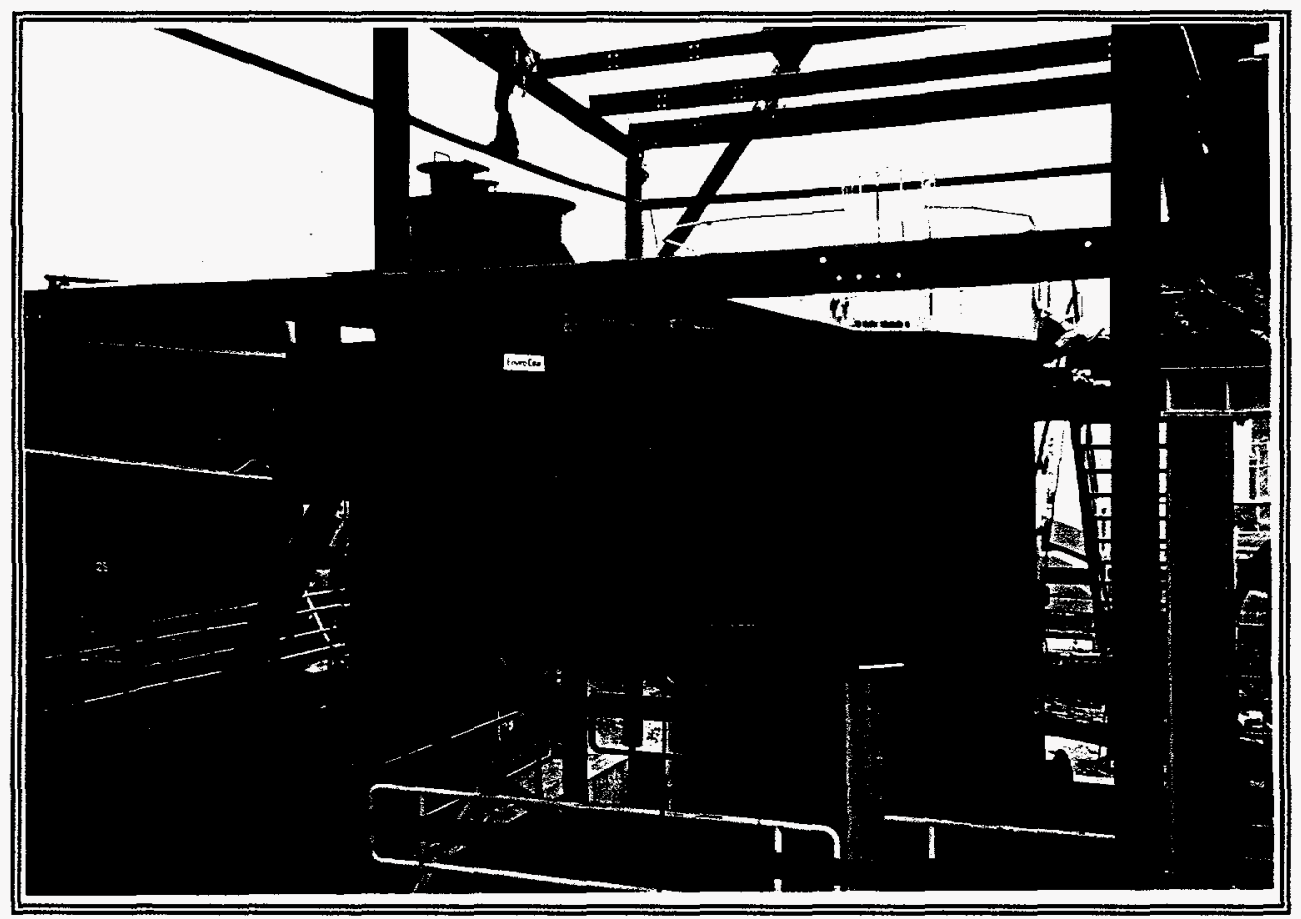

Figure 5.8a: Process Water Clarifier.

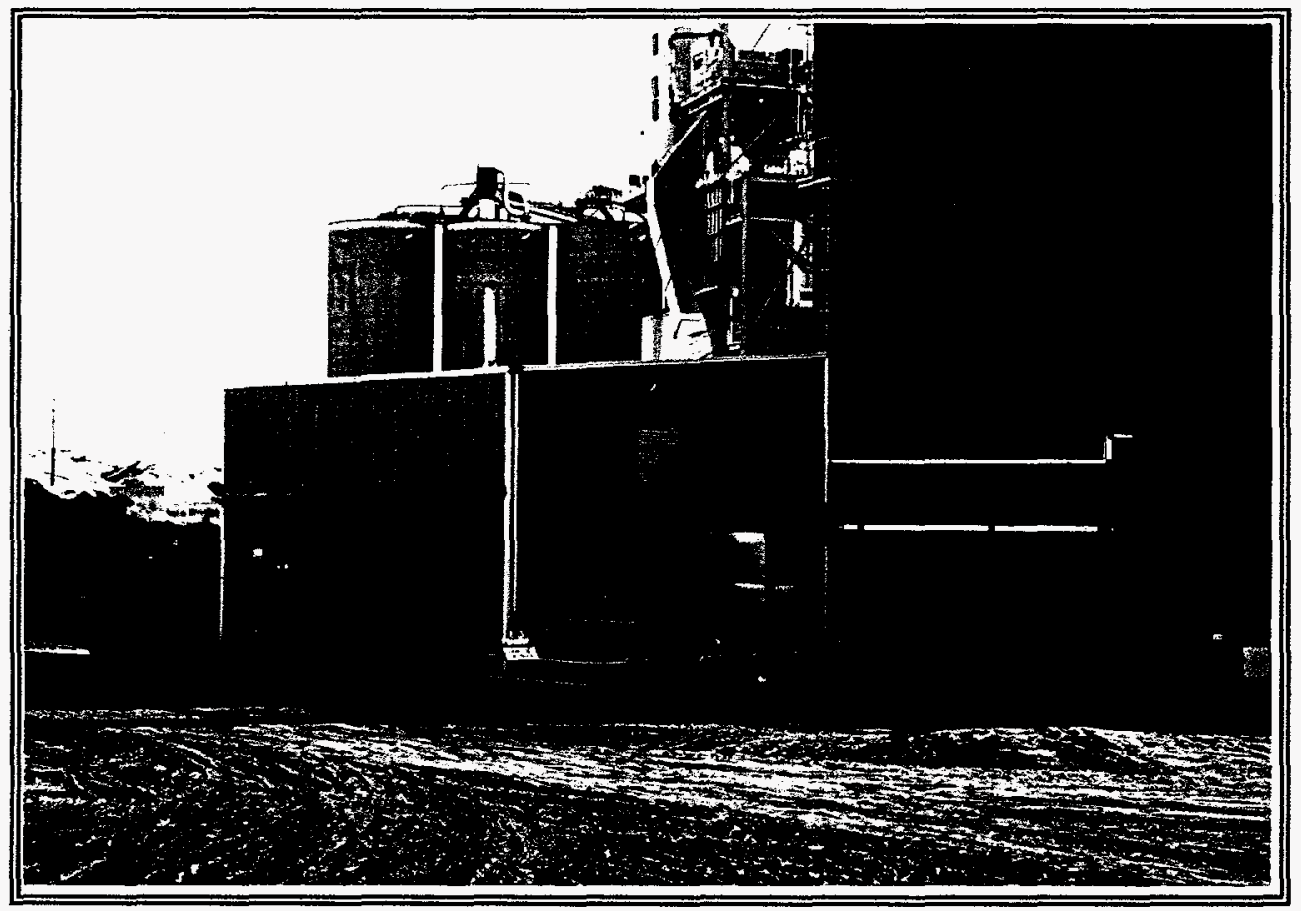

Figure 5.8b: Process Water Fines Removal Building. 
Figure 5.8c: Process Water Clarifier General Arrangement Drawing

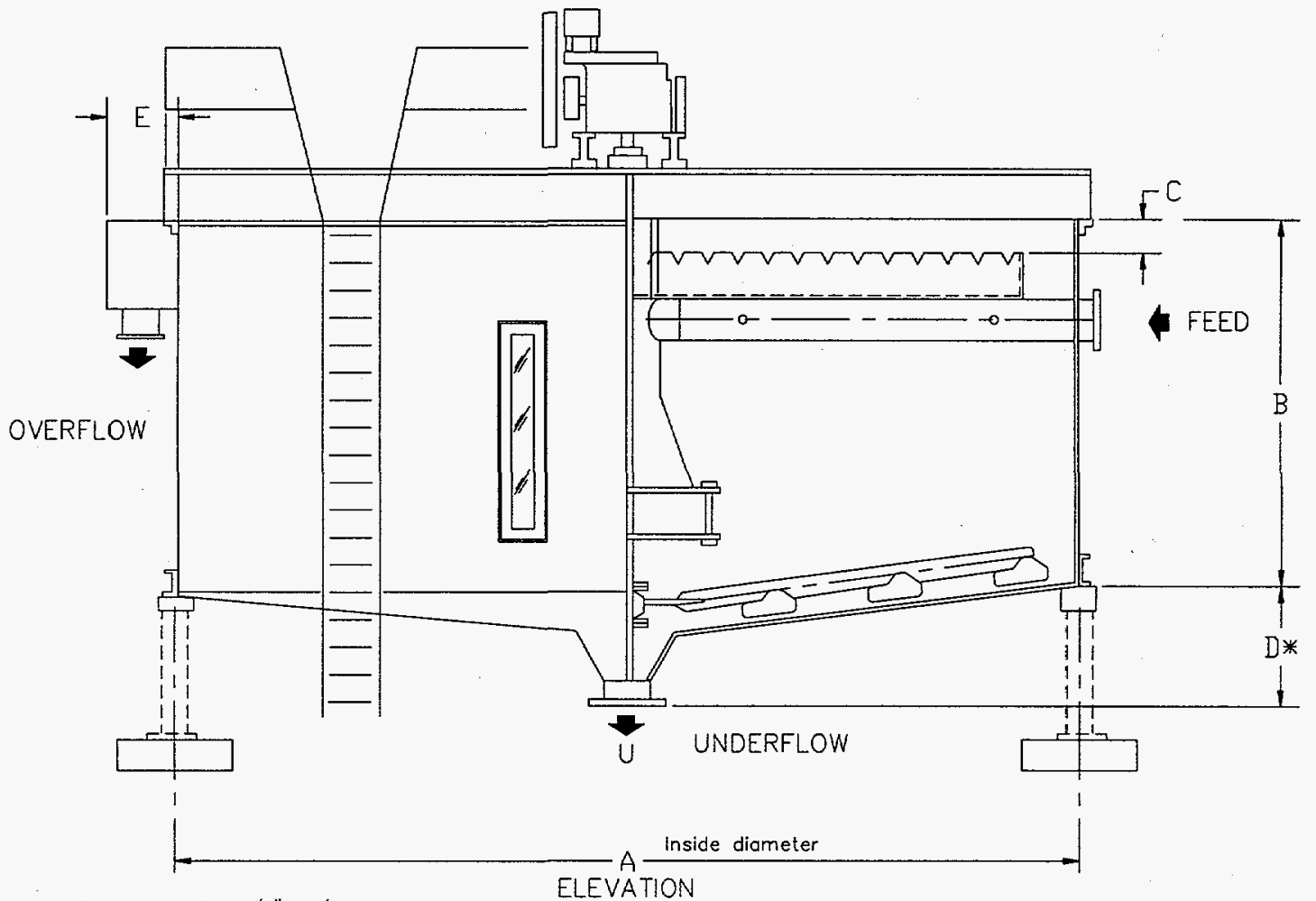

* D based on bottom slope of $11 / 2$ " in. $/ \mathrm{ft}$.

ELEVATION

\begin{tabular}{|c|c|c|c|c|c|c|c|c|c|c|c|c|}
\hline \multirow{3}{*}{$\begin{array}{l}\text { ENVIRO- } \\
\text { CLEAR } \\
\text { MODEL } \\
\text { NUMBER }\end{array}$} & \multirow{2}{*}{\multicolumn{5}{|c|}{ PRINCIPAL DIMENSIONS }} & \multicolumn{4}{|c|}{$\begin{array}{l}\text { SUBJECT TO CHANGE } \\
\text { DEPENDING ON FLOW } \\
\text { AND SOLIDS FEED }\end{array}$} & \multicolumn{2}{|c|}{$\begin{array}{c}\text { FILLED WITH } \\
\text { WATER TO } \\
\text { OPERATING LEVEL }\end{array}$} & \multirow{3}{*}{$\begin{array}{l}\text { AREA } \\
\text { SQ. FT. }\end{array}$} \\
\hline & & & & & & \multicolumn{3}{|c|}{$\begin{array}{l}\text { PIPE CONNECTIONS } \\
\text { NOMINAL } \\
\text { PIPE SIZE }\end{array}$} & \multirow{2}{*}{$\begin{array}{c}\begin{array}{c}\text { MOTOR } \\
\text { DRIVE } \\
\text { MAXIMUM }\end{array} \\
\text { H.P. }\end{array}$} & \multirow{2}{*}{$\begin{array}{c}\begin{array}{c}\text { NO. } \\
\text { OF } \\
\text { SUPPORT }\end{array} \\
\text { NO. }\end{array}$} & \multirow{2}{*}{$\begin{array}{c}\text { LOAD } \\
\text { PER } \\
\text { SUPPORT }\end{array}$} & \\
\hline & A & $\mathrm{B}$ & C & D & $E$ & $S$ & $\mathrm{~T}$ & $U$ & & & & \\
\hline$C-3$ & $3^{\prime}-0^{\prime \prime}$ & $3^{\prime}-6^{\prime \prime}$ & $6 "$ & $11^{\prime \prime}$ & $6 "$ & $2^{\prime \prime}$ & $2^{\prime \prime}$ & $2 "$ & $3 / 4$ & 4 & 1 & 7 \\
\hline$C-5$ & $5^{\prime}-0^{\prime \prime}$ & $3^{\prime}-6^{\prime \prime}$ & 6" & $1 '-3 "$ & $9 "$ & $2^{\prime \prime}$ & $3 "$ & $2 "$ & 1 & 4 & 2 & 20 \\
\hline $\mathrm{C}-7$ & $7^{\prime}-0^{\prime \prime}$ & $4^{\prime}-6^{\prime \prime}$ & 6" & $1^{\prime}-6 "$ & $1^{\prime}-10^{\prime \prime}$ & $4 "$ & $4 "$ & $3 "$ & $11 / 2$ & 4 & 4 & 38 \\
\hline$c-9$ & $9^{\prime}-0^{\prime \prime}$ & $4^{\prime}-6^{\prime \prime}$ & 6" & $1^{\prime}-8 "$ & $1^{\prime}-10^{\prime \prime}$ & $4 "$ & $4 "$ & $3^{\prime \prime}$ & $11 / 2$ & 4 & 7 & 64 \\
\hline $\mathrm{c}-11$ & $11^{\prime}-0^{\prime \prime}$ & $4^{\prime}-6^{\prime \prime}$ & 6" & $1^{\prime}-10^{\prime \prime}$ & $1^{\prime}-10^{\prime \prime}$ & $6^{\prime \prime}$ & $6 "$ & $4 "$ & $11 / 2$ & 4 & 10 & 95 \\
\hline$c-12.5$ & $12^{\prime}-6^{\prime \prime}$ & $4^{\prime}-10^{\prime \prime}$ & $6^{\prime \prime}$ & $2^{\prime}-1^{\prime \prime}$ & $1^{\prime}-10^{\prime \prime}$ & $10^{\prime \prime}$ & $10^{\prime \prime}$ & $8^{\prime \prime}$ & $11 / 2$ & 4 & 12 & 123 \\
\hline$c-15$ & $15^{\prime}-0^{\prime \prime}$ & $5^{\prime}-5^{\prime \prime}$ & $6 "$ & $2^{\prime}-3^{\prime \prime}$ & $1^{\prime}-10^{\prime \prime}$ & $12^{\prime \prime}$ & $12 "$ & $8^{\prime \prime}$ & 2 & 4 & 18 & 177 \\
\hline$C-17$ & $17^{\prime}-0^{\prime \prime}$ & $6^{\prime}-0^{\prime \prime}$ & $6 "$ & 2'-4" & $1^{\prime}-10^{\prime \prime}$ & $12^{\prime \prime}$ & $12^{\prime \prime}$ & $8^{\prime \prime}$ & 2 & 4 & 27 & 227 \\
\hline$c-20$ & $20^{\prime}-0^{\prime \prime}$ & $6^{\prime}-6^{\prime \prime}$ & $6 "$ & 2'-6" & $1^{\prime}-10^{\prime \prime}$ & $12 "$ & $12^{\prime \prime}$ & 8" & 2 & 4 & 24 & 314 \\
\hline$c-23$ & $23^{\prime}-0^{\prime \prime}$ & $7^{\prime}-0^{\prime \prime}$ & $6 "$ & $2^{\prime}-9^{\prime \prime}$ & $1^{\prime}-10^{\prime \prime}$ & $14 "$ & $14^{\prime \prime}$ & 8" & 3 & 8 & 28 & 415 \\
\hline$C-26$ & $26^{\prime}-0^{\prime \prime}$ & $7^{\prime}-0^{\prime \prime}$ & $6 "$ & $2^{\prime}-11^{\prime \prime}$ & $1^{\prime}-10^{\prime \prime}$ & $14 "$ & $14^{\prime \prime}$ & $8 "$ & 3 & 8 & 35 & 531 \\
\hline
\end{tabular}




\subsection{ENVIRONMENTAL MODIFICATIONS}

ENCOAL's policy is to always operate in an environmentally responsible manner. The goal is to have no citations or Notice Of Violations (NOV's). The original plant was designed to have no effluents other than normal coal washdown water and no solids waste streams. Emissions were designed to be less than 100 tons per year of $\mathrm{SO}_{x}, \mathrm{NO}_{x}$, methane, particulates or $\mathrm{CO}$. As expected, the demonstration plant has provided a great learning experience in the control of environmental releases.

The following list includes some of the more significant environmental modifications to the ENCOAL facilities;

1) Solids collected in the process water stream as described above can not be recovered in the product stream via rehydration as originally conceived. They are very expensive to recover in the quantities produced so a biological disposal method or landfarm was developed.

2) The requirement of atmospheric exposure for finishing PDF has led to the need for longer term laydown and storage areas than envisioned for PDF pile testing in the original plant concepts.

3) Production at less than design capacity resulted in modifications to the operating permits requested from the State of Wyoming.

4) Low production totals delayed the need for installation of the Permanent Precipitate Storage Reservoir. This resulted in permit revisions and addition of an evaporation system to the temporary reservoir.

5) Odors in the processing plant proved to be very objectionable for many operators. Extensive ambient air monitoring work revealed no EPA listed toxins in concentrations anywhere close to Federal limits. However, it was decided to install a vapor recovery system on all process water holding vessels as described in Section 5.7.

\subsection{Air Quality Issues}

Late in 1992, ENCOAL staff members met with the WDEQ to discuss the status of plant operation, notification requirements and the status of stack gas monitoring. As a result of this meeting, a letter was sent to the WDEQ confirming the stack gas monitoring schedule and explaining ENCOAL's temporary noncondensible gas venting arrangements installed for the PDF quench table. The letter, which also discussed the quench table steam condenser tests scheduled for January 1993, was approved in December 1992. 
In mid-1993, ENCOAL submitted a permit application for the vapor collection system exhaust on the process water system. Although a permit was not required by current regulations, it was agreed that a permit would be prudent, and data were collected from plant runs to support a permit application.

\section{$\underline{\text { Stack Gas Emissions }}$}

In October 1995, a third-party testing firm mobilized to perform emission testing necessary to obtain ENCOAL's permit to operate from the WDEQ. The stack and emissions testing using DEQ-approved protocol was successfully completed in November 1995, and indicated that the plant is operating within permitted limits for $\mathrm{NO}_{\mathrm{x}}$, sulfur oxides, carbon monoxide, volatile organic compounds, and particulates. The $\mathrm{SO}_{2}$ Continuous Emission Rate Monitoring System for the ENCOAL plant stack gas was certified as a result of the testing.

\section{$\underline{\text { Air Quality Permit }}$}

Revisions to the AQ permit, delayed since the beginning of Phase III by interruptions in plant operation, were reviewed by the WDEQ in March 1996, and ENCOAL responded to the Department's questions. In mid-1996, ENCOAL received a notice of completeness for its application for Section 21 AQ permit from the WDEQ. The permit included a 5acre laydown area that was not anticipated in the original application. The application proceeded smoothly through the technical review and was formally approved in November 1996.

\subsection{Land Quality Issues}

\section{Permanent Precipitate Storage Reservoir}

A permanent storage reservoir was part of ENCOAL's original plan, but because the WDEQ questioned the location of the permanent precipitate disposal pond, an alternative permit application was submitted, modifying an existing mine sediment pond. Because the temporary pond proved adequate far longer than originally believed, ENCOAL was allowed to defer permitting and construction of the permanent disposal pond until 1995, when geotechnical survey holes were drilled on a secondary site for the permanent precipitate storage reservoir. After core sample testing indicated that soils were acceptable at the construction site, the design for the pond was completed in cooperation with the WDEQ, and the permit application was finalized in June 1995. When the WDEQ determined that public notice would be required, construction was deferred, this time until 1996, and options to extend the life of the temporary pond were again evaluated. After weighing several options, a system designed to improve the evaporation rate was installed. The system included a portable diesel powered pump, floating platform and a nozzle bank to spray the effluent into the air. It was approved by the WDEQ and started up in September 1996. (See Figure 6.1: Portable Evaporation System) 


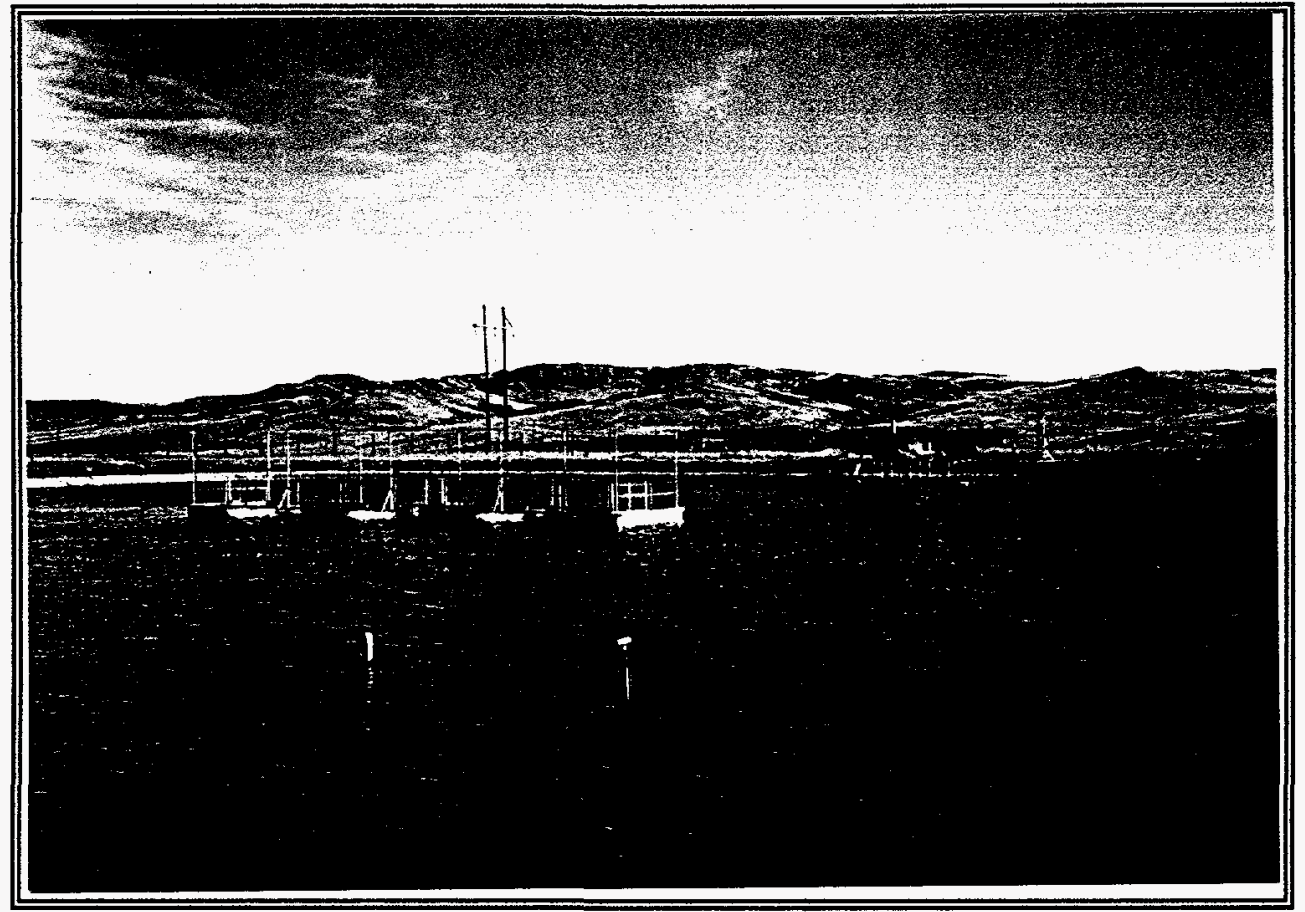

Figure 6.1: Portable Evaporation System.

The WDEQ reviewed the application for revisions to the permanent pond, and ENCOAL responded to WDEQ questions in March 1996. At that time, a bid package for construction of the permanent reservoir was sent to potential contractors. The permit for construction cleared public comment and was sent to WDEQ's head office; final approval for the reservoir was received in June. Reservoir construction began the first week in July and continued through 1996. This reservoir is scheduled to be commissioned for use in July 1997. (See Figure 6.2: Permanent Precipitate Storage Reservoir)

\section{Land Farm}

Early in 1993, ENCOAL initiated discussions for construction and permitting of an onsite land farm. The land farm, conceived in response to the collection of greater amounts of process water fines than originally anticipated, would biologically eliminate hydrocarbons from process fines prior to onsite disposal. It was intended as a temporary facility, since the ultimate plan was to recover fines back into the PDFTM solid product.

The first step in the development of the land farm was the collection and testing of fines samples and the gathering of information from plant runs. In the fall of 1993, ENCOAL reviewed a preliminary design for the land farm before submission to the WDEQ, and construction began when informal approval from the WDEQ was received. The earthwork and underground piping were completed in November 1993, and commissioning was scheduled for mid-January of the following year. Final approval was received in August 1994. 
In the fall of 1995, the LQD of the WDEQ approved a permit for revisions to the land farm that included a new concrete holding area for wet fines, a higher retaining dike to increase capacity, and provisions for continuous operation with pit disposal of treated fines. Specifications to complete the modifications were developed, and a bid package was issued. Modifications began in July 1996 and were completed 2 months later, and the facility was commissioned in October of the same year. (See Figure 6.3: ENCOAL Land Farm)

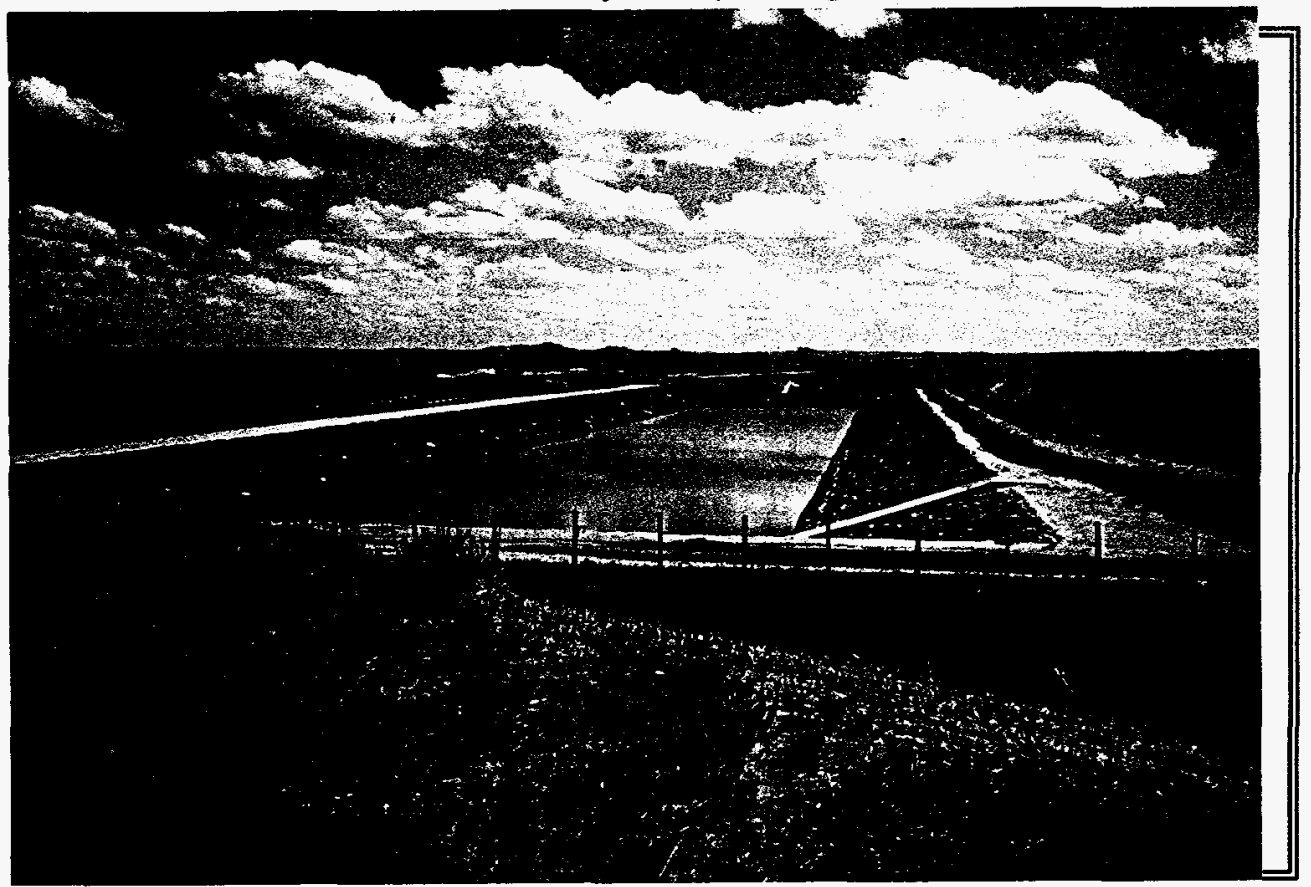

Figure 6.2: Permanent Precipitate Storage Reservoir.

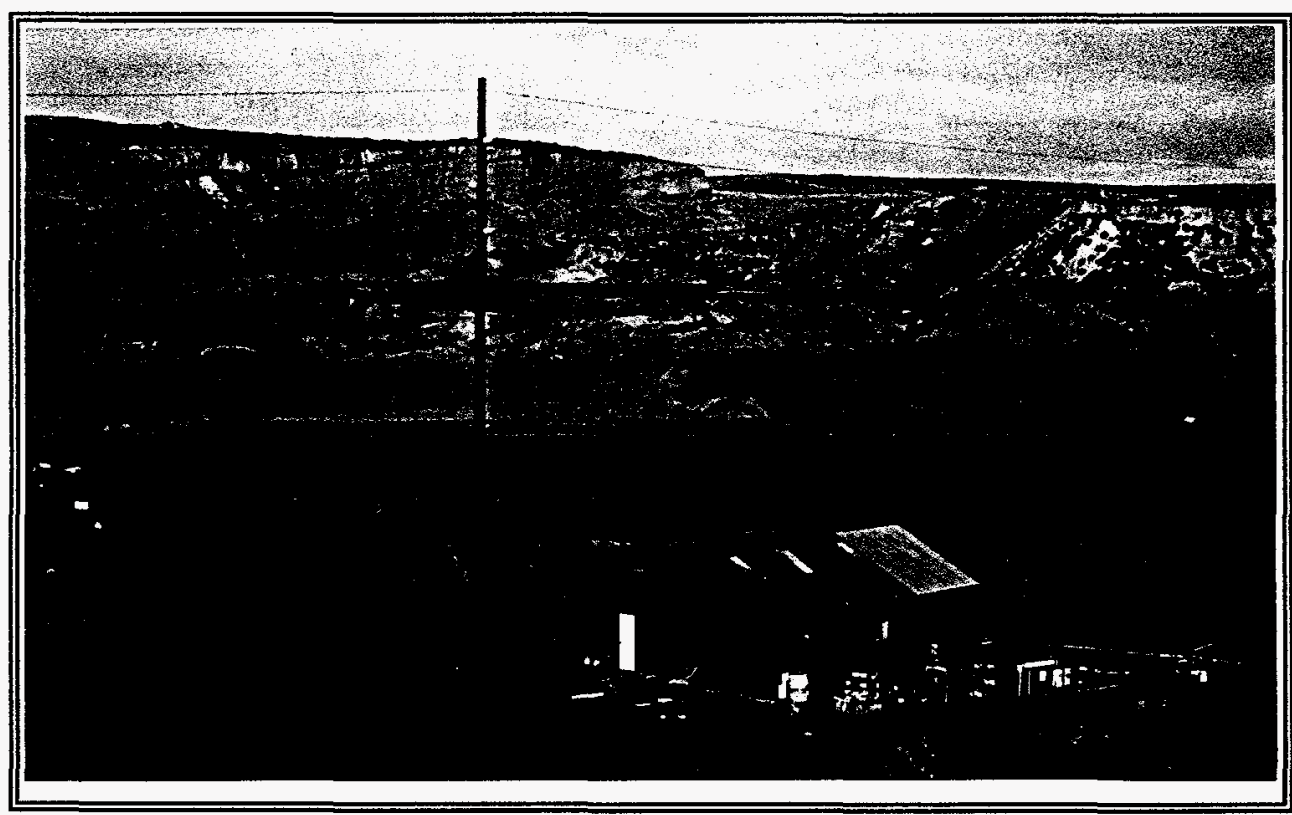

Figure 6.3: ENCOAL Land Farm. 
One of ENCOAL's most important accomplishments during the life of the project is its safety record. Since October 1990, only nine reportable accidents and four lost time accidents were reported for all personnel, including contractors and associated workers. This lost time accident rate is less than one-third the most recent available rate for petroleum and coal processing industries, while the number of reportables is less than one-fifth.

ENCOAL achieved this by consistently supporting a policy that encouraged operator and contractor involvement in plant operations to ensure proper safety awareness. Modifications that reduced or removed the potential for injury were continually made to the facility as a result of this policy. Some of these modifications included installation of platforms, handrails, stairways, guards, blinds, and man-ways all oriented to ease maintenance of the plant while providing safe access to the equipment. Other modifications made to the facility for administration purposes are discussed below.

1) A 40 foot by 80 foot maintenance shop and warehouse was constructed in 1992 . This facility is used for a welding shop, tool storage, and commonly used parts warehouse. (See Figure 7.0a: ENCOAL Maintenance Shop)

2) A 25 foot by 45 foot addition to the original control room building was constructed in 1995. The expansion was necessary to provide storage space, a larger training/lunchroom, a maintenance office/library, and additional offices. (See Figures 7.0b and c: ENCOAL Control Room Building Expansion)

\subsection{CONCLUSIONS}

The goals of the ENCOAL Project have not only been met, but exceeded. Sixteen unit trains of PDF have been shipped and successfully burned at seven utilities. PDF has also been tested as a reductant (combined with iron ore) in the DRI process, and holds promise as a blast furnace injectant. The LFC process has been demonstrated and improved through the modifications discussed in this report. (Table A.1 in Appendix A summarizes the changes and additions to the ENCOAL plant equipment list over the 5 year period). Almost 5 years of operating data have been collected as a basis for the evaluation and design of a commercial plant. Finally, the licensing effort has reached the international level: agreements have been signed, and many opportunities are being developed.

Although major DOE objectives have been reached, some issues need to be resolved before a commercial plant project can proceed. The ENCOAL Demonstration Plant must continue to test the viability of alternate commercial-scale equipment, deliver additional test burn quantities of products, train operators for the commercial plant and provide additional design and economic data for the commercial plant. ENCOAL also needs to install an in-plant finisher that will substantiate the large-scale testing of PDF finishing, the final stage of stabilization.

Efforts to license the technology will proceed under the auspices of TEK-KOL, both domestically and internationally. These activities are in progress as further described in other reports. ${ }^{[1,3]}$ 


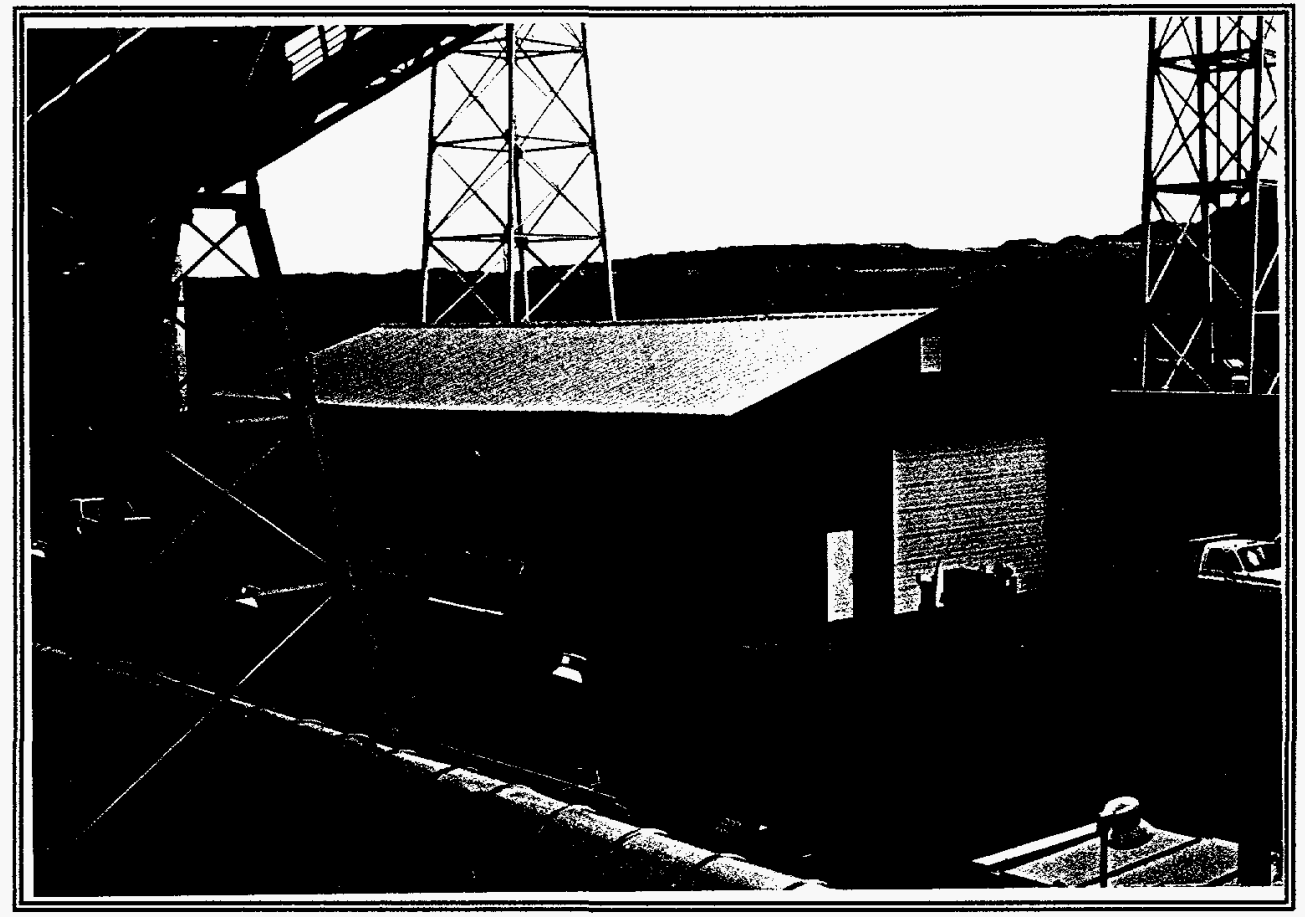

Figure 7.0a: ENCOAL Maintenance Shop.

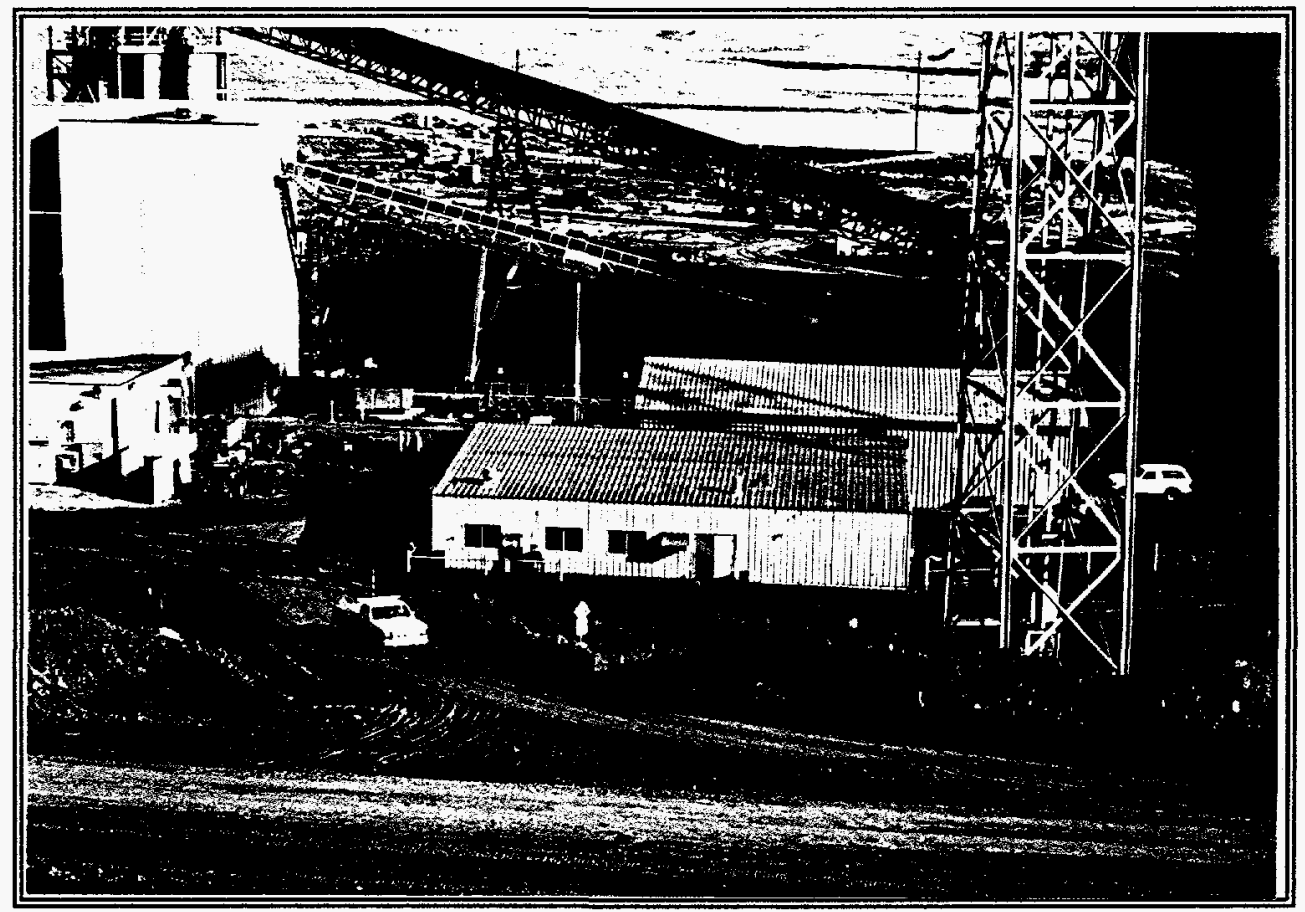

Figure 7.0b: ENCOAL Control Building. 
Figure 7.0c: ENCOAL Control Room Building Expansion Floor Plan

$\$$

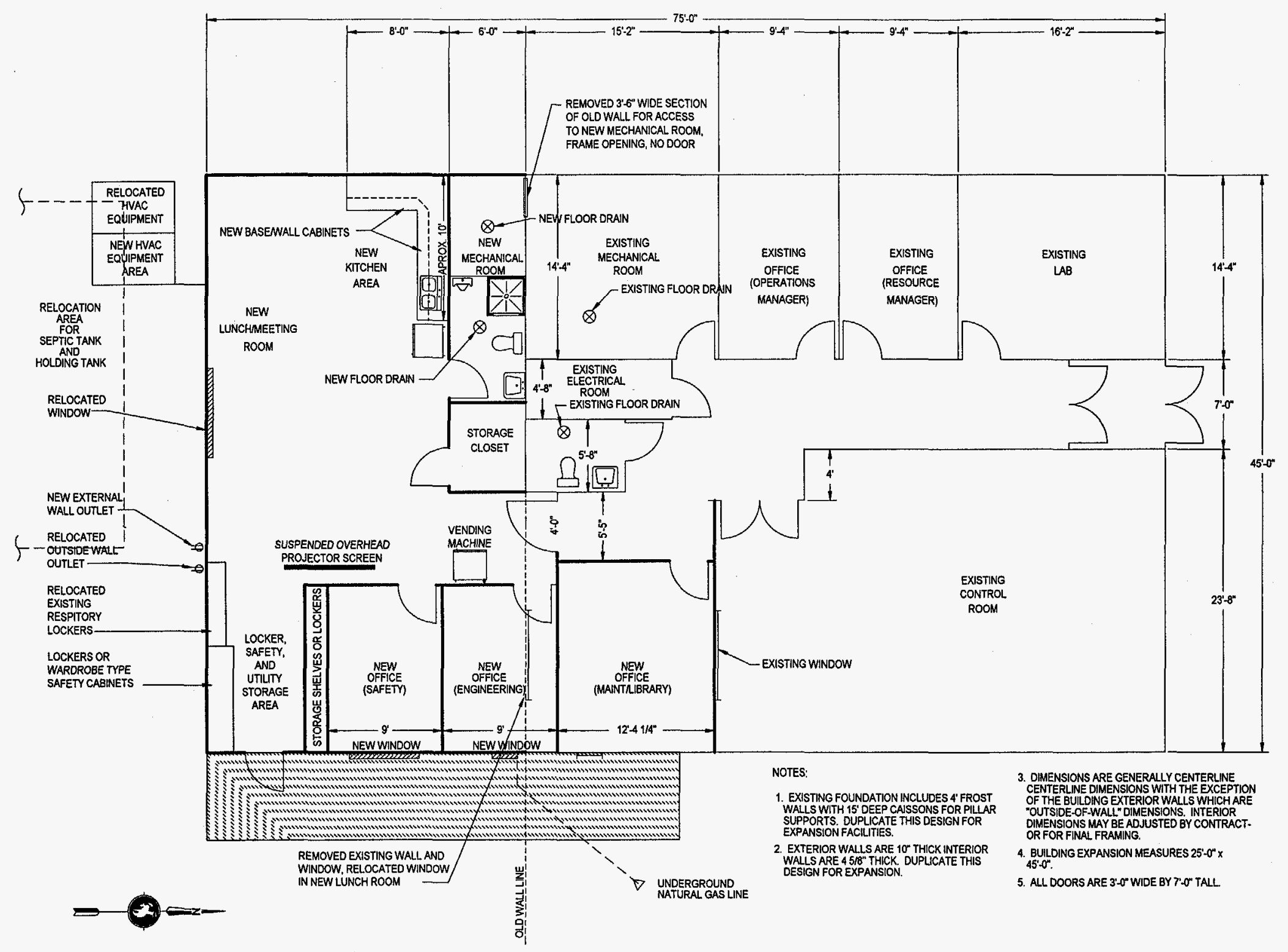




\section{REFERENCES}

1. "ENCOAL Mild Coal Gasification Project: ENCOAL Project Final Report," U.S. Department of Energy Report, July 1997.

2. "ENCOAL Mild Coal Gasification Public Design and Construction Report," U.S. Department of Energy Report, December 1994.

3. "ENCOAL Mild Coal Gasification Project: Commercial Plant Feasibility Study," U.S. Department of Energy Report, July 1997. 


\section{APPENDIX A}

\section{Table of Contents}

Table A.1: ENCOAL Mild Coal Gasification Plant Updated Equipment List...................... A1-A6

Figures A.1-A.6: PDF Deactivation Building Floor Plans ................................................. A7-A8

Figure A.7: Process Water Fines Removal Building Floor Plans................................................A9 
TABLE A.1 : ENCOAL MILD COAL GASIFICATION PLANT

UPDATED EQUIPMENT LIST

AS OF 2/28/97

Page 1 of 6

\begin{tabular}{|c|c|c|c|}
\hline STATUS & TAG \# & DESCRIPTION & VENDOR \\
\hline & AT101 & Dryer 02 Analyzer & AMETEK \\
\hline & AT102 & Dryer $\mathrm{O} 2$ Analyzer & Servomex \\
\hline DELETED & AT107 & Feeed Coal Analyzer & Gammametrics \\
\hline \multirow[t]{15}{*}{ DELETED } & AT140 & PDF(tm) Analyzer & Gammametrics \\
\hline & AT220 & Pyrolyzer $\mathrm{O} 2$ Analyzer & Rosemount (Pastech) \\
\hline & AT221 & Pyrolyzer $\mathrm{O} 2$ Analyzer & Rosemount (Pastech) \\
\hline & AT222 & Pyrolyzer Hydrocarbon Analyzer & Rosemount \\
\hline & AT223 & Pyrolyzer CO Analyzer & Horiba \\
\hline & AT224 & VFB CO2 Analyzer & Horiba \\
\hline & AT841 & Finishing $\mathrm{O} 2$ Analyzer & AMETEK \\
\hline & AT842 & Finishing $\mathrm{O} 2$ Analyzer & Servomex \\
\hline & AT843 & Finishing $\mathrm{O} 2$ Analyzer & Horiba \\
\hline & AT844 & Finishing $\mathrm{O} 2$ Analyzer & Horiba \\
\hline & AT845 & Finishing $\mathrm{O} 2$ Analyzer & AMETEK \\
\hline & AT3042 & Dryer Combuster Analyzer & AMETEK \\
\hline & AT3542 & Pyrolyzer Combuster Analyzer & AMETEK \\
\hline & LE105 & Dryer YO-YO & Enders \& Hauser \\
\hline & LE106 & Pyrolyzer YO-YO & Enders \& Hauser \\
\hline ADDED & EF1 & N-West $5^{\text {th }}$ Floor $(37,500$ CFM) & Prop Master \\
\hline \multirow[t]{9}{*}{ ADDED } & EF2 & N-East $5^{\text {th }}$ Floor $(37,500$ CFM $)$ & Prop Master \\
\hline & EF3 & S-East $5^{\text {th }}$ Floor $(37,500$ CFM $)$ & Prop Master \\
\hline & EF4 & S-West $5^{\text {th }}$ Floor $(37,500$ CFM $)$ & Prop Master \\
\hline & EF5 & S-West $9^{\text {th }}$ Floor $(23,100$ CFM $)$ & Prop Master \\
\hline & EF6 & N-East $9^{\text {th }}$ Floor $(23,100$ CFM) & Prop Master \\
\hline & EF7 & North $10^{\text {th }}$ Floor $(6,200$ CFM $)$ & Prop Master \\
\hline & EF8 & South $10^{\text {th }}$ Floor $(6,200$ CFM) & Prop Master \\
\hline & EF9 & Elevator Shaft $(2,500$ CFM $)$ & Prop Master \\
\hline & EF10 & Screening Building (15,600 CFM) & Prop Master \\
\hline ADDED & EF11 & VFB Building $(23,000 \mathrm{CFM})$ & Prop Master \\
\hline ADDED & EF12 & Drive-in Sump $(15,600$ CFM $)$ & Prop Master \\
\hline \multirow[t]{8}{*}{ ADDED } & EF13 & Oily Fines Building ( 15,600 CFM) & Prop Master \\
\hline & MOV101 & Above $101 \mathrm{~V}$ Dryer & State Wide \\
\hline & MOV102 & Above Pyrolyzer & State Wide \\
\hline & MOV120 & Below 104V & State Wide \\
\hline & HU1 & Main Heating Unit $(61,000$ CFM) & Weather-Rite \\
\hline & HU2 & Head HSE Heating Unit $(19,160$ CFM) & Weather-Rite \\
\hline & HU3 & Screen Building Heating Unit $(10,600$ CFM $)$ & Weather-Rite \\
\hline & HU4 & VFB Heating Unit & Weather-Rite \\
\hline ADDED & HU5 & Oily Fines Building Heating Unit & Weather-Rite \\
\hline DELETED & $101 \mathrm{~F}$ & Fines Slurry Mix Tank. & J.W. Williams, Inc. \\
\hline \multirow[t]{7}{*}{ DELETED } & $101 \mathrm{FC}$ & Fines Slurry Mix Tank Cooler & J.W. Williams, Inc. \\
\hline & $101 \mathrm{~J}$ & Dryer Off Gas Blower & Novenco Sheldons, Inc. \\
\hline & $101 \mathrm{JC}$ & Voith Coupling for 101J Blower & Voith Transmissions, Inc. \\
\hline & $101 \mathrm{~V}$ & Coal Dryer (Included W/120V) & Salem Furnace Company \\
\hline & $101 \mathrm{VF}$ & Coal Dryer Feed Hopper & Salem Furnace Company \\
\hline & $102 \mathrm{~L}$ & Stub Axle Idler Wheels for AT-107 & Inwin Car \& Equipment \\
\hline & $102 \mathrm{~V}$ & Dryer Cyclone (With 101V) (4ea) & Salem Furnace Company \\
\hline \multirow[t]{4}{*}{ DELETED } & $103 \mathrm{~J}$ & Fines Slurry Transfer Pump & Kirst Engineering \\
\hline & $103 \mathrm{~L}$ & Stub Axle Idler Wheels for AT-140 & Inwin Car \& Equipment \\
\hline & $104 \mathrm{~N}$ & Adjust. Frequency Drive/Pyrolyzer & Specialty Control Systems \\
\hline & $104 \mathrm{~V}$ & Pyrolyzer & Salem Furnace Company \\
\hline DELETED & $105 \mathrm{~F}$ & Seal Water Surge Tank (W/Cooling Coil) & J.W. Williams, Inc. \\
\hline
\end{tabular}


STATUS

\begin{tabular}{|c|c|c|}
\hline DELETED & $\begin{array}{l}105 J \\
105 \mathrm{~V}\end{array}$ & $\begin{array}{l}\text { Seal Water Circulation Pump W/Motor } \\
\text { Pyrolyzer Cyclone }\end{array}$ \\
\hline CHANGED & $106 \mathrm{CA}$ & Pyrolyzer Quench Steam Condenser A \\
\hline \multirow[t]{2}{*}{ ADDED } & $106 \mathrm{CB}$ & Pyrolyzer Quench Steam Condenser B \\
\hline & $106 \mathrm{~F}$ & Pyrolyzer Quench Water Tank \\
\hline DELETED & $106 \mathrm{~J}$ & Pyrolyzer Quench Water Circ Pump W/Motor \\
\hline ADDED & $107 \mathrm{C}$ & Pyrolyzer Quench Steam Fines Knout-out Drum \\
\hline MOVED & $107 \mathrm{~J}$ & $\begin{array}{l}\text { Fines Slurry Feed Pump W/Motor } \\
\text { PDF Cooler }\end{array}$ \\
\hline DELETED & $\begin{array}{l}107 \mathrm{~V} \\
109 \mathrm{~V} \\
110 \mathrm{~V}\end{array}$ & $\begin{array}{l}\text { PDF Cooler } \\
\text { Dryer Fines Screw Cooler } \\
\text { Rotary Valve Below } 102 \mathrm{~V}\end{array}$ \\
\hline CHANGED & $\begin{array}{l}112 \mathrm{~V} \\
120 \mathrm{~V}\end{array}$ & $\begin{array}{l}\text { Rotary Valve Below } 105 \mathrm{~V} \\
\text { Pyrolyzer Quench Chamber }\end{array}$ \\
\hline MOVED & $121 \mathrm{~V}$ & PDF Rotary Valve \\
\hline ADDED & $128 \mathrm{~V}$ & Char Drag Conveyor \\
\hline ADDED & $129 \mathrm{~F}$ & VFB Char Surge Bin \\
\hline ADDED & $130 \mathrm{~V}$ & Vibrating Fluid Bed \\
\hline ADDED & $131 \mathrm{~V}$ & Finishing Cyclone \\
\hline ADDED & $132 \mathrm{C}$ & VFB Heat Exchanger \\
\hline ADDED & $133 \mathrm{~V}$ & Char Rotary Valve \\
\hline ADDED & $134 \mathrm{~V}$ & VFB Fines Rotary Valve \\
\hline ADDED & $135 \mathrm{~V}$ & PDF Drag Conveyor \\
\hline ADDED & $136 \mathrm{~V}$ & PDF Diverter Gate \\
\hline \multirow[t]{9}{*}{ ADDED } & $137 \mathrm{~V}$ & VFB Diverter Rotary Valve \\
\hline & $201 \mathrm{Cl}$ & Quench Oil Cooler \\
\hline & $201 \mathrm{C} 2$ & Quench Oil Cooler \\
\hline & $201 \mathrm{E}$ & Quench Tower W/Internals \\
\hline & $201 \mathrm{~J}$ & Quench Tower Circulation Pump \\
\hline & 201JA & Spare for $201 \mathrm{~J}$ \\
\hline & 201VA & Coal Liquid Electrostatic Precipitator \\
\hline & 201VB & Coal Liquid Electrostatic Precipitator \\
\hline & $201 \mathrm{VC}$ & Coal Liquid Electrostatic Precipitator \\
\hline \multirow[t]{8}{*}{ ADDED } & $202 \mathrm{~J}$ & CDL Strainer Clean-up Pump \\
\hline & $203 \mathrm{~F}$ & Wash Oil Surge Drum (W/Heating Coil) \\
\hline & $203 \mathrm{~J}$ & ESP Wash Oil Pump \\
\hline & 301B & Dryer On-Gas Combustor \\
\hline & $301 \mathrm{~J}$ & Recycle Gas Blower \\
\hline & $302 \mathrm{~B}$ & Pyrolyzer On-Gas Combustor \\
\hline & $302 J$ & Forced Draft Air Blower to 302B \\
\hline & $303 \mathrm{~J}$ & Forced Draft Air Blower to 301B \\
\hline CHANGED & $304 \mathrm{~J}$ & PDF Air Cooler Fan W/Motor \\
\hline ADDED & $305 \mathrm{~J}$ & VFB Finishing Blower \\
\hline ADDED & $305 \mathrm{JC}$ & Voith Coupling for $305 \mathrm{~J}$ \\
\hline ADDED & $307 \mathrm{~J}$ & VFB Booster Blower \\
\hline ADDED & $308 \mathrm{~J}$ & VFB Cooling Blower \\
\hline ADDED & 309J & Oily Fines Vapor Fan \\
\hline \multirow[t]{6}{*}{ ADDED } & 309L & Oily Fines Vapor Filter \\
\hline & $401 \mathrm{C}$ & MK Application Heater \\
\hline & $403 \mathrm{~J}$ & MK Appl Pump W/Var. Freq. Mtr., Dr, Jacket \\
\hline & $501 \mathrm{E}$ & Horizontal Scrubber \\
\hline & $501 \mathrm{~F}$ & Scrubber Surge Tank \\
\hline & $501 \mathrm{~J}$ & Scrubber Circulation Pump W/Mech. Seal \\
\hline
\end{tabular}

VENDOR

Kirst Engineering

Mark Steel Corporation

Chico

Chico

Paragon Fabricators, Inc.

Ingersoll Rand

ENCOAL

Falcon Pump \& Supply

Heyl \& Patterson, Inc.

Christian Engineering

Smoot Company

W.M. Meyer

Salem Furnace Company

W.M. Meyer

Wolf \& Assoc., Falk, Woods

Brewer Steel

Carrier

Ducon Environmental Sys.

Thermal Transfer

W.M. Meyer

W.M. Meyer

Wolf \& Assoc., Falk, Woods

Raco International

Rotolok, Inc.

Superior Hard Surfacing

Superior Hard Surfacing

Eaton Metals

Union Pump Company

Union Pump Company

Lodge-Cottrell

Lodge-Cottrell

Lodge-Cottrell

Roper

J.W. Williams, Inc.

Goulds Pumps, Inc.

IT-McGill

Novenco Sheldons, Inc.

IT-McGill

Robinson c/o Longhorn

Robinson c/o Longhorn

Buffalo Forge

TLT Babcock

Voith

Illinois Blower, Inc.

Buffalo Forge

Buffalo Forge

Powder River Heating

Alco Products

Bullen Pumps

Dust Technology

Dust Technology

Kirst Engineering 


\section{UPDATED EQUIPMENT LIST \\ AS OF 2/28/97}

Page 3 of 6

STATUS

\begin{tabular}{|c|c|}
\hline & $501 L$ \\
\hline & $502 \mathrm{~F}$ \\
\hline & $502 \mathrm{~J}$ \\
\hline & 502JA \\
\hline & $503 \mathrm{~F}$ \\
\hline \multirow[t]{4}{*}{ CHANGED } & $503 \mathrm{~J}$ \\
\hline & $504 \mathrm{~V}$ \\
\hline & $505 \mathrm{~V}$ \\
\hline & $506 \mathrm{~V}$ \\
\hline \multirow[t]{10}{*}{ ADDED } & $2000 \mathrm{U}$ \\
\hline & $2001 C$ \\
\hline & $2001 F$ \\
\hline & $2001 \mathrm{FC}$ \\
\hline & $2001 U$ \\
\hline & $2002 F$ \\
\hline & $2002 F C$ \\
\hline & $2002 \mathrm{~J}$ \\
\hline & 2002LA \\
\hline & 2002LB \\
\hline CHANGED & $2002 \mathrm{UJ}$ \\
\hline \multirow[t]{9}{*}{ CHANGED } & $2002 \mathrm{UJA}$ \\
\hline & $2002 \mathrm{UL}$ \\
\hline & $2003 C$ \\
\hline & $2003 \mathrm{CA}$ \\
\hline & $2003 \mathrm{CB}$ \\
\hline & $2003 \mathrm{CC}$ \\
\hline & $2003 \mathrm{CD}$ \\
\hline & $2003 \mathrm{~F}$ \\
\hline & $2003 \mathrm{FC}$ \\
\hline \multirow[t]{4}{*}{ CHANGED } & $2003 \mathrm{~J}$ \\
\hline & $2003 \mathrm{~L}$ \\
\hline & 2003LA \\
\hline & $2003 \mathrm{U}$ \\
\hline \multirow[t]{2}{*}{ ADDED } & $2004 \mathrm{~F}$ \\
\hline & $2004 \mathrm{FA}$ \\
\hline \multirow[t]{9}{*}{ ADDED } & $2004 \mathrm{~J}$ \\
\hline & 2004LA/LB \\
\hline & $2005 \mathrm{C}$ \\
\hline & $2005 \mathrm{~F}$ \\
\hline & $2005 \mathrm{~J}$ \\
\hline & $2005 \mathrm{JA}$ \\
\hline & 2005JC \\
\hline & $2005 \mathrm{JCA}$ \\
\hline & $2005 \mathrm{JF}$ \\
\hline \multirow[t]{2}{*}{ CHANGED } & $2005 \pi$ \\
\hline & 2005L \\
\hline \multirow[t]{2}{*}{ ADDED } & $2006 \mathrm{C}$ \\
\hline & $2006 \mathrm{~F}$ \\
\hline CHANGED & $2006 \mathrm{~J}$ \\
\hline \multirow[t]{2}{*}{ ADDED } & $2006 \mathrm{JA}$ \\
\hline & $2006 \mathrm{~L}$ \\
\hline CHANGED & $2006 \mathrm{LC}$ \\
\hline
\end{tabular}

DESCRIPTION

Sodium Carbonate Mix Tank Agitator

Sodium Carbonate Mix Tank

PPSR Sodium Carbonate Pump

PPSR Sodium Carbonate Pump (Spare)

Wet Gas Scrubber

Solution Makeup Pump with Motor

Sodium Carbonate Storage Silo

Bin Vent Filter for 504V

Sodium Carbonate Rotary Feeder

2,000Lb/Hr Steam Boiler Package

Steam/Glycol Heat Exchanger

MK Storage Tank

MK Storage Suction Heater

$10,000 \mathrm{Lb} / \mathrm{Hr}$ Steam Boiler Package

Coal Derived Liquid Storage Tank

CDL Tank Heating Coil

Coal Liquid Prod Transfer/Load Out Pump

Mixer for $2002 \mathrm{~F}$

Mixer for $2002 \mathrm{~F}$

BFW Pump

Boiler Feedwater Pump Aux.

De-Aerator

Glycol-Water Air Cooler

Glycol-Water Air Cooler

Glycol-Water Air Cooler

Glycol-Water Air Cooler

Glycol-Water Air Cooler

Offspec Oil Storage Tank

Heating Coil for 2003F

Coal Liquid Offspec Transfer Pump

Offspec Oil Tank Mixer

Mixer for 2003F

Water Softener

Portable MK Dust Suppressant Tank

Portable MK Tank Heater

Portable MK Dust Suppressant Pump

Portable MK Pump Strainers

Glycol-Water Trim Cooler

Glycol-Water Storage Tank

Plant Air Compressor

Plant Air Compressor - Spare for 2005J

Compressor Air/Oil Cooler

Spare Compressor Air/Oil Cooler

Air Receiver - Plant Air Compressor

Air Dryer for Plant Air Compressor

Coal Liquid Rail Car/Truck Loading Arm

Oily Water Heat Exchanger

Oily Water Storage Tank

Oily Water Pump

Oily Water Pump (Spare)

Nitrogen Dewar

Nitrogen Vaporizer
VENDOR

The Eads Company

J.W. Williams, Inc.

Kirst Engineering

Kirst Engineering

Dust Technology

Roper

The Datum Company

The Datum Company

The Datum Company

High Country Fabrication

J.W. Williams, Inc.

Alco Products

York Shipley

J.W. Williams, Inc.

J.W. Williams, Inc.

Union Pump Company

The Eads Company

The Eads Company

Grundfus

Grundfus

York Shipley

Ecodyne Corporation

Ecodyne Corporation

Ecodyne Corporation

Ecodyne Corporation

Ecodyne Corporation

J.W. Williams, Inc.

J.W. Williams, Inc.

Blackmer

The Eads Company

The Eads Company

York Shipley (Kisco)

ENCOAL

Appleton

Roper

Rosedale

High Country Fabrication

J.W. Williams, Inc.

Compression \& Com.

Compression \& Com.

Compression \& Com.

Compression \& Com.

Compression \& Com.

Pneumatech

Progressive Product Mktg.

Chico

J.W. Williams, Inc.

Georgia Iron Works

Georgia Iron Works

Taylor Wharton

Cryogenic Experts 
UPDATED EQUIPMENT LIST

AS OF 2/28/97

Page 4 of 6

STATUS

TAG \#

DESCRIPTION

VENDOR

\begin{tabular}{|c|c|c|c|}
\hline & 2007J & Glycol-Water Circulating Pump & Union Pump Company \\
\hline & 2007JA & Spare for $2007 \mathrm{~J}$ & Union Pump Company \\
\hline & $2007 \mathrm{~L}$ & Boiler Chemical Injection & York Shipley \\
\hline & $2007 \mathrm{LJ}$ & Injection Pump for $2007 \mathrm{~L}$ & York Shipley \\
\hline CHANGED & $2008 \mathrm{~J}$ & Process Water Booster Pump & Goulds \\
\hline ADDED & 2008JA & Process Water Booster Pumps & Goulds \\
\hline & $2008 \mathrm{~L}$ & Ammonia Chemical Injection System & York Shipley \\
\hline & $2008 \mathrm{LJ}$ & Ammonia Injection Pump & York Shipley \\
\hline & 2009LA & Offspec Oil Filter & The Eads Company \\
\hline & 2009LB & Offspec Oil Filter & The Eads Company \\
\hline ADDED & $2010 \mathrm{~F}$ & MK Car Topper Tank & J.W. Williams \\
\hline ADDED & $2010 \mathrm{~J}$ & MK Car Topper Pump & Roper \\
\hline ADDED & 2010LA/LB & MK Car Topper Pump Ștrainers & Rosedale \\
\hline & $2012 \mathrm{~J}$ & Offspec Chemical Injection Pump & The Eads Company \\
\hline & $2013 \mathrm{~J}$ & Emergency Glycol Tracing Pump & Blackmer \\
\hline ADDED & $2014 \mathrm{~J}$ & Nitrogen Vaporizer Glycol Pump & Quadna, Kenflow \\
\hline TEMP/DELTD & $2020 \mathrm{~F}$ & Oily Fines Circulation Tank & Wilson Welding \\
\hline TEMP/DELTD & $2020 \mathrm{~J}$ & Oily Fines Circulation Pump & Georgia Iron Works \\
\hline ADDED & $2021 \mathrm{~F}$ & Filtrating Receiver & Westech \\
\hline ADDED & 2021L & Filter Tub Agitator & Westech \\
\hline ADDED & $2021 \mathrm{~V}$ & Vacuum Drum Filter & Westech \\
\hline ADDED & $2022 \mathrm{~F}$ & Clarifier Dearation Tank & Enviroclear \\
\hline ADDED & $2022 \mathrm{~J}$ & Clarifier Underflow Pump & Roper \\
\hline ADDED & $2022 \mathrm{~L}$ & Clarifier Rake & Enviroclear \\
\hline ADDED & $2022 \mathrm{~V}$ & Clarifier & Enviroclear \\
\hline ADDED & $2023 F$ & Water Trap & Westech \\
\hline ADDED & $2023 \mathrm{~J}$ & Vacuum Pump & Westech \\
\hline ADDED & $2023 \mathrm{~L}$ & Flocculant Blending Unit & Great-FLOC \\
\hline ADDED & $2024 \mathrm{~F}$ & Oily Water Surge Tank & Kissack Water \& Hot Oil Svc \\
\hline ADDED & $2024 \mathrm{~J}$ & Filtrate Pump & Westech \\
\hline ADDED & $2025 \mathrm{~J}$ & Discharge Blower & Westech \\
\hline ADDED & $2026 \mathrm{~F}$ & Oily Water Bulk Tank & Kissack Water \& Hot Oil Svc \\
\hline ADDED & $2026 \mathrm{~J}$ & Oily Water Return Pump & Roper \\
\hline ADDED & $2027 \mathrm{~J}$ & Coagulant Pump & Great-FLOC \\
\hline & $2101 \mathrm{~A}$ & Coal Storage Silo & Hoffman \\
\hline & $2101 \mathrm{~F}$ & PDF Bin & Hoffman \\
\hline & $2101 \mathrm{~J}$ & Fire Water Booster Pump & Power Services \\
\hline & $2101 \mathrm{~L}$ & Hyudraulic Power Supply for $2123 \mathrm{~V}$ & Pebco \\
\hline & 2101LM & Motor for Hydraulic Power Supply & Pebco \\
\hline & $2101 \mathrm{~V}$ & Coal Screen & Tabor Machine \\
\hline & 2101VM & Motor for Coal Screen & Tabor Machine \\
\hline & $2102 \mathrm{~A}$ & Screening Plant Sump & \\
\hline DELETED & $2102 \mathrm{~F}$ & Slurry Injection & Krebs Engineers \\
\hline DELETED & $2102 \mathrm{~L}$ & Manifold W/Hydro-Cyclones (4ea) & Krebs Engineers \\
\hline & $2102 \mathrm{~V}$ & Screening Plant Feed Conveyor & Robins Engrs \& Constr., Inc. \\
\hline & $2103 \mathrm{~A}$ & PDF Plant Containment Sump & \\
\hline CHANGED & $2103 \mathrm{~F}$ & MK Dust Suppresser & Von's Welding \\
\hline & $2103 \mathrm{~V}$ & Feed Coal Crusher & R \& F Coal \\
\hline & $2104 \mathrm{~A}$ & PDF Cooler Area Sump & \\
\hline & $2104 \mathrm{~F}$ & Screening Plant Dust Scrubber & Dust Technology \\
\hline & $2104 \mathrm{~J}$ & PDF Cooler Sump Pump & Trans. Equipment \& Supply \\
\hline & $2104 \mathrm{~V}$ & Variable Speed Vibrating Feeder & Carmen Industries \\
\hline & $2104 \mathrm{VN}$ & Rate Control for $2104 \mathrm{~V}$ Feeder & Carmen Industries \\
\hline
\end{tabular}


UPDATED EQUIPMENT LIST

AS OF 2/28/97

Page 5 of 6

STATUS

TAG \#

DESCRIPTION

VENDOR

2105A PDF Silo Sump

2105F - Coal Feed Silo Dust Scrubber

2105J PDF Silo Sump Pump

2105V Sized Coal Surge Chute

2106A Coal Storage Silo Sump

ADDED 2106F Dust Scrubber $\left(8^{\text {th }}\right.$ Floor $)$

2106J Coal Storage Silo Sump Pump

2106V "S" Belt Coal Conveyor

2107A PDF Elevator Sump

ADDED 2107F

CHANGED $\quad 2107 \mathrm{~J}$

$2108 \mathrm{~J}$

$2108 \mathrm{~V}$

2109J

ADDED 2110J

ADDED 2111J

ADDED 2112J

$2115 \mathrm{~V}$

$2116 \mathrm{~V}$

$2117 \mathrm{~V}$

$2119 \mathrm{~V}$

$2123 \mathrm{~V}$

Dust Scrubber (2 $1 / 2$ Level)

PDF Elevator Sump Pump

Blower for SCR Plant Dust Scrubber 2104F

"S" Belt PDF Conveyor

Blower F/Coal Feed Silo Scrubber (2105F)

Blower for $8^{\text {th }}$ Floor Scrubber

Blower for $2 \frac{1}{2}$ Level Scrubber

VFB Area Sump Pump

Tramp Iron Magnet

Fines Collection Bin

Existing No. 16 Conveyor Extension \& Mod

Vibrating Feeder Under Fines Bin 2116V

$2123 \mathrm{VL}$

Mass Flow PDF Feeder

Cutoff Gate for PDF Bin (2101F)

$2124 \mathrm{~V}$

$2125 \mathrm{~V}$

Conveyor W/Motor for Coal Storage Silo

Diverter Valve

$2126 \mathrm{~V}$

$2128 \mathrm{~V}$

$2129 \mathrm{~V}$

CHANGED $2130 \mathrm{~V}$

$2134 \mathrm{~V}$

$2135 \mathrm{~V}$

$2139 \mathrm{~V}$

$2140 \mathrm{~V}$

$2141 \mathrm{~V}$

$2142 \mathrm{~V}$

PDF Truck Loading Conveyor

Coal Analyzer Belt Conveyor

Coal Fines Truck Loading Conveyor

Fines Truck Loading Telescopic Spout

Fines Bin Cutoff Gate for $2116 \mathrm{~V}$

Fines Bin Cutoff Gate for $2116 \mathrm{~V}$

Cutoff Gate for 504V - Vendor Package

Cutoff Gate for 2101A

Feed Coal Silo Heater

PDF Bin Heater

DELETED 2143V

Dryer Fines Conveyor

$2144 \mathrm{~V}$

ADDED $2145 \mathrm{~V}$

$2201 \mathrm{~A}$

$2201 \mathrm{~J}$

2201JA

2201LA

2201LB

ADDED

2202J

DELETED 2401J

$2402 \mathrm{~J}$

DELETED 2403J

$2404 \mathrm{~J}$

$2405 \mathrm{~J}$

ADDED

$2410 \mathrm{~J}$

ADDED

$2411 \mathrm{~J}$

ADDED

2412J

ADDED

2413J

Dust Collection Baghouse

Raw Coal S-Belt Cleanup Screw Conveyor

Cooling Water Intake Structure

Cooling Water Pump

Spare for 2201J

Cooling Water Filter W/Motor

Cooling Water Filter W/Motor

Cooling Water Chemical Injection Pump

SCR Plant Fines Sump Pump

PDF Plant Containment Pump

Oil Transfer Area Sump Pump

Leakage Sump Pump

SCR Plant Coarse Sump Pump

Drive-In Sump Pump

Pipe Trench Sump Pump

Oily Water Return Sump Pump

Boiler Room Sump Pump

Dust Technology

Trans. Equipment \& Supply

Von's Welding

Dust Technology

Trans. Equipment \& Supply

Lakeshore, Inc.

Dust Technology

Trans. Equipment \& Supply

Cincinnati Fan \& Ventilator

Lakeshore, Inc.

Cincinnati Fan \& Ventilator

New York Blower

New York Blower

Trans. Equipment \& Supply

Dings Magnetics

Paragon Fabricators, Inc.

Robins Engrs \& Constr., Inc.

Carmen Industries

Pebco

Pebco

Robins Engrs \& Constr., Inc.

Robins Engrs \& Constr., Inc.

Robins Engrs \& Constr., Inc.

Robins Engrs \& Constr., Inc

Buhler Miag, Inc.

Pebco

Paragon Fabricators, Inc.

Paragon Fabricators, Inc.

The Datum Company

Pebco

Powder River Heating

Powder River Heating

Buhler Miag, Inc.

Air-Cure Howden

Wolf \& Associates

Hladky Construction

Goulds Pumps, Inc.

Goulds Pumps, Inc.

Hayward Industrial Products

Hayward Industrial Products

Betz Chemical

Goulds Pumps, Inc.

Trans. Equipment \& Supply

Trans. Equipment \& Supply

Texas Process Equipment

Trans. Equipment \& Supply

Flygt

Trans. Equipment \& Supply

Trans. Equipment \& Supply

Trans. Equipment \& Supply 
UPDATED EQUIPMENT LIST

AS OF 2/28/97

Page 6 of 6

\begin{tabular}{llll}
\multicolumn{1}{c}{ STATUS } & \multicolumn{1}{c}{ TAG \# } & \multicolumn{1}{c}{ DESCRIPTION } & \multicolumn{1}{c}{ VENDOR } \\
\hline \hline CHANGED & 2501J & Lift Station Pump & Trans. Equipment \& Supply \\
MOVED & $2605 \mathrm{~K}$ & 2T Hoist - VFB Building & Trans. Equipment \& Supply \\
& $2610 \mathrm{~K}$ & 5T Hoist (Main Drop Area) & Trans. Equipment \& Supply \\
& $2621 \mathrm{~K}$ & 2T Hoist (Top of PDF Silo) & Trans. Equipment \& Supply \\
ADDED & $2622 \mathrm{~K}$ & 2T Hoist (VFB Building) & Trans. Equipment \& Supply \\
& $3406 \mathrm{~B}$ & Emergency Generator & Caterpillar \\
& PV-150 & 48" Emergency Pressure Relief Valve & Masoneilan N. American
\end{tabular}




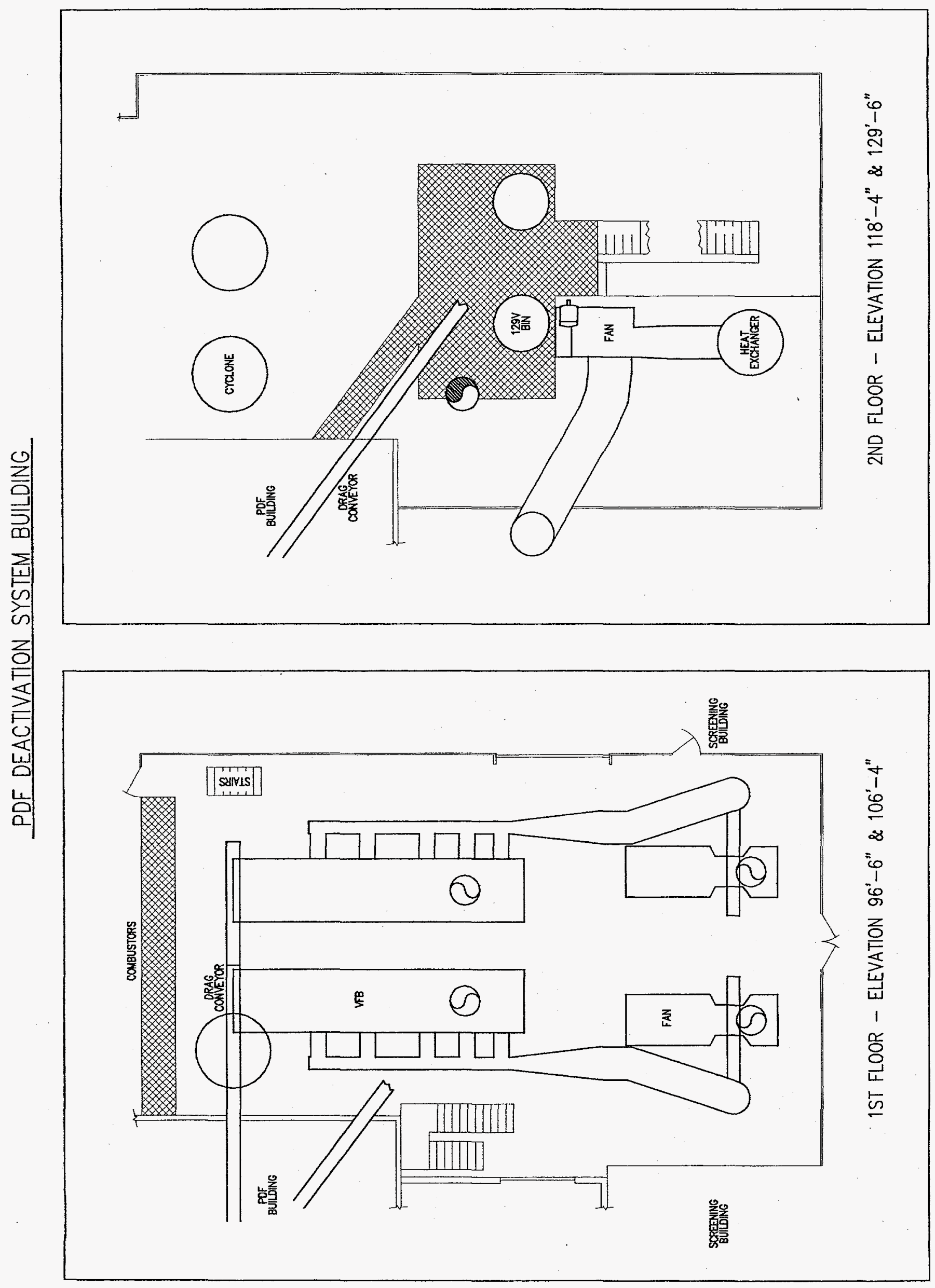




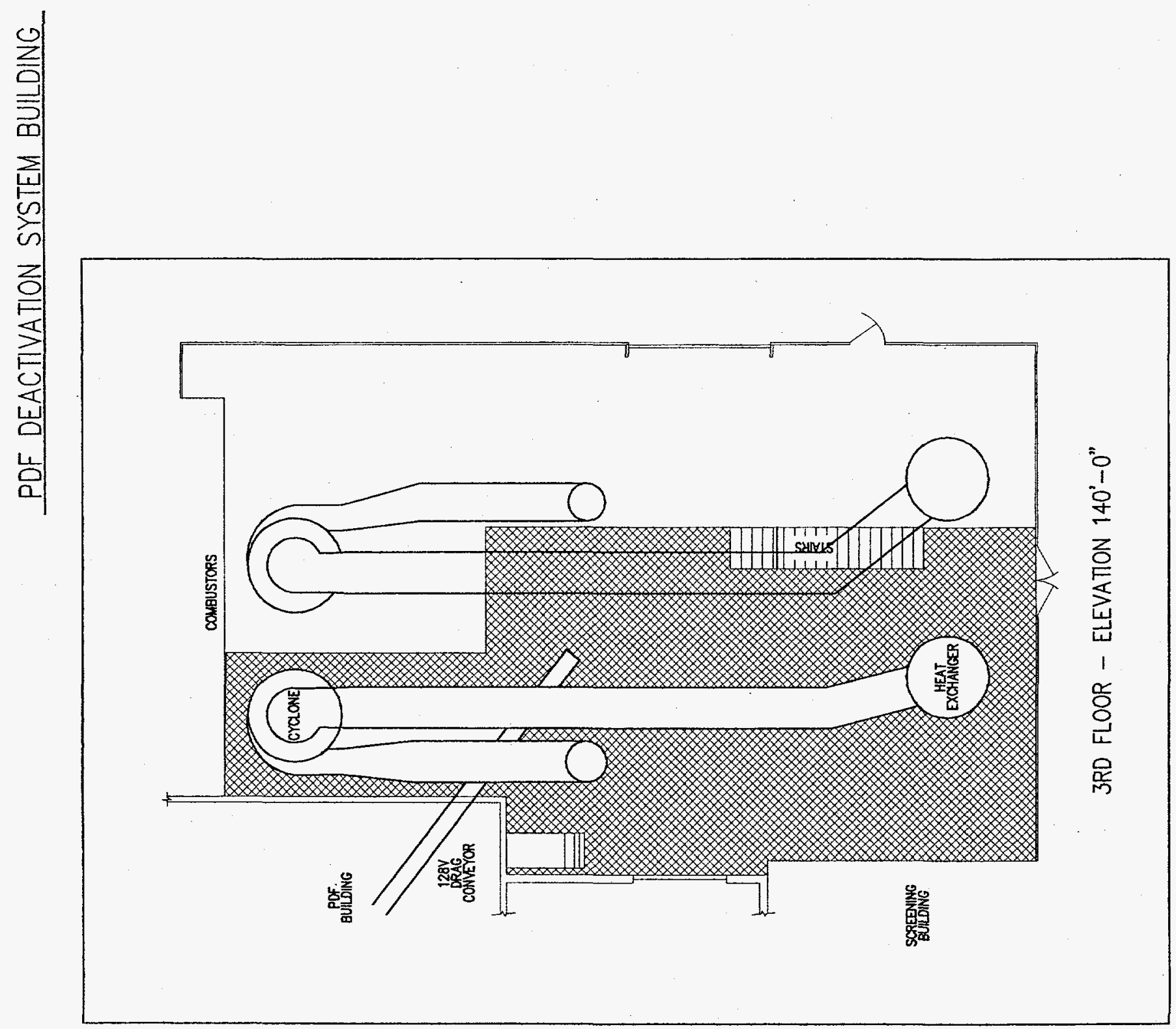




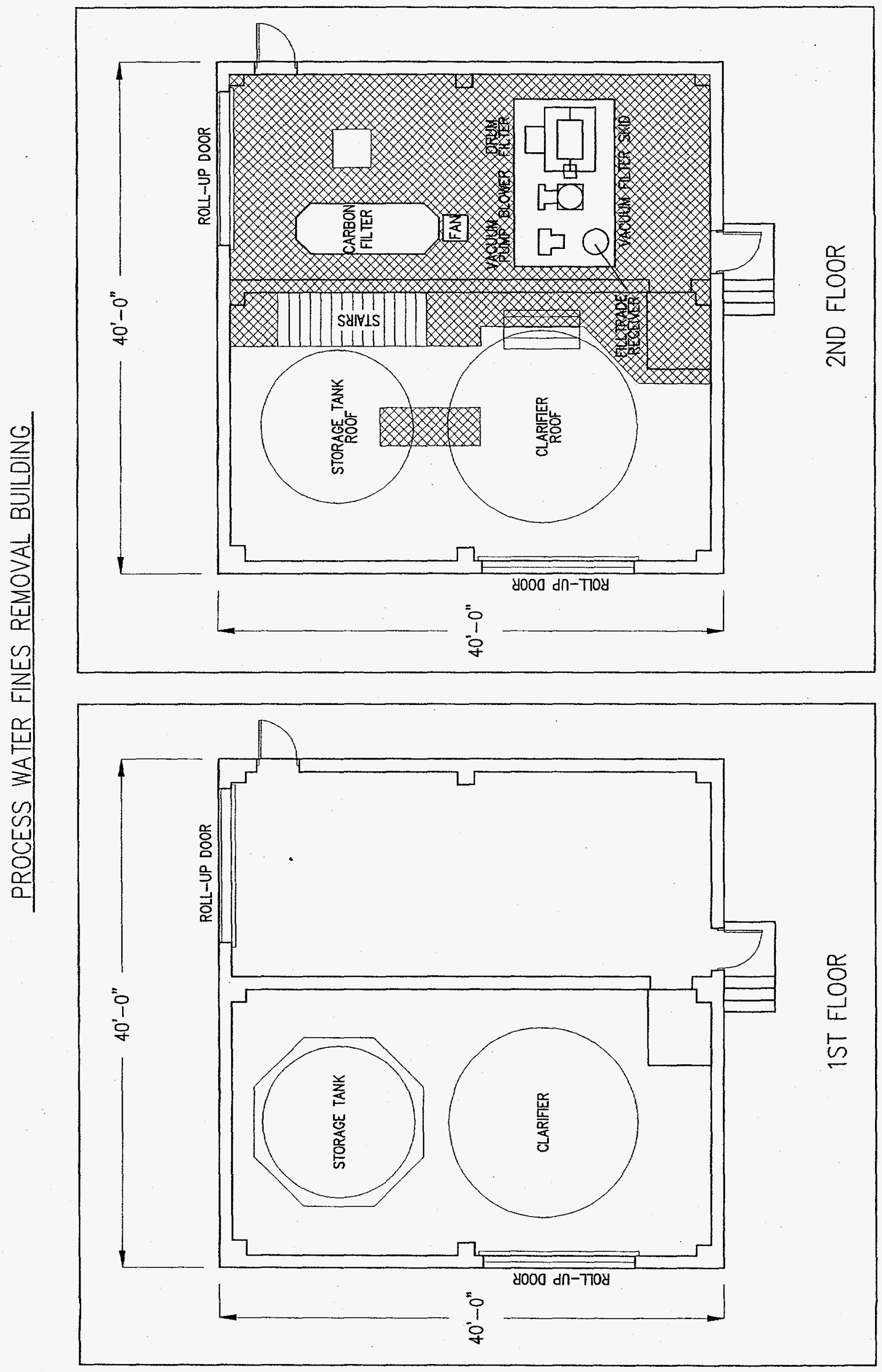

